\author{
Universidade de São Paulo \\ Instituto de Física
}

\title{
Otimização de Doses em Procedimentos de Tomografia Computadorizada Pediátrica
}

\author{
Vivian Heidorne Guerra
}

Orientador: Prof. Dr. Paulo Roberto Costa

Dissertação de mestrado apresentada ao Instituto de Física para a obtenção do título de Mestre em Ciências.

Banca Examinadora:

Prof. Dr. Paulo Roberto Costa (IFUSP)

Profa. Dra. Patrícia Nicolucci (FFCLRP/USP)

Prof. Dr. Hugo Reuters Schelin (UTFPR) 


\section{FICHA CATALOGRÁFICA \\ Preparada pelo Serviço de Biblioteca e Informação do Instituto de Física da Universidade de São Paulo}

Guerra, Vivian Heidorne

Otimização de doses em procedimentos de tomografia computadorizada pediátrica. São Paulo, 2020.

Dissertação (Mestrado) - Universidade de São Paulo. Instituto de Física. Depto. de Física Nuclear

Orientador: Prof. Dr. Paulo Roberto Costa

Área de Concentração: Física Médica

Unitermos: 1. Tomografia computadorizada por raios X; 2. Dosimetria; 3. Pediatria; 4. Física médica. 


\title{
University of São Paulo \\ Institute of Physics
}

\section{Dose Optimization in Pediatric Computed Tomography Procedures}

\author{
Vivian Heidorne Guerra
}

Supervisor: Prof. Dr. Paulo Roberto Costa

Dissertation submitted to the Institute of Physics of the University of São Paulo for the Master of Science degree.

Examination Committee:

Prof. Dr. Paulo Roberto Costa (IFUSP)

Profa. Dra. Patrícia Nicolucci (FFCLRP/USP)

Prof. Dr. Hugo Reuters Schelin (UTFPR) 
"If you can dream it you can do it."

(Walt Disney) 


\section{AGRADECIMENTOS}

Agradeço muito ao meu orientador Paulo por me guiar nesta jornada. Obrigada por seu tempo, paciência e especialmente por sua confiança em mim e em meu trabalho.

Sou especialmente grata à Denise, cujo apoio foi fundamental para este trabalho. Obrigada por ficar até tarde comigo no INRAD, me acompanhando em todos os conjuntos de medições e por responder gentilmente todas as minhas perguntas.

Agradeço à Nancy por seu tempo e paciência em responder todas as minhas dúvidas sobre o Riso e dosímetros OSL. Obrigada por me socorrer todas as vezes em que tive receio estragar meu conjunto de leituras e quebrar o Riso.

Agradeço ao INRAD por prover os equipamentos e os dados utilizados no desenvolvimento deste trabalho.

Agradeço aos funcionários e professores do IFUSP.

Agradeço à oficina mecânica do IFUSP, por fabricarem os suportes de dosímetros utilizados neste trabalho.

Agradeço ao Dr. Márcio Sawamura por me ajudar pacientemente com os cálculos de volume pulmonar e pela colaboração com as avaliações de qualidade de imagens tomográficas.

Meu muito obrigada a todo o Grupo de Dosimetria das Radiações e Física Médica por todas as conversas no horário do almoço e especialmente por me acolherem e me receberem tão bem nesta família.

À minha amiga de infância Bárbara, que apesar da distância sempre se faz presente. Às minhas amigas Gabriela e Jussara pelos anos de amizade. Ao meu amigo Lima pelos anos de companheirismo no IFUSP.

À minha gatinha Marie, que ronronou no meu colo enquanto eu escrevia as primeiras páginas deste trabalho e virou estrelinha cedo demais. Aos meus gatinhos sapecas Luke e Mingau, que trouxeram alegria (e pelos!) de volta à casa.

Ao Luís, pai da minha irmã e meu pai de coração, que se foi cedo demais, deixando muitas saudades.

À minha querida avó Ione por todo seu amor e carinho, mesmo durante meus terríveis anos de adolescência. Que sorte a minha ter tido você como avó. Saudades eternas.

Ao meu cunhado Rafael por sempre cuidar e apoiar a nossa família.

À minha linda irmã Walkyria, que sempre cuidou de mim e em quem eu sempre me inspirei. Obrigada por seu amor e carinho. 
À minha querida mãe Fátima, por todo o apoio e amor incondicionais. Obrigada por sempre me ouvir e aconselhar. Obrigada por todas as vezes em que você deixou tudo para trás e veio me socorrer quando eu precisei.

Ao Artur, meu noivo, minha melhor metade. Obrigada por todo seu amor e carinho, por me acalmar nas minhas crises de ansiedade e por dizer que tudo ficará bem, mesmo quando você não tem certeza disso. Obrigada por me ajudar pacientemente com as "coisas de computador" sempre que eu preciso e por me apoiar em todos os meus projetos, por mais desafiadores que fossem. 


\section{RESUMO}

Desde a introdução da Tomografia Computadorizada (TC), no início dos anos 1970, sua tecnologia foi bastante aprimorada, principalmente em busca de tempos de aquisição mais curtos. Esta é uma modalidade que pode estar associada à administração de doses de radiação relativamente altas aos pacientes, se comparada a procedimentos convencionais de radiologia. Entretanto, quando usada de maneira ideal, a TC é uma ferramenta extremamente valiosa para o diagnóstico médico por imagens. Seu uso crescente nas últimas duas décadas tem despertado o interesse da comunidade cientifica para a otimização de seus protocolos, em especial para as tomografias pediátricas, dada a maior expectativa de vida das crianças. Algumas abordagens técnicas e clínicas têm sido utilizadas para uma otimização eficaz da radiação, como o uso de ferramentas para reconstrução de imagens e a redução da tensão e corrente do tubo de raios X, que podem ser adotadas dependendo dos níveis de ruídos toleráveis para o diagnóstico. A estimativa de dose administrada durante a TC é essencial para sua otimização na rotina clínica. Este trabalho apresenta uma abordagem experimental para a estimativa de dose absorvida em órgãos utilizando dosímetros por luminescência opticamente estimulada (OSLDs) em um objeto simulador antropomórfico (phantom) equivalente a um paciente de cinco anos de idade. A avaliação de dose foi realizada para seis diferentes protocolos clínicos pediátricos de TC, frequentemente aplicados a pacientes desta faixa etária no Instituto de Radiologia da Faculdade de Medicina da Universidade de São Paulo, sendo três protocolos novos e otimizados, implementados como um processo de otimização de procedimentos radiológicos pediátricos desenvolvido em parceria com o Instituto de Física da USP, e três protocolos não otimizados, adotados anteriormente ao processo de otimização. Os resultados foram comparados com simulações Monte Carlo, apresentando diferenças percentuais entre doses experimentais e simuladas dentro do intervalo de $\pm 20 \%$. Em especial, destaca-se a otimização dos protocolos de crânio, que proporcionaram reduções de até $72 \%$ na dose absorvida dos órgãos avaliados.

Palavras-Chave: Tomografia Computadorizada; Dosimetria OSL; Pacientes Pediátricos; Doses em Órgãos; Otimização de Doses. 


\begin{abstract}
Since the introduction of Computed Tomography (CT) in the early 1970s, its technology has been greatly improved, especially in search of shorter acquisition times. This type of exam can be linked with relatively high radiation doses to patients when compared to conventional radiology procedures. However, when used optimally, CT is an extremely valuable tool for medical imaging diagnosis. Its increasing use in the last two decades has aroused the interest of the scientific community for its optimization, especially for pediatric tomography, given the longer life expectancy of children. Some technical and clinical approaches have been used for effective optimization of radiation, such as the use of tools for image reconstruction and the $\mathrm{X}$ ray tube voltage and current reduction, which can be adopted depending on the noise levels tolerable for diagnosis. Estimating the dose administered during CT is essential for its optimization in the clinical routine. This work presents an experimental approach to estimate the absorbed organ dose using optically stimulated luminescence dosimeters (OSLDs) in an anthropomorphic simulator object (phantom) equivalent to a five-year-old patient. The dose assessment was performed for six different pediatric CT protocols, frequently applied to patients of this age group at the Radiology Institute of the University of São Paulo School of Medicine, three of which are new and optimized protocols, implemented as an optimization process of pediatric radiological procedures developed in partnership with the University of São Paulo Physics Institute, and three non-optimized protocols, adopted prior to the optimization process. The results were compared with Monte Carlo simulations, showing percentage differences between experimental and simulated results within the range of $\pm 20 \%$. In particular, the optimization of the brain protocols stands out, which provided reductions of up to $72 \%$ in the absorbed dose of the evaluated organs.
\end{abstract}

Keywords: Computed Tomography; Pediatric Patients; OSL Dosimetry; Organ Doses; Dose Optimization. 


\section{LISTA DE FIGURAS}

Figura 2.1 - Panorama histórico da evolução tecnológica dos equipamentos de TC. A primeira geração de tomógrafos fazia apenas exames de cabeça e operava com um feixe de lápis, num sistema de translação/rotação. A segunda geração, embora ainda como o mesmo sistema translação/rotação, já operava com um feixe de leque estreito. Com os tomógrafos da terceira geração, a aquisição de dados torna-se continua com a rotação do conjunto detector-fonte. Na quarta geração, o sistema de detectores tornou-se estacionário para que apenas o tubo de raios X girasse em torno do paciente. Fonte: Kalender 2011

Figura 2.2 - Componentes do gantry de um tomógrafo da chamada "terceira geração" de TC. Fonte: Ulzheimer \& Flohr, 2009.

Figura 2.3 - Tubo de raios X e seus componentes. Fonte: Fosbinder \& Orth, 2011.

Figura 2.4 - Tubo de raios X Straton da Siemens. Fonte: https://www.siemens-healthineers.com/pressroom/press-media-gallery/im-2015070926hc.html.

Figura 2.5 - Detectores cintiladores. Posicionados na parte de trás dos detectores, os fotodiodos fazem a conversão da luz em sinal elétrico. Fonte: Fosbinder \& Orth, 2011.

Figura 2.6 - O filtro bowtie é utilizado nos tomógrafos para compensar a forma elipsoidal do corpo humano e fica acoplado ao tubo de raios X. O uso deste filtro atenua o feixe de radiação na periferia do campo, reduzindo a dose de radiação entregue ao paciente sem perda de qualidade para a imagem. Fonte: Bushberg et al., 2011

Figura 2.7 - Modo de aquisição axial de tomografia computadorizada, em que a irradiação do paciente é feita passo a passo. $\mathrm{O}$ tubo de raios $\mathrm{X}$ é desligado entre os ciclos consecutivos de aquisição. $\mathrm{O}$ processo é repetido até que toda a região de interesse seja escaneada. Fonte: Bushberg et al., 2011

Figura 2.8 - Modo de aquisição helicoidal de tomografia computadorizada, em que a irradiação é feita durante a translação da mesa do paciente. $\mathrm{O}$ tubo de raios $\mathrm{X}$ descreve uma trajetória em hélice ao redor do paciente. Fonte: Bushberg et al., 2011.

Figura 2.9 - Seções transversais de feixe de raios $\mathrm{X}$ e os respectivos arranjos de seus detectores para três modelos de TC: (a) único detector, (b) múltiplos detectores (MDCT) e (c) conjunto grande de múltiplos detectores (CBCT). Fonte: Bushberg et al., 2011.

Figura 2.10 - A intensidade de radiação atenuada. Ilustração de três casos de atenuação, considerando feixes de raios $\mathrm{X}$ mono energéticos e poli energéticos atenuados por objetos homogêneos e não homogêneos. Para objetos não homogêneos, a imagem tomográfica é necessária para determinar a distribuição $\mu(\mathrm{x}, \mathrm{y})$. Fonte: Kalender (2011).

Figura 2.11 - Simuladores cilíndricos de PMMA utilizados para medição de CTDI. O cilindro menor (com $16 \mathrm{~cm}$ de diâmetro) é adotado como simulador de cabeça e o cilindro maior (com $32 \mathrm{~cm}$ de diâmetro) é adotado como simulador de corpo. Fonte: <http://www.universalmedicalinc.com/ct-dosephantom.html>.

Figura 2.12 - Diferentes estágios do fenômeno OSL: (a) excitação do cristal OSL devido a exposição à radiação ionizante, criando elétrons livre e buracos; (b) período de latência, em que os elétrons e buracos estão presos nos defeitos da rede cristalina e (c) estímulo do detector com luz e a resultante recombinação dos pares elétron-buraco com a emissão de luz (OSL). Fonte: Yukihara \& McKeever (2011).............48

Figura 3.1 - Phantom antropomórfico pediátrico ATOM da CIRS, modelo 705 (CIRS, EUA). .51

Figura 3.2 - Fatia 11 do phantom pediátrico ATOM modelo 705 (CIRS, EUA) dotada de cavidades para inserção de dosímetros. O material em cor-de-rosa representa os pulmões. 
Figura 3.3 - À esquerda: Leitor Risø TL/OSL modelo DA-20 (DTU Nutech., Dinamarca). À direita: Carrossel com copinhos de aço inoxidável para o posicionamento de até 48 dosímetros do leitor Ris $\emptyset$. Fonte: DTU Nutech, 2015.

Figura 3.4 - Fita OSL Landauer Luxel ${ }^{\mathrm{TM}}$ (Landauer, Inc., Glenwood, EUA) de óxido de alumínio dopado com carbono $\left(\mathrm{Al}_{2} \mathrm{O}_{3}: \mathrm{C}\right)$ fracionada em discos de $3 \mathrm{~mm}$ de diâmetro e $0,3 \mathrm{~mm}$ de espessura. .53

Figura 3.5 - Porta-dosímetros utilizados para conter os OSLDs durante as irradiações. À esquerda: portadosímetro cilíndrico utilizado para inserção dos OSLDs nas cavidades dos pulmões e tireoide do phantom. À direita: envelopes escuros de PVC utilizados para conter os OSLDs posicionados nos olhos do phantom e durante a irradiação para calibração dos dosímetros OSL

Figura 3.6 - Phantom comercial de qualidade de imagem CATPHAN 500 (The Phantom Laboratory,

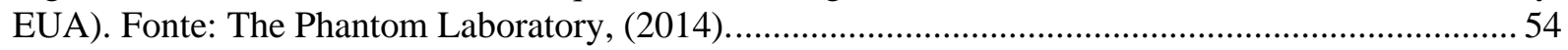

Figura 3.7 - Exemplo de uma curva de contagens obtida na leitura de um dosímetro OSL $\mathrm{Al}_{2} \mathrm{O}_{3}: \mathrm{C}$ Landauer Luxel ${ }^{\mathrm{TM}}$ (Landauer, Inc., Glenwood, EUA) após prévia irradiação. 55

Figura 3.8 - Câmara de ionização de 0,6 $\mathrm{cm}^{3}$ modelo 10X6-0,6 alinhada no centro do gantry do tomógrafo Philips Brilliance 64 CT scanner (Philips, Holanda). Após a medição do kerma no ar, os conjuntos de dosímetros OSL foram posicionados com suporte acrílico na mesma posição da câmara de ionização. 56

Figura 3.9 - À esquerda: imagens da tomografia de tórax do phantom em análise no software IntelliSpace ${ }^{\circledR}$ PACS (Philips, Holanda). As linhas em roxo representam o contorno feito pelo usuário. À direita: resultado da reconstrução volumétrica do pulmão direito do phantom pediátrico realizada pelo software. 58

Figura 3.10 - Distribuição dos dosímetros OSL nas cavidades do phantom pediátrico para avaliação de dose absorvida. À esquerda: na região da tireoide (fatia 8) do phantom. Centro: na região pulmonar (fatia 11) do phantom. À direita: na região do cristalino do phantom.

Figura 3.11 - Interface do software NCICT versão 3.0, utilizado para simular dose absorvida em órgãos críticos de phantoms de referência, proveniente de exames tomográficos, via método Monte Carlo... 66

Figura 4.1 - Box-plots comparativos da grandeza dosimétrica CTDI $_{\text {vol }}$ para os exames de crânio avaliados antes e após o processo de otimização dos protocolos pediátricos para as quatro faixas etárias analisadas. 70

Figura 4.2 - Box-plots comparativos da grandeza dosimétrica DLP para os exames de crânio avaliados antes e após o processo de otimização dos protocolos pediátricos para as quatro faixas etárias analisadas.

Figura 4.3 - Box-plots comparativos da grandeza dosimétrica CTDI $_{\text {vol }}$ para os exames de tórax avaliados antes e após o processo de otimização dos protocolos pediátricos para as quatro faixas etárias analisadas.

Figura 4.4 - Box-plots comparativos da grandeza dosimétrica DLP para os exames de crânio avaliados antes e após o processo de otimização dos protocolos pediátricos para as quatro faixas etárias analisadas.

Figura 4.5 - Gráfico de Bland-Altman das diferenças percentuais em relação à média das doses em órgãos obtidas com o software NCICT e as medições com OSLDs. A média das diferenças percentuais é apresentada na linha azul (3,5\%) e os limites de concordância são apresentados em linhas tracejadas. 


\section{LISTA DE TABELAS}

Tabela 2.1- Acontecimentos importantes da história da tomografia computadorizada (BERGER; MARCON; SALTYBAEVA; KALENDER et al., 2019; BUZUG, 2008; HSIEH, 2009; KALENDER, 2011; KALENDER, 2014; LELL; KACHELRIEß, 2020; LELL; WILDBERGER; ALKADHI;

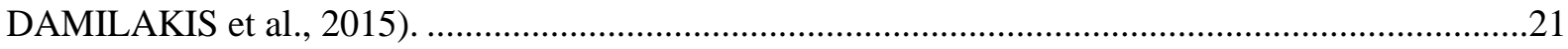

Tabela 2.2 - Características de desempenho da TC no de 1972 a 2010 (KALENDER, 2011).

Tabela 3.1 - Parâmetros usados na construção das curvas de calibração dos OSLDs.

Tabela 3.2 - Parâmetros de aquisição das imagens de tomografia de crânio realizadas no phantom pediátrico. Valores de $\mathrm{CTDI}_{\mathrm{vol}}$ e DLP exibidos pelo display do tomógrafo.

Tabela 3.3 - Distribuição dos porta-dosímetros nas fatias dos órgãos de interesse do phantom pediátrico ATOM para os protocolos de tórax avaliados.

Tabela 3.4 - Parâmetros de aquisição das imagens de tomografia de tórax realizadas no phantom pediátrico. Valores de $\mathrm{CTDI}_{\mathrm{vol}}$ e DLP exibidos pelo display do tomógrafo.

Tabela 3.5 - Valores calculados para os coeficientes de atenuação mássicos e suas respectivas energias efetivas, para os feixes de raios X de 100 e $120 \mathrm{kV}$.

Tabela 3.6 - Coeficientes de absorção mássicos para as energias de 51,6 keV e 56,0 keV calculados para estimativa de dose absorvida nos órgãos.

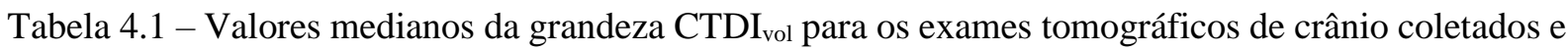
os DRLs propostos por três trabalhos internacionais. Valores entre parêntesis representam o intervalo interquartil.

Tabela 4.2 - Valores medianos da grandeza DLP para os exames tomográficos de crânio coletados e os DRLs propostos por três trabalhos internacionais. Valores entre parêntesis representam o intervalo interquartil.

Tabela 4.3 - Valores medianos da grandeza CTDI $_{\text {vol }}$ para os exames tomográficos de tórax coletados e os DRLs propostos por três trabalhos internacionais. Valores entre parêntesis representam o intervalo interquartil.

Tabela 4.4 - Valores medianos da grandeza DLP para os exames tomográficos de tórax coletados e os DRLs propostos por três trabalhos internacionais. Valores entre parêntesis representam o intervalo interquartil.

Tabela 4.5 - Parâmetros de qualidade de imagem calculados para os protocolos de TC de crânio helicoidais avaliados.

Tabela 4.6 - Parâmetros de qualidade de imagem calculados para os protocolos de TC de crânio axiais avaliados.

Tabela 4.7 - Parâmetros de qualidade de imagem calculados para os protocolos de TC de tórax avaliados

Tabela 4.8 - Fatores $Q_{\text {CтDI }}$ calculados para os protocolos de crânio helicoidais avaliados. ...................76

Tabela 4.9 - Fatores $Q_{\text {CтDI }}$ calculados para os protocolos de crânio axiais avaliados. ...........................76

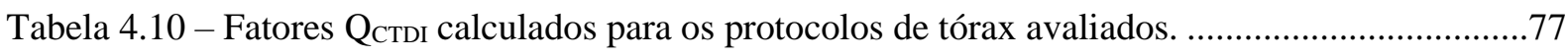

Tabela 4.11- Frações volumétricas dos órgãos avaliados contidas nas fatias do phantom pediátrico...77 
Tabela 4.12 - Curvas de calibração, parâmetros dosimétricos do exame e dose absorvida no cristalino e na tireoide para os protocolos de crânio helicoidais avaliados. 78

Tabela 4.13 - Curvas de calibração, parâmetros dosimétricos do exame e dose absorvida no cristalino e na tireoide para os protocolos de crânio axiais avaliados.

Tabela 4.14 - Curvas de calibração, parâmetros dosimétricos do exame e dose absorvida na tireoide nos pulmões para os protocolos de tórax avaliados.

Tabela 4.15 - Resultados comparativos de dose absorvida provenientes dos protocolos de crânio helicoidais avaliados e suas respectivas diferenças percentuais com valores simulados.

Tabela 4.16 - Resultados comparativos de dose absorvida provenientes dos protocolos de crânio axial avaliados e suas respectivas diferenças percentuais com valores simulados 81

Tabela 4.17 - Resultados comparativos de dose absorvida provenientes dos protocolos de tórax avaliados e suas respectivas diferenças percentuais com valores simulados. 


\section{ACRÔNIMOS}

AAPM - American Association of Physicists in Medicine

ALARA - As Low As Reasonably Achievable

CIRS - Computerized Imaging Reference Systems

CRP - Coordinated Research Project

CSR - Camada Semi-Redutora

CTDI - Computed Tomography Dose Index

DECT - Dual Energy Computed Tomography

DLP - Dose Length Product

DRL - Diagnostic Reference Levels

HU - Hounsfield Unit

IAEA - International Atomic Energy Agency

ICRP - International Comission on Radiation Protection

ICRU - International Comission on Radiation Units

LED - Light Emitting Diode

MC - Monte Carlo

MDCT - Multi-Detector Computed Tomography

MSCT - Multi-Slice Computed Tomography

NCICT - National Cancer Institute Dosimetry System for CT

NIST - National Institute of Standards and Technology

OSL - Optically Stimulated Luminescence

OSLD - Optically Stimulated Luminescent Dosimeter

PACS - Picture Archiving and Communication System

PMMA - Poli-metil-metacrilato

PVC - Policloreto de Vinil

RCR - Razão Contraste Ruído

RSR - Razão Sinal Ruído

RIS - Radiology Information System

SSDE - Size Specific Dose Estimates

TC - Tomografia Computadorizada

TLD - Thermoluminescent Dosimeter 


\section{SUMÁRIO}

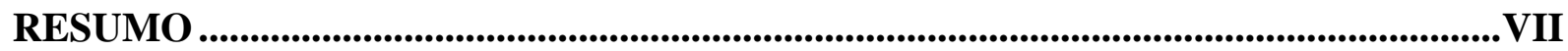

ABSTRACT .............................................................................................................

LISTA DE FIGURAS ............................................................................................................... IX

LISTA DE TABELAS ................................................................................................................... XI

ACRÔNIMOS .............................................................................................................................XIII

1. INTRODUÇÃO...........................................................................................................17

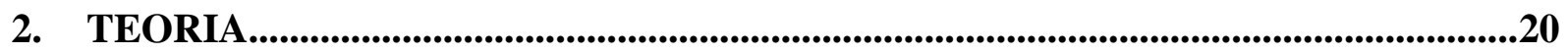

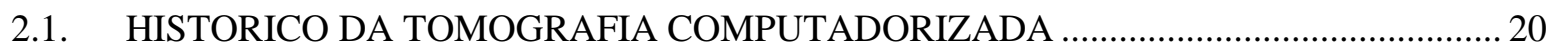

2.1.1. Anos 70: Do Exame de Cabeça ao Exame de Corpo Inteiro ........................................... 22

2.1.2. Anos 80: Escaneamento Rápido de Detector Único ....................................................... 23

2.1.3. Anos 90: Escaneamento Rápido de Volume ………......................................................... 24

2.1.4. Anos 2000: Diversidade e Escaneamentos de Volume Mais Rápidos ............................ 24

2.1.5. Anos 2010: A Década da Redução de Dose .................................................................. 25

2.2. O EQUIPAMENTO DE TOMOGRAFIA COMPUTADORIZADA …................................. 26

2.2.1. Gantry e a Mesa de Suporte para Paciente .................................................................... 26

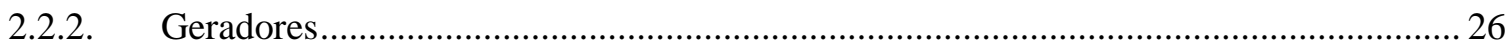

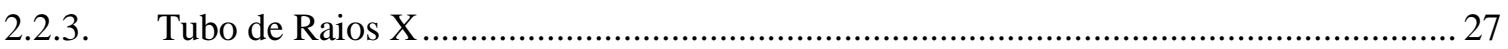

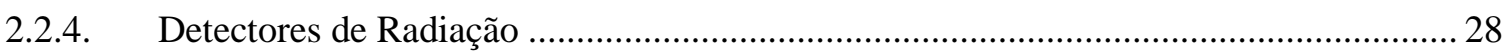

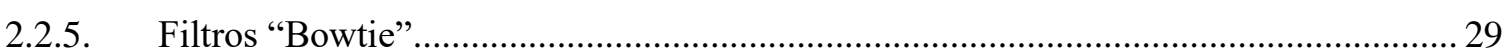

2.3. MODOS DE AQUISIÇÃO DE IMAGENS EM TOMOGRAFIA COMPUTADORIZADA 30

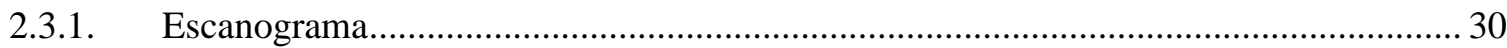

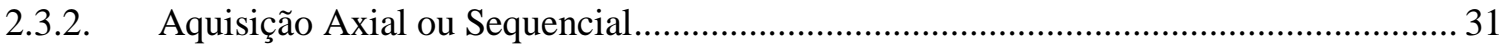

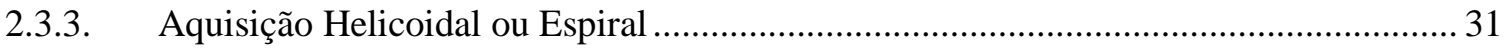

2.3.4. Tomografia Computadorizada de Múltiplos Detectores (MDCT) e Tomografia

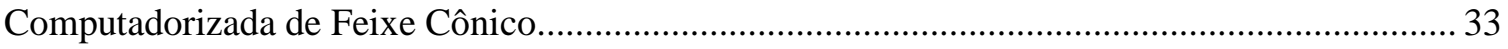

2.3.5. Tomografia Computadorizada de Dupla Energia ............................................................. 33

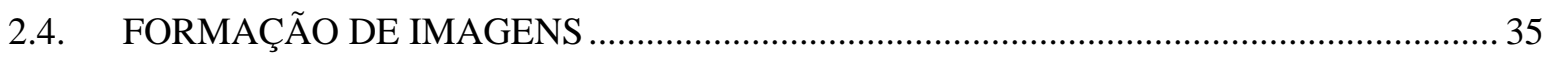

2.4.1. Número TC e Unidade Hounsfield ........................................................................................ 37

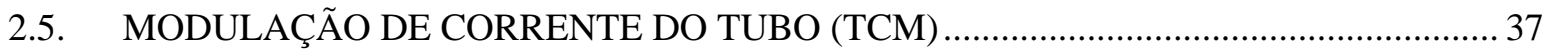

2.6. DOSIMETRIA PARA TOMOGRAFIA COMPUTADORIZADA ……............................... 38

2.6.1. Índice de Dose em Tomografia Computadorizada (CTDI) e Produto Dose-Comprimento (DLP) 38

2.6.2. Estimativa de Dose Específica por Tamanho (SSDE) ................................................... 41

2.6.3. Níveis de Referência de Diagnóstico (DRL) ............................................................... 41

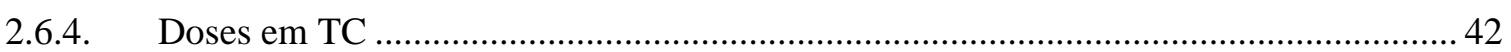


2.6.5. Otimização de Doses em TC

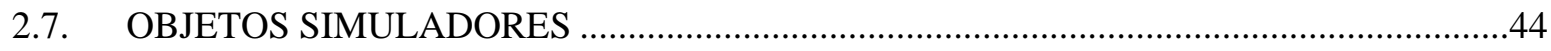

2.8. NATIONAL CANCER INSTITUTE DOSIMETRY SYSTEM FOR CT (NCICT) .............45

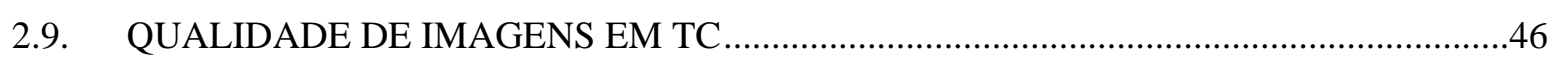

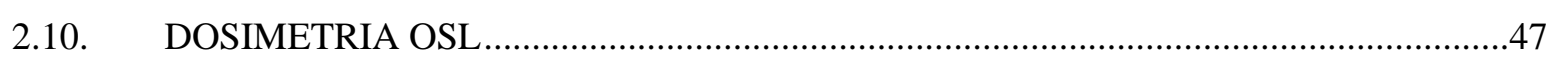

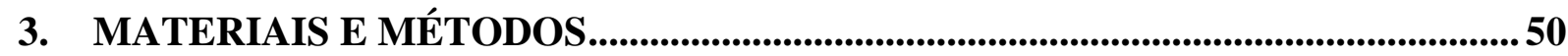

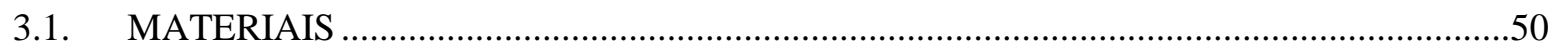

3.1.1. Phantom Pediátrico ATOM modelo 705 …......................................................................

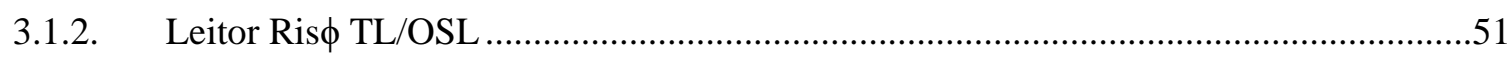

3.1.3. Dosímetros por Luminescência Opticamente Estimulada..............................................52

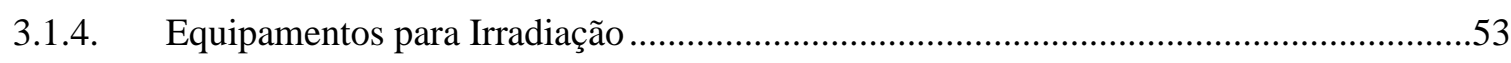

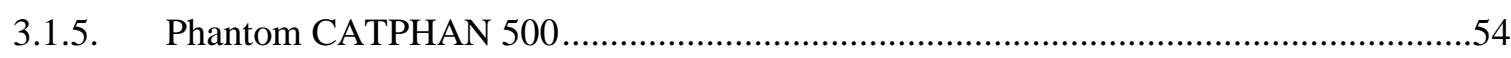

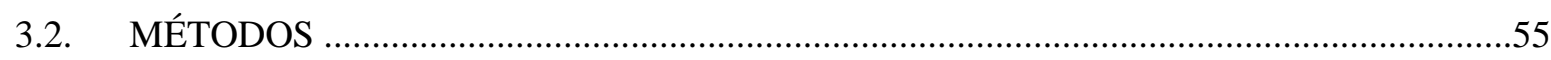

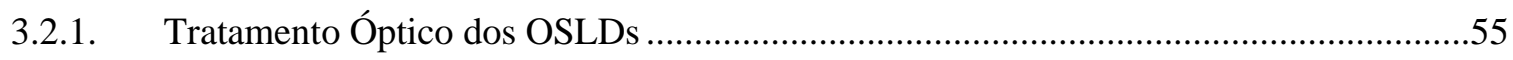

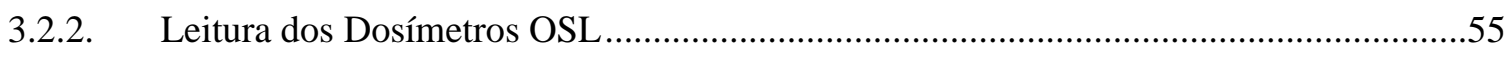

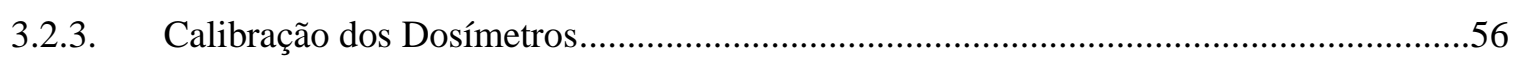

3.2.4. Estimativa do Volume Pulmonar do Phantom Pediátrico .................................................57

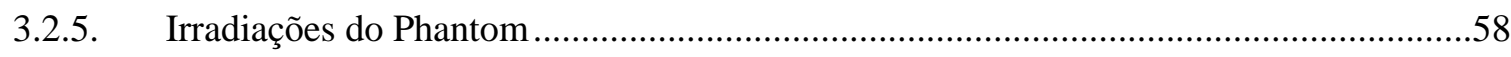

3.2.6. Estimativa de Dose Absorvida em Órgãos ......................................................................

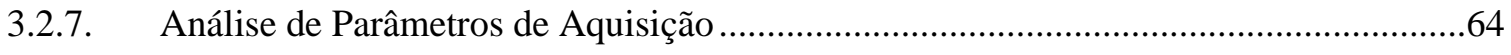

3.2.8. Avaliação Comparativa entre Doses Experimentais e Simuladas ....................................65

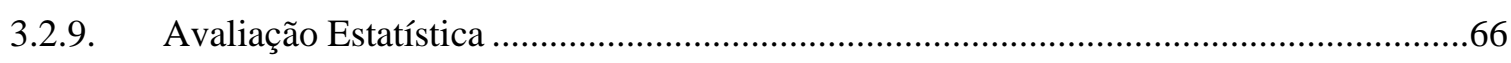

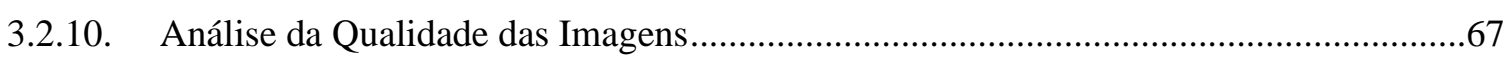

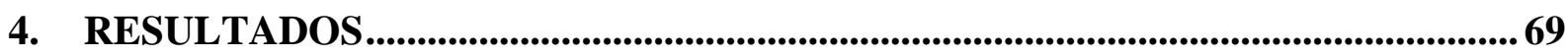

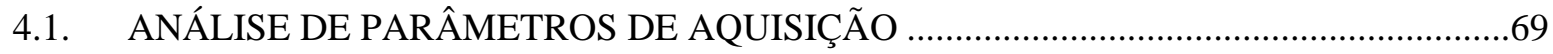

4.2. ANÁLISE DA VARIAÇÃO DA QUALIDADE DAS IMAGENS......................................74

4.3. ESTIMATIVA DO VOLUME PULMONAR DO PHANTOM PEDIÁTRICO ....................77

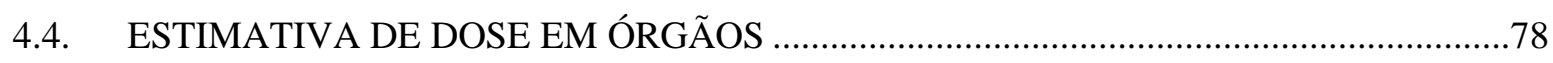

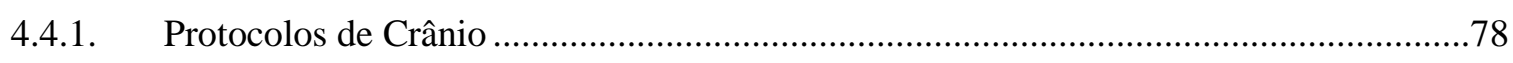

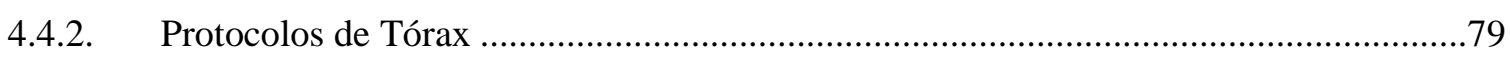

4.5. AVALIAÇÃO COMPARATIVA ENTRE DOSES EXPERIMENTAIS E SIMULADAS ..80

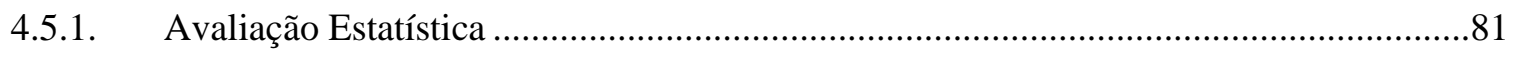

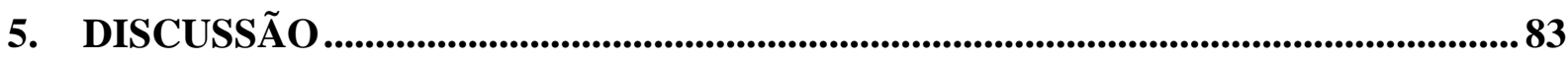

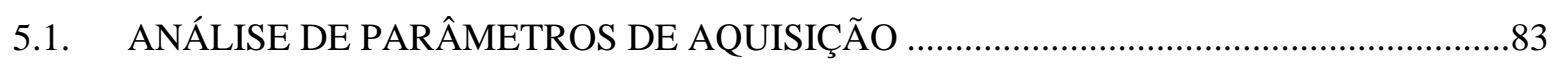

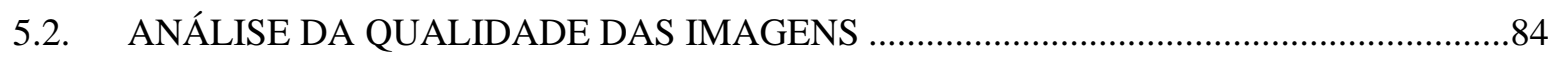

5.3. ESTIMATIVA DO VOLUME PULMONAR DO PHANTOM PEDIÁTRICO ....................85 


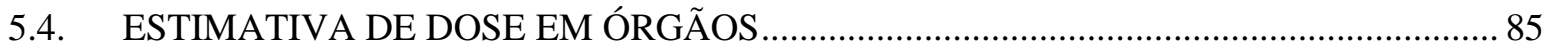

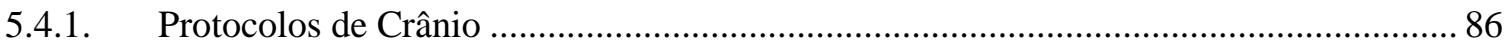

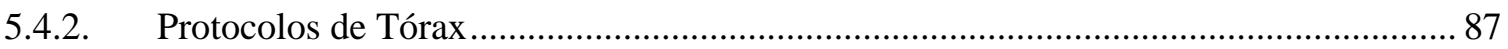

5.5. AVALIAÇÃO COMPARATIVA ENTRE DOSES EXPERIMENTAIS E SIMULADAS . 89

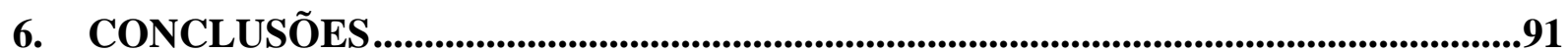

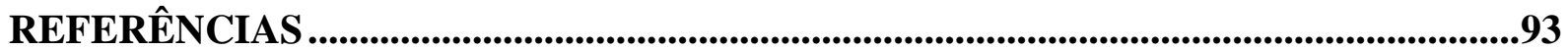

APÊNDICE A ..............................................................................................................................101

APÊNDICE B ................................................................................................................103 


\section{INTRODUÇÃO}

A Tomografia Computadorizada (TC) é um procedimento médico não invasivo que utiliza radiação ionizante (raios X) para produzir imagens do corpo humano. A TC foi a primeira modalidade de imagens médicas a produzir imagens digitais do corpo sem superposição de estruturas anatômicas (BUSHBERG; SEIBERT; LEIDHOLDT JR; BOONE, 2011; KALENDER, 2011). Em seu processo de aquisição o tubo de raios $\mathrm{X}$ gira rapidamente ao redor do paciente, e o arranjo de detectores, colocado à frente do tubo de raios X, é responsável pela coleta de dados. Os dados coletados são tratados para produzir imagens tomográficas do paciente, que podem ser digitalmente empilhadas na formação de uma imagem tridimensional.

A Tomografia Computadorizada tem sido uma das modalidades de imagem mais populares para salvar a vida de pacientes ou melhorar sua qualidade de vida, dado o esforço dedicado por cientistas e pesquisadores para torná-la mais potente para a excelência clínica (TANG; XIE, 2017). Como consequência, o uso da TC no mundo cresceu nas últimas décadas. Em geral, o crescente uso da TC em crianças pode ser atribuído à aquisição rápida do exame, que reduz a necessidade de sedação e possibilita o exame de crianças mais jovens, mais doentes e de difícil cooperação (WAGNER; BIZE; RACINE; LE COULTRE et al., 2018).

As estimativas de doses em tomografia computadorizada pediátrica têm sido uma área de grande interesse por causa da maior conscientização dos riscos de radiação associados à exposição desta modalidade na infância (VASSILEVA; REHANI; KOSTOVA-LEFTEROVA; AL-NAEMI et al., 2015). A preocupação com a exposição à radiação tem sido acompanhada pelo interesse em reduzir as doses de radiação mantendo a qualidade da imagem para o diagnóstico (PRINSEN; TRATTNER; WIEGERT; GERLAND et al., 2019). Atualmente existem campanhas de proteção radiológicas como Latin Safe (LATIN SAFE, 2015), EuroSafe (EUROSAFE, 2014), Image Wisely (IMAGE WISELY, 2010-20) e Image Gently (IMAGE GENTLY, 2014) (para pacientes pediátricos) que promovem boas práticas e fornecem diretrizes e orientações para o uso consciente da radiação ionizante para imagens médicas.

A otimização de dose em TC para pacientes pediátricos pode ser mais desafiadora do que a otimização para pacientes adultos, dada a grande variação de tamanhos e composições corporais (porcentagens de gordura, músculo e osso) presente em cada faixa etária e em diferentes grupos (AL MAHROOQI; NG; SUN, 2015). Adicionalmente, as crianças têm muitos anos de vida restantes para o desenvolvimento dos possíveis efeitos da radiação (BRENNER; ELLISTON; HALL; BERDON, 2001; ICRP, 2017). Os protocolos de imagem pediátrica devem ser adaptados ao tamanho ou idade da criança para evitar doses excessivas de radiação 
(NOTO; FUNAMA; KITAJIMA; UTSUNOMIYA et al., 2015). A otimização dos protocolos pediátricos de TC é uma tarefa contínua, que requer ajustes constantes (STRAUSS; GOSKE; KASTE; BULAS et al., 2010).

A avaliação da dose para essa população submetida a exames de TC é fundamental para avaliar o risco potencial associado e, possivelmente, identificar a necessidade de otimizar a prática atual (ABDULKADIR; RAHIM; MAZLAN; DAUD et al., 2020). Atualmente, abordagens experimentais envolvendo o uso de dosímetros termoluminescentes ou por luminescência opticamente estimulada em objetos simuladores têm sido utilizadas para estimativa de dose absorvida. Outro tipo de abordagem adotada é a computacional, baseada em simulações pelo método Monte Carlo.

Este trabalho foi parte de um projeto de pesquisa coordenado pela Agência Internacional de Energia Atômica (International Atomic Energy Agency - IAEA) (IAEA, 2013) (Coordinated Research Project - CRP E2.40.20), sob contrato 19047, chamado "Avaliação e Otimização de Imagens Pediátricas" (Evaluation and Optimizations of Pediatric Imaging). Este projeto de pesquisa consistiu num consórcio de 10 países para o estudo da otimização de doses administradas em procedimentos de diagnóstico por imagem para pacientes pediátricos. Neste CRP, o Instituto de Radiologia do Hospital das Clínicas da Faculdade de Medicina da USP (INRAD-FMUSP) em parceria com o Grupo de Dosimetria das Radiações e Física Médica do Instituto de Física da USP, iniciou a implementação de um processo de otimização de procedimentos radiológicos pediátricos ${ }^{\mathrm{a}}$, incluindo protocolos pediátricos de $\mathrm{TC}$ de crânio e tórax (GUERRA; NERSISSIAN; MELO; VASCONCELLOS et al., 2019).

O presente estudo tem como objetivo principal estimar a dose de radiação absorvida em alguns órgãos críticos resultantes de seis protocolos pediátricos de TC, utilizando dosímetros por luminescência opticamente estimulada (OSLDs) posicionados nas cavidades de um simulador antropomórfico pediátrico (phantom), equivalente a um paciente de cinco anos de idade. Foram avaliados três protocolos de TC previamente estabelecidos no Instituto de Radiologia do Hospital das Clínicas da Faculdade de Medicina da USP (INRAD-FMUSP) e três protocolos de TC novos, adotados após o processo de otimização de procedimentos radiológicos pediátricos. Os resultados de dose absorvida em órgãos foram validados através da comparação a valores de dose simulados via método Monte Carlo. Como objetivos específicos, foram realizadas uma avaliação de qualidade das imagens tomográficas e uma 
análise de parâmetros de aquisição de exames tomográficos de crânio e tórax, para a investigação e acompanhamento dos protocolos pré e pós implementação da otimização de procedimentos radiológicos pediátricos realizados na instituição.

Para apresentar o arranjo experimental adotado, a metodologia aplicada e resultados obtidos, este trabalho é dividido em seis capítulos:

- Capítulo 1 apresenta a motivação e justificativa deste projeto.

- Capítulo 2 apresenta os fundamentos teóricos na qual este trabalho é baseado.

- Capítulo 3 descreve os arranjos experimentais utilizados bem como as metodologias adotadas nas irradiações do phantom pediátrico e na estimativa da dose de radiação absorvida pelos órgãos de interesse.

- Capítulo 4 apresenta os principais resultados obtidos neste estudo: a estimativa da dose de radiação absorvida por alguns órgãos de interesse, provenientes de protocolos pediátricos de TC, a comparação com simulações do método Monte Carlo, a análise dos parâmetros de aquisição de TC coletados e avaliação da qualidade das imagens tomográficas.

- Capítulo 5 traz uma discussão dos resultados, baseada na comparação com simulações de dose via método Monte Carlo e em estudos semelhantes disponíveis na literatura.

- Capítulo 6 aponta as principais conclusões e sugestões para futuros projetos. 


\section{TEORIA}

\subsection{HISTORICO DA TOMOGRAFIA COMPUTADORIZADA}

$\mathrm{O}$ advento da tomografia computadorizada (TC) revolucionou a radiologia (LELL; WILDBERGER; ALKADHI; DAMILAKIS et al., 2015). Esta modalidade de exame tornou-se fundamental na rotina clínica por tratar-se do primeiro método de aquisição de imagens não invasiva a fornecer imagens de dentro do corpo humano sem a superposição de outras estruturas (BUSHBERG; SEIBERT; LEIDHOLDT JR; BOONE, 2011; BUZUG, 2008; KALENDER, 2011). A tecnologia da TC substituiu cirurgias exploratórias e forneceu melhores opções de tratamento, contribuindo para a melhoria da qualidade de vida e da expectativa de vida para milhões de pacientes (DAUER; CHU; ZANZONICO, 2018).

A Tomografia Computadorizada evoluiu em todos os aspectos de sua capacidade para aplicações clínicas desde sua introdução no início dos anos 1970, sendo o avanço técnico mais notável a velocidade de aquisição de dados e formação de imagens (TANG; XIE, 2017). No início, eram precisos cinco minutos para que os primeiros scanners de TC fizessem a aquisição do conjunto de dados necessários para a reconstrução de uma única fatia de imagem. Nos tomógrafos de múltiplos cortes (Multi Slice CT - MSCT) atuais, são necessários, em média, aproximadamente um milissegundo para a adquirir os dados necessários para gerar uma fatia de imagem, com sua tecnologia avançando constantemente para enfrentar os desafios impostos por aplicações clínicas avançadas (TANG; XIE, 2017). A conscientização dos riscos associados com a exposição à radiação ionizante desencadeou o desenvolvimento de uma variedade de técnicas para redução de dose (LELL; WILDBERGER; ALKADHI; DAMILAKIS et al., 2015).

Desde 2015, o desenvolvimento da tecnologia de TC passou de aumentar a velocidade de rotação do gantry, adicionando mais linhas ao painel do detector, e melhorar o desempenho dos tubos de raios $\mathrm{X}$ em direção a tecnologias interessantes, como detectores de contagem de fótons e algoritmos de aprendizado de máquina (machine learning) para pré-processamento de imagens (LELL; KACHELRIEß, 2020).

A viabilização da tomografia computadorizada deu-se graças ao desenvolvimento da moderna tecnologia dos computadores nos anos 60 (BUSHBERG; SEIBERT; LEIDHOLDT JR; BOONE, 2011; KALENDER, 2006), mas algumas ideias e experimentos produzidos anteriormente também contribuíram com o desenvolvimento dessa modalidade de exame. A Tabela 2.1 resume alguns dos principais acontecimentos históricos da TC. 
Usualmente, os equipamentos de TC são classificados em gerações, de acordo com a tecnologia utilizada pelo equipamento - como a geometria do feixe de raios $\mathrm{X}$, a maneira que o conjunto fonte-detectores se movimentava em torno do paciente, entre outros. Entretanto, neste trabalho, o desenvolvimento tecnológico do equipamento de TC será abordado em ordem cronológica, como proposto por Kalender (2011). O autor considera os avanços técnicos alcançados ao longo de décadas, desde a implementação do primeiro equipamento de tomografia computadorizada, no início dos anos 70.

Tabela 2.1- Acontecimentos importantes da história da tomografia computadorizada (BERGER; MARCON; SALTYBAEVA; KALENDER et al., 2019; BUZUG, 2008; HSIEH, 2009; KALENDER, 2011; KALENDER, 2014; LELL; KACHELRIEß, 2020; LELL; WILDBERGER; ALKADHI; DAMILAKIS et al., 2015).

\begin{tabular}{|c|c|}
\hline Ano & Acontecimento \\
\hline 1895 & Descobrimento dos raios X por W.C. Roentgen. \\
\hline 1901 & Roentgen recebe o prêmio Nobel de Física. \\
\hline 1917 & Transformada de Radon: solução do problema inverso da reconstrução por J.H. Radon. \\
\hline 1963 & $\begin{array}{c}\text { Desenvolvimento de uma técnica para calcular a distribuição de absorção no corpo humano } \\
\text { por A.M. Cormack. }\end{array}$ \\
\hline 1972 & $\begin{array}{c}\text { Produção das primeiras imagens clínicas com o equipamento de TC de cabeça EMI por } \\
\text { G.N. Hounsfield e J. Ambrose. }\end{array}$ \\
\hline 1975 & $\begin{array}{l}\text { Introdução do primeiro equipamento de TC de corpo inteiro em uso clínico com o chamado } \\
\text { "feixe de leque" de raios X. }\end{array}$ \\
\hline 1979 & Hounsfield e Cormack recebem o prêmio Nobel de Medicina e Fisiologia. \\
\hline 1989 & Primeiros exames clínicos com a TC helicoidal, conduzidos por W.A. Kalender e P. Vock. \\
\hline 1998 & Introdução dos tomógrafos com múltiplos cortes (quatro cortes). \\
\hline 1999 & Introdução da modulação de corrente do tubo. \\
\hline 2004 & Introdução dos tomógrafos de 64 cortes. \\
\hline 2006 & Introdução do equipamento de TC de Dupla Energia. \\
\hline $\begin{array}{l}\text { Década } \\
\text { de } 2010\end{array}$ & $\begin{array}{l}\text { Introdução da reconstrução interativa de imagem; Busca por redução e otimização de doses; } \\
\text { Melhorias gerais na velocidade e na qualidade das imagens; Uso de algoritmos machine } \\
\text { learning; Realização de testes clínicos in vivo de tomografia computadorizada de mama } \\
\text { equipada com detectores de contagem de fótons. }\end{array}$ \\
\hline
\end{tabular}




\subsubsection{Anos 70: Do Exame de Cabeça ao Exame de Corpo Inteiro}

A chamada "primeira geração" de tomógrafos foi o protótipo desenvolvido pelo engenheiro Godfrey Newbold Hounsfield, no início dos anos 70. Em 1969, quando foram realizados os primeiros testes com phantoms e uma fonte radioativa, o tempo de aquisição era cerca de nove dias por imagem. Seu funcionamento era baseado na translação linear do tubo de raios $\mathrm{X}$ e do detector, seguida pela rotação de grau em grau do conjunto fonte-detector escaneando a mesma região do objeto em ângulos diferentes (KALENDER, 2011). O feixe de raios $\mathrm{X}$ deste equipamento era bastante colimado e sua geometria era conhecida como "feixe lápis".

Para acelerar o processo de escaneamento, detectores foram adicionados e a geometria do feixe tornou-se divergente, num formato conhecido como "feixe de leque estreito". O tempo total do exame diminuiu para 35 minutos, com 5 minutos para a aquisição (KALENDER, 2011). Este foi o primeiro tomógrafo comercial, conhecido como "segunda geração" de tomógrafos.

Até então só era possível a realização de exames de cabeça, devido ao longo tempo de aquisição das imagens. Na metade dos anos 70, a meta de escaneamento dos tomógrafos era de apenas 20 segundos, o que permitiria um exame de corpo inteiro sem a interferência de movimento da respiração do paciente. Este objetivo foi atingido em 1976, com a introdução da chamada "terceira geração" de tomógrafos. Estes equipamentos baseavam-se na rotação $360^{\circ}$ do sistema fonte-detector em torno do paciente, cujo feixe dos raios $\mathrm{X}$ foi definido com "feixe de leque largo".

Pouco tempo depois, a "quarta geração" de tomógrafos foi desenvolvida. Nestes equipamentos, detectores estacionários eram dispostos em $360^{\circ}$, na forma de um anel, para que somente a fonte de raios $\mathrm{X}$ fizesse a rotação em torno do paciente. Esta geração de tomógrafos logo foi descontinuada, devido ao alto custo de fabricação e grande produção de radiação espalhada, prevalecendo assim os tomógrafos da "terceira geração".

As quatro gerações de tomógrafos são apresentadas na Figura 2.1. 
pencil beam (1970)

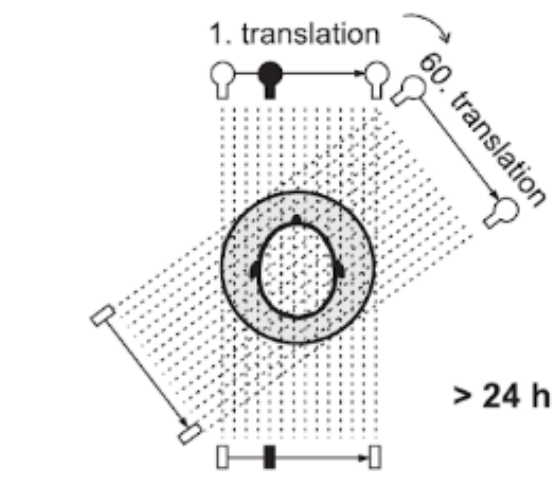

$1^{\text {st }}$ generation: translation / rotation partial fan beam (1972)

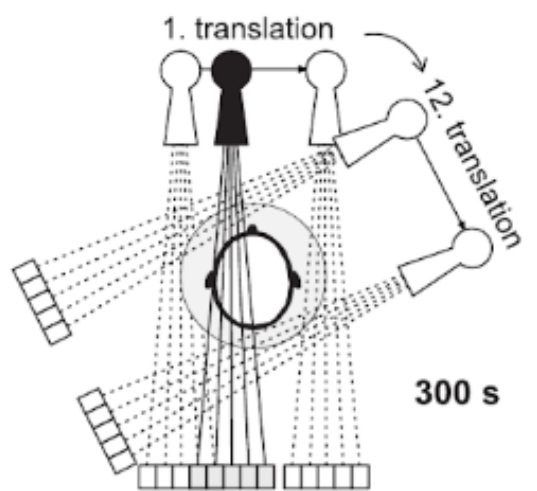

$2^{\text {nd }}$ generation: translation / rotation

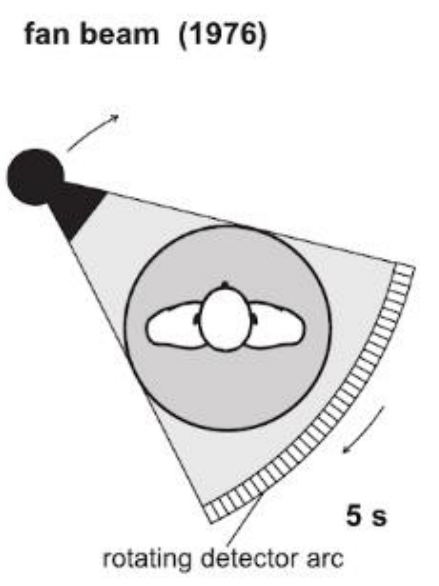

$3^{\text {rd }}$ generation: continuous rotation

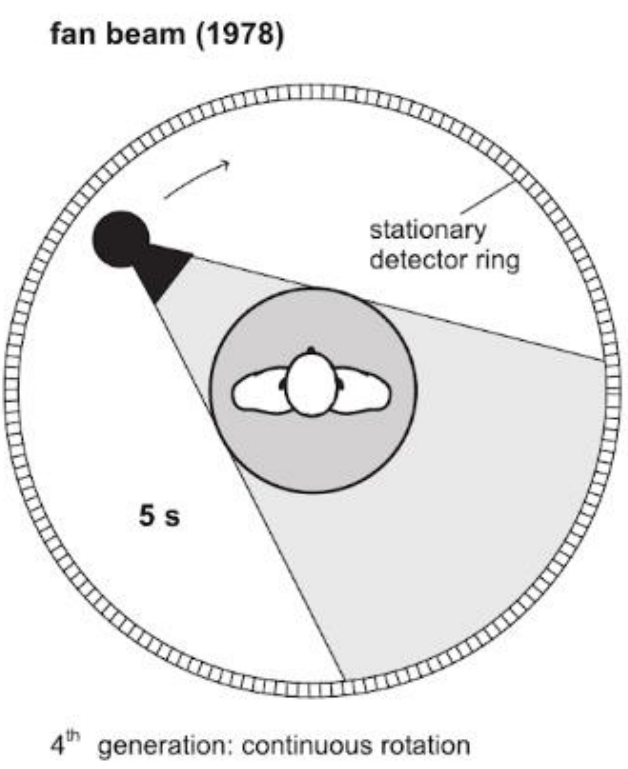

Figura 2.1 - Panorama histórico da evolução tecnológica dos equipamentos de TC. A primeira geração de tomógrafos fazia apenas exames de cabeça e operava com um feixe de lápis, num sistema de translação/rotação. A segunda geração, embora ainda como o mesmo sistema translação/rotação, já operava com um feixe de leque estreito. Com os tomógrafos da terceira geração, a aquisição de dados torna-se continua com a rotação do conjunto detector-fonte. Na quarta geração, o sistema de detectores tornou-se estacionário para que apenas o tubo de raios $\mathrm{X}$ girasse em torno do paciente. Fonte: Kalender 2011.

\subsubsection{Anos 80: Escaneamento Rápido de Detector Único}

Foi nesta década que ocorreu o avanço tecnológico responsável por diminuir ainda mais o tempo de aquisição das imagens tomográficas: a tecnologia de anéis deslizantes (slip rings). Esta tecnologia foi introduzida no mercado pela Siemens Medical Systems e Toshiba Medical Systems. Os anéis deslizantes foram a solução para o problema de alimentação do tubo de raios $\mathrm{X}$ feita por espessos cabos de alta tensão que impediam uma rotação contínua e mais 
rápida do sistema. Então, com esta nova tecnologia, a aquisição de dados pôde ser realizada de maneira contínua, diminuindo o tempo do exame de dois segundos para cerca de um segundo. Os slip rings também serviram de base para a TC helicoidal, amplamente utilizada atualmente.

\subsubsection{Anos 90: Escaneamento Rápido de Volume}

Desde a introdução da TC helicoidal, no início dos anos 90, a tecnologia e as capacidades dos equipamentos de tomografia computadorizada mudaram bastante (AAPM, 2008). Em 1992 a maioria dos fabricantes anunciou tomógrafos helicoidais com a tecnologia dos anéis deslizantes (KALENDER, 2011). Nos anos de 1994 e 1998, foram introduzidos os equipamentos com detectores de fileira dupla (dual-row detector) e com múltiplos detectores (multi-detector CT - MDCT ou também multi-slice CT - MSCT), respectivamente, marcando o fim da quarta geração de tomógrafos (KALENDER, 2011). Os equipamentos mais modernos de TC disponíveis atualmente são tomógrafos da chamada terceira geração, adaptados com a tecnologia dos slip rings e detectores para tomografias de cortes múltiplos.

\subsubsection{Anos 2000: Diversidade e Escaneamentos de Volume Mais Rápidos}

As tendências reveladas nos anos 90 continuaram neste período. Dentre os avanços tecnológicos alcançados nos anos 2000, destacam-se a introdução das modalidades de tomógrafos dual source e dual energy.

Embora a resolução de contraste tenha atingido um platô, os feixes de raios $\mathrm{X}$ mais largos foram responsáveis por diminuir ainda mais os tempos de escaneamento. A Tabela 2.2 oferece um resumo geral de algumas características de desempenho da TC no decorrer do tempo (KALENDER, 2011). 
Tabela 2.2 - Características de desempenho da TC no de 1972 a 2010 (KALENDER, 2011).

\begin{tabular}{|c|c|c|c|c|c|}
\hline & 1972 & 1980 & 1990 & 2000 & 2010 \\
\hline Tempo de rotação $360^{\circ}$ & $300 \mathrm{~s}$ & $5-10 s$ & $1-2 s$ & $0,33-0,5 \mathrm{~s}$ & $0,27-0,35 \mathrm{~s}$ \\
\hline $\begin{array}{l}\text { Tempo mínimo de } \\
\text { escaneamento }\end{array}$ & $300 \mathrm{~s}$ & $3 \mathrm{~s}$ & $0,7 \mathrm{~s}$ & $0,2-0,3 \mathrm{~s}$ & $0,075-0,2 \mathrm{~s}$ \\
\hline $\begin{array}{c}\text { Dados por escaneamento } \\
\mathbf{3 6 0}^{\circ}\end{array}$ & $57,6 \mathrm{kB}$ & $0,2-1 \mathrm{MB}$ & $1-2 \mathrm{MB}$ & $5-20 \mathrm{MB}$ & $0,1-1 \mathrm{~GB}$ \\
\hline $\begin{array}{c}\text { Dados por escaneamento } \\
\text { helicoidal }\end{array}$ & - & - & $12-24 \mathrm{MB}$ & $0,1-1 \mathrm{~GB}$ & $1-100 \mathrm{~GB}$ \\
\hline Matriz de imagem & $80 \times 80$ & $256 \times 256$ & $512 \times 512$ & $512 \times 512$ & $512 \times 512$ \\
\hline Potência & $2 \mathrm{~kW}$ & $10 \mathrm{~kW}$ & $40 \mathrm{~kW}$ & $60-100 \mathrm{~kW}$ & $80-120 \mathrm{~kW}$ \\
\hline Espessura de corte & $13 \mathrm{~mm}$ & $2-10 \mathrm{~mm}$ & $1-10 \mathrm{~mm}$ & $0,5-1 \mathrm{~mm}$ & $0,4-0,6 \mathrm{~mm}$ \\
\hline Resolução espacial & $3 \mathrm{Lp} / \mathrm{cm}$ & $8-12 \mathrm{Lp} / \mathrm{cm}$ & $\begin{array}{l}10-15 \\
\mathrm{Lp} / \mathrm{cm}\end{array}$ & $12-15 \mathrm{Lp} / \mathrm{cm}$ & $12-25 \mathrm{Lp} / \mathrm{cm}$ \\
\hline Resolução de contraste & $\begin{array}{c}5 \mathrm{~mm} / \\
5 \mathrm{HU} / \\
50 \mathrm{mGy}\end{array}$ & $\begin{array}{c}3 \mathrm{~mm} / \\
3 \mathrm{HU} / \\
30 \mathrm{mGy}\end{array}$ & $\begin{array}{c}3 \mathrm{~mm} / \\
3 \mathrm{HU} / \\
30 \mathrm{mGy}\end{array}$ & $\begin{array}{c}3 \mathrm{~mm} / \\
3 \mathrm{HU} / \\
30 \mathrm{mGy}\end{array}$ & $\begin{array}{c}3 \mathrm{~mm} / \\
3 \mathrm{HU} / \\
30 \mathrm{mGy}\end{array}$ \\
\hline
\end{tabular}

\subsubsection{Anos 2010: A Década da Redução de Dose}

Com o aumento da incidência dos exames tomográficos no mundo todo, a dose de radiação administrada aos pacientes durante um exame de TC tornou-se um assunto de extrema importância para a comunidade cientifica (BRENNER; HALL, 2007; IAEA, 2014; KALENDER, 2014). A década de 2010 está marcada pelo empenho em reduzir e otimizar as doses administradas durante o exame de tomografia computadorizada.

No início dos anos 2010, destaca-se a busca por tubos de raios X mais eficientes e por tomógrafos mais rápidos e com mais fileiras de detectores (LELL; KACHELRIEß, 2020). Mais recentemente, a TC vislumbrou tecnologias inovadoras, como a tecnologia dos detectores de contagem de fótons (photon counting detectors), que oferecem maior resolução espacial e menor ruído na imagem, e algoritmos de machine learning aplicados em reconstrução, préprocessamento, e análise de imagens (LELL; KACHELRIEß, 2020).

Recentemente, Berger e colegas (BERGER; MARCON; SALTYBAEVA; KALENDER et al., 2019) apresentaram os resultados dos primeiros testes in vivo realizados num equipamento de tomografia computadorizada dedicada a mama, equipada com detectores de contagem de fótons. O estudo forneceu imagens de boa qualidade com dose de radiação baixa, revelando potencial para a triagem e diagnóstico de câncer de mama. 


\subsection{O EQUIPAMENTO DE TOMOGRAFIA COMPUTADORIZADA}

O equipamento de tomografia computadorizada possui alguns elementos principais. São eles o gantry, a mesa de suporte para o paciente, o sistema computacional e o console de operação (FOSBINDER; ORTH, 2011). Tais componentes serão descritos nas próximas seções.

\subsubsection{Gantry e a Mesa de Suporte para Paciente}

O gantry é o principal componente do tomógrafo. Trata-se de uma estrutura em forma de anel, que abriga outros elementos: o tubo de raios $\mathrm{X}$, os detectores, colimadores e filtros, os geradores de alta tensão e o circuito elétrico de raios X (FOSBINDER; ORTH, 2011). A Figura 2.2 apresenta uma visão interna do gantry e de seus elementos.

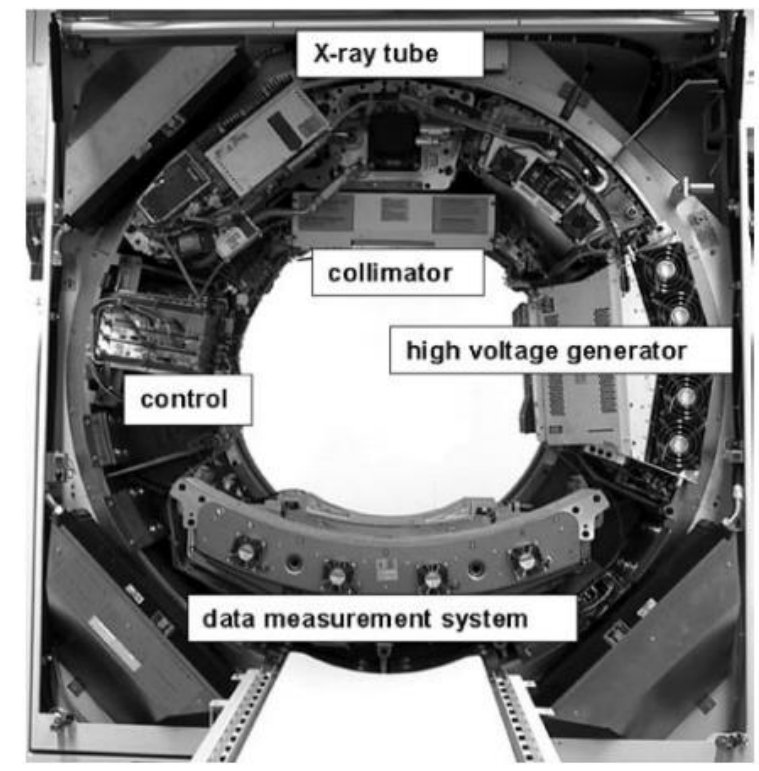

Figura 2.2 - Componentes do gantry de um tomógrafo da chamada "terceira geração" de TC. Fonte: Ulzheimer \& Flohr, 2009.

A mesa de suporte do paciente é geralmente feita com fibra de carbono-grafite de baixo número atômico, para reduzir a atenuação da radiação. Seu formato pode ser curvo ou plano (FOSBINDER; ORTH, 2011). O gantry também possui um sistema de alinhamento a laser, utilizado para auxiliar no posicionamento correto do paciente.

\subsubsection{Geradores}

Tomógrafos mais antigos funcionavam com geradores de baixa frequência (cerca de $60 \mathrm{~Hz}$ ), tão grandes que precisavam ficar do lado de fora do gantry, e se conectavam ao tubo 
rotativo de raios $\mathrm{X}$ por meio de cabos grossos de alta tensão. Este arranjo impedia que o tubo girasse continuamente e por este motivo caiu em desuso (FOSBINDER; ORTH, 2011).

Já os tomógrafos modernos operam com geradores de alta frequência (cerca de 3000Hz), pequenos o suficiente para que caibam dentro do gantry. Os cabos de alta tensão foram substituídos pelos anéis deslizantes (slip rings), permitindo a rotação contínua do sistema fontedetector ao redor do paciente e possibilitando também a aquisição das imagens de TC helicoidais (FOSBINDER; ORTH, 2011).

\subsubsection{Tubo de Raios $X$}

Um componente essencial para o tomógrafo, o tubo de raios X (Figura 2.3) é responsável pela produção dos fótons de raios X necessários para a realização do exame de TC (HSIEH, 2009). A TC não apenas revolucionou a prática clínica, mas também iniciou invenções importantes no campo da tecnologia dos tubos de raios X (BEHLING, 2015).

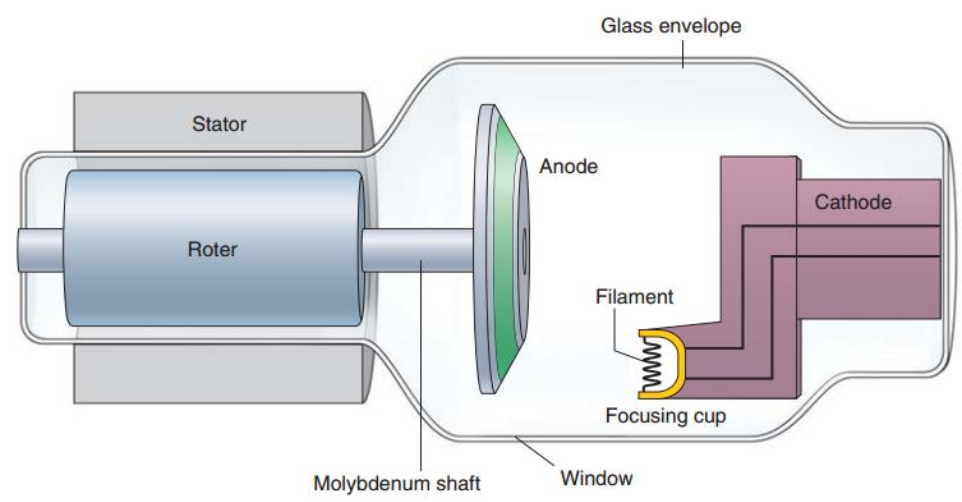

Figura 2.3 - Tubo de raios X e seus componentes. Fonte: Fosbinder \& Orth, 2011.

O tubo de raios X consiste em dois eletrodos - o cátodo e o ânodo (ou alvo) - dentro de um tubo de vidro mantido a vácuo (DANCE; CHRISTOFIDES; MAIDMENT; MCLEAN et al., 2014; FOSBINDER; ORTH, 2011). O cátodo é o eletrodo negativo do sistema, composto de um ou mais filamentos que, quando energizados, liberam elétrons por emissão termiônica. A aceleração dos elétrons é causada por um campo elétrico entre o cátodo e o ânodo (BEHLING; GRÜNER, 2018). O ânodo rotativo é normalmente carregado positivamente, nos chamados tubos bipolares (BEHLING; GRÜNER, 2018). Na colisão com o material do ânodo, grande parte da energia dos elétrons é depositada na forma de calor, sendo apenas uma pequena fração - cerca de $1 \%$ - emitida na forma de raios X (BUSHBERG; SEIBERT; LEIDHOLDT JR; BOONE, 2011; FOSBINDER; ORTH, 2011). Recentemente, tubos polares simples ganharam popularidade, por exemplo, para aplicação de alto desempenho em tomografia 
computadorizada. Nestes tubos, apenas o cátodo é carregado (negativamente). Para evitar artefatos, os sistemas de ponta de TC oferecem a capacidade de alternar, eletronicamente, a posição do ponto focal dentro do tubo de raios X (BEHLING; GRÜNER, 2018). Introduzido no mercado pela Siemens em 2003, o tubo de raios X Straton (Figura 2.4) possui um pequeno ânodo com apenas $120 \mathrm{~mm}$ de diâmetro que gira com toda a estrutura do tubo e cujos rolamentos são lubrificados com óleo e não no vácuo (BEHLING, 2015).

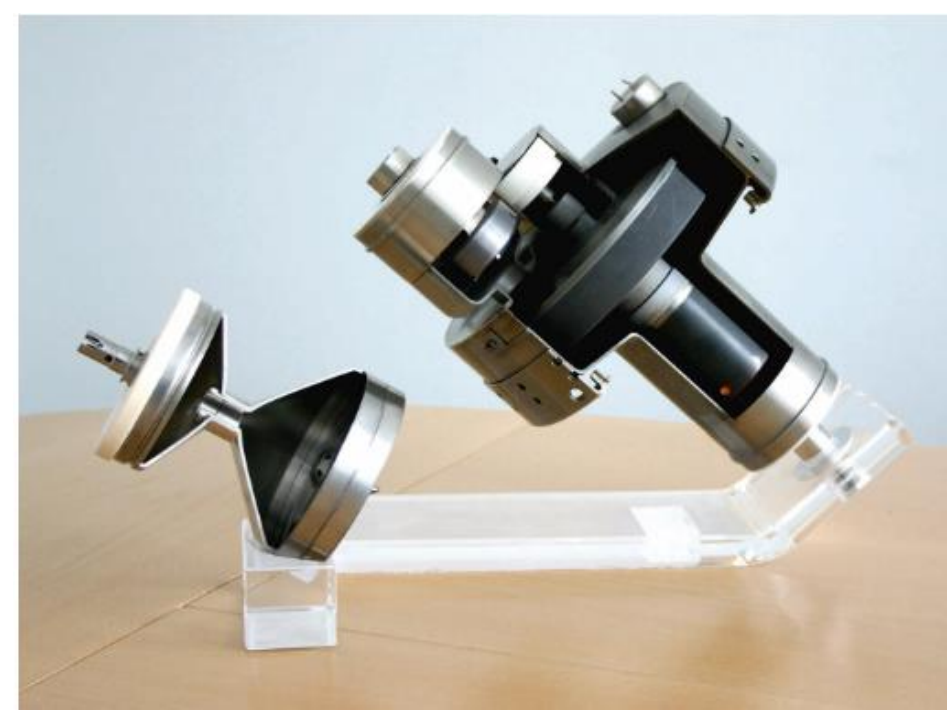

Figura 2.4 - Tubo de raios X Straton da Siemens. Fonte: https://www.siemens-healthineers.com/press-room/pressmedia-gallery/im-2015070926hc.html

A escolha usual do tungstênio como material para o ânodo deve-se ao seu alto ponto de fusão, capaz de suportar as altas temperaturas atingidas em virtude do grande fluxo de fótons necessário ao exame. Para evitar a destruição do ânodo pelo calor, os tomógrafos modernos adotam tubos de raios $\mathrm{X}$ com ânodos rotativos, pois estes espalham o calor numa área maior que os ânodos estacionários, permitindo maiores correntes e tempos de exposição mais longos (BUSHBERG; SEIBERT; LEIDHOLDT JR; BOONE, 2011).

\subsubsection{Detectores de Radiação}

Os detectores são os elementos do tomógrafo responsáveis pela recepção dos fótons de raios X após a sua interação com o paciente. Estão dispostos em forma de arco rotativo, posicionados do lado oposto ao tubo de raios $\mathrm{X}$, em número suficiente para captar o feixe em leque da radiação. $\mathrm{O}$ arranjo estacionário dos detectores, característico da quarta geração dos tomógrafos, não é mais adotado nos equipamentos modernos (FOSBINDER; ORTH, 2011), devido ao elevado custo de produção. 
Os equipamentos de TC têm utilizado, basicamente, dois tipos de detectores: detectores a gás ou detectores cintiladores. A interação dos raios X com os detectores cintiladores (Figura 2.5) gera luz, que será convertida em sinal elétrico por fotodiodos fixados na parte de trás dos detectores (DANCE; CHRISTOFIDES; MAIDMENT; MCLEAN et al., 2014). Já os detectores a gás fazem a conversão da radiação incidente diretamente em sinal elétrico. Os tomógrafos modernos utilizam os detectores cintiladores (ULZHEIMER; FLOHR, 2009).

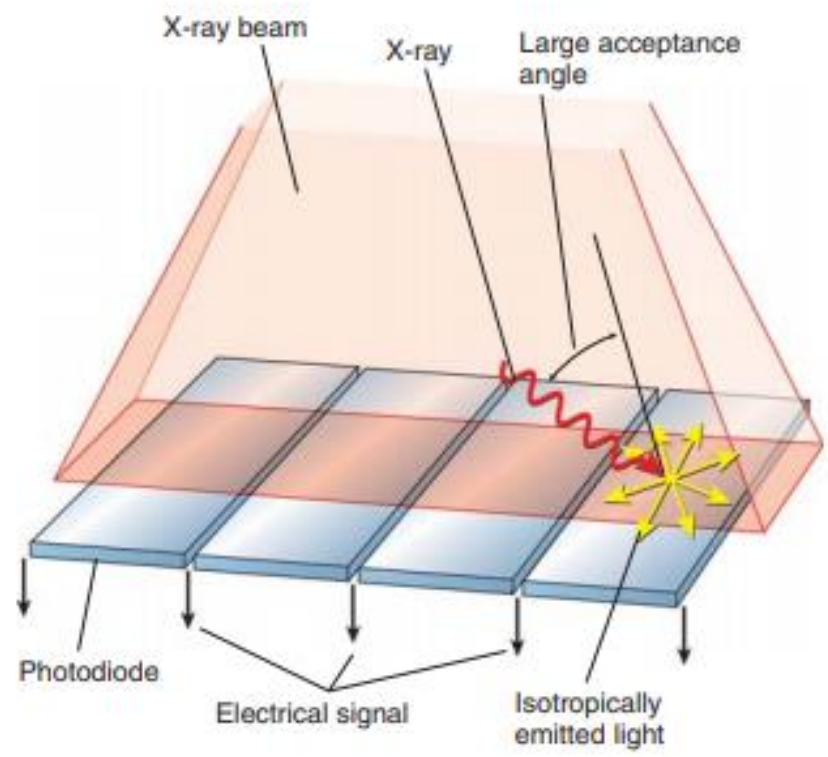

Figura 2.5 - Detectores cintiladores. Posicionados na parte de trás dos detectores, os fotodiodos fazem a conversão da luz em sinal elétrico. Fonte: Fosbinder \& Orth, 2011.

\subsubsection{Filtros "Bowtie"}

Os equipamentos de tomografia computadorizada utilizam filtros em formatos de uma gravata borboleta, conhecidos como filtros bowtie (Figura 2.6), posicionados entre o tubo de raios X e o paciente. A geometria deste filtro uniformiza o fluxo de radiação, uma vez que reduz a intensidade do feixe na periferia, onde a região do corpo humano é menos espessa.

Outra vantagem do uso do filtro é a redução da dose de radiação entregue ao paciente, sem perda na qualidade da imagem. Isso acontece porque o filtro absorve os fótons de raios $\mathrm{X}$ menos energéticos do espectro, que seriam absorvidos pelo paciente antes de atingir os detectores, tornando o feixe de raios $\mathrm{X}$ mais penetrante - processo conhecido como endurecimento do feixe. 


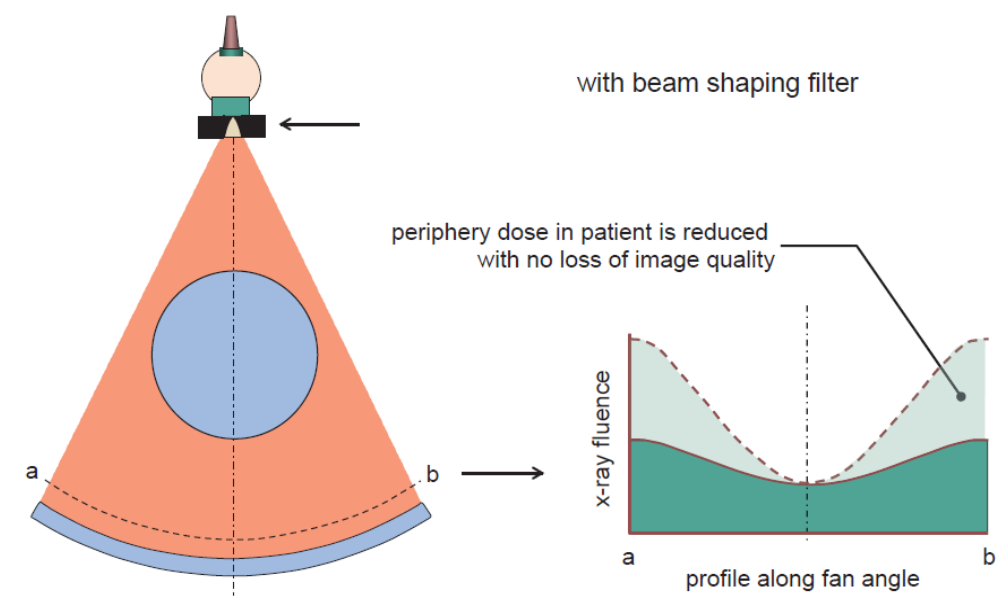

Figura 2.6 - O filtro bowtie é utilizado nos tomógrafos para compensar a forma elipsoidal do corpo humano e fica acoplado ao tubo de raios $\mathrm{X}$. O uso deste filtro atenua o feixe de radiação na periferia do campo, reduzindo a dose de radiação entregue ao paciente sem perda de qualidade para a imagem. Fonte: Bushberg et al., 2011.

\subsection{MODOS DE AQUISIÇÃO DE IMAGENS EM TOMOGRAFIA COMPUTADORIZADA}

Como consequência da evolução tecnológica dos tomógrafos, alguns modos de aquisição de imagens foram desenvolvidos. O escanograma, as aquisições axial e helicoidal, a aquisição de feixe cônico, a TC Cardíaca e a TC de Dupla Energia são alguns exemplos de modos de aquisição de imagens em TC. Serão descritas nas próximas seções a radiografia de TC, a TC de Dupla Energia e as aquisições axial, helicoidal e de feixe cônico.

\subsubsection{Escanograma}

Também conhecida como scout view ou topograma, o escanograma, é uma imagem 2D adquirida com o tomógrafo antes da aquisição completa de TC rotacional (HOYE; SHARMA; ZHANG; FU et al., 2019). É utilizada na rotina clínica para o posicionamento do paciente, sendo adquirida com tubo de raios $\mathrm{X}$ e detectores estacionários, semelhante a uma radiografia convencional, em que o paciente é deslocado através do gantry a uma velocidade baixa e constante. As projeções mais frequentemente adquiridas são as projeções anteroposterior (AP), póstero-anterior (PA) e lateral (LAT) (BUSHBERG; SEIBERT; LEIDHOLDT JR; BOONE, 2011).

Baseando-se no escanograma, o operador seleciona a região de varredura do exame e os parâmetros de aquisição das imagens, como a tensão do tubo no de raios $\mathrm{X}(\mathrm{kV})$, a corrente anódica (mA), o tempo (s) de rotação do gantry, tipo de varredura (helicoidal ou axial), o pitch 
(a ser definido na próxima seção) entre outros (BUSHBERG; SEIBERT; LEIDHOLDT JR; BOONE, 2011).

\subsubsection{Aquisição Axial ou Sequencial}

Na tomografia computadorizada axial, a mesa de suporte é mantida a uma distância fixa do gantry e o tubo de raios $\mathrm{X}$ rotaciona em torno do paciente para escanear uma fatia da área clínica de interesse. Em seguida, a mesa de suporte é deslocada para o escaneamento da próxima fatia e este processo é repetido até que toda a área clínica de interesse seja escaneada (FOSBINDER; ORTH, 2011; ULZHEIMER; FLOHR, 2009). Este tipo de aquisição ficou conhecida como "step and shoot mode" (aquisição passo a passo) e leva mais tempo que a TC helicoidal por que o tubo de raios $\mathrm{X}$ é desligado durante o deslocamento da mesa (FOSBINDER; ORTH, 2011). A Figura 2.7 ilustra o processo de aquisição axial da TC.

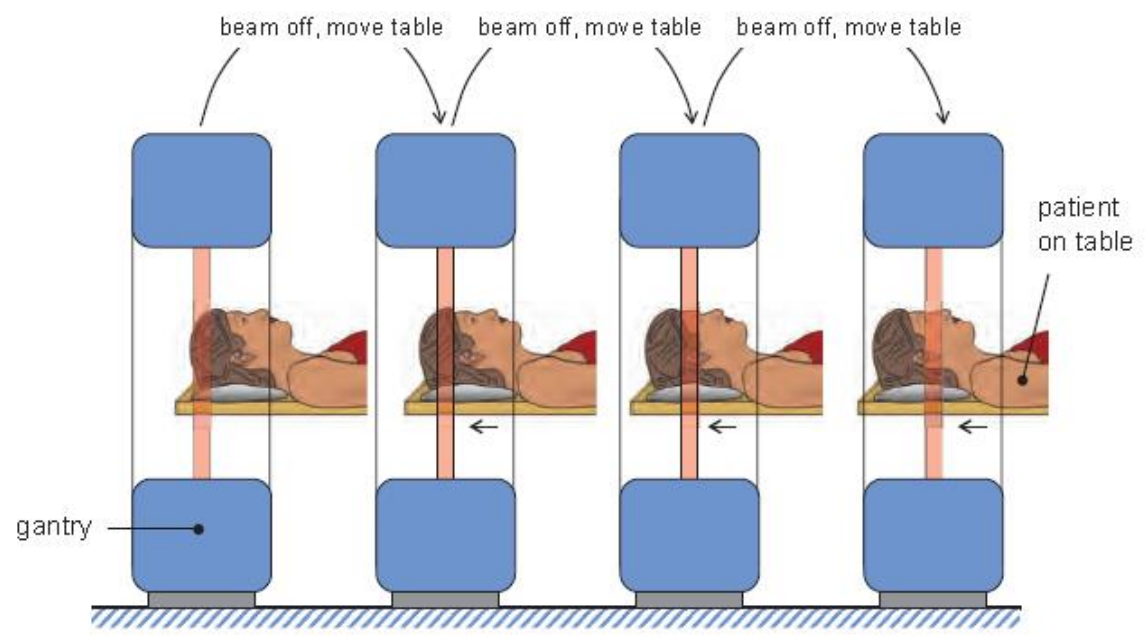

Figura 2.7 - Modo de aquisição axial de tomografia computadorizada, em que a irradiação do paciente é feita passo a passo. $\mathrm{O}$ tubo de raios $\mathrm{X}$ é desligado entre os ciclos consecutivos de aquisição. O processo é repetido até que toda a região de interesse seja escaneada. Fonte: Bushberg et al., 2011.

\subsubsection{Aquisição Helicoidal ou Espiral}

Neste tipo de aquisição as imagens são obtidas continuamente, formando uma trajetória em hélice (Figura 2.8). Neste processo, a mesa é movida a uma velocidade constante enquanto o conjunto fonte-detector rotaciona em torno do paciente (BUSHBERG; SEIBERT; LEIDHOLDT JR; BOONE, 2011). A aquisição helicoidal tornou-se possível graças a tecnologia dos slip-rings. Uma de suas maiores vantagens é a rapidez da aquisição das imagens, 
já que não há interrupções da fonte para a translação da mesa, permitindo o escaneamento completo da região clínica de interesse em apenas uma única respiração (HSIEH, 2009).

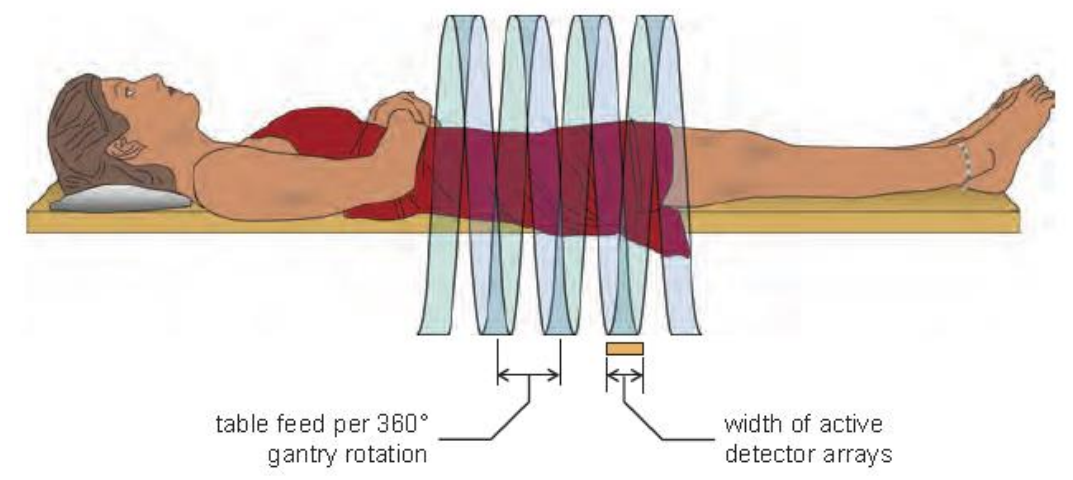

Figura 2.8 - Modo de aquisição helicoidal de tomografia computadorizada, em que a irradiação é feita durante a translação da mesa do paciente. $\mathrm{O}$ tubo de raios X descreve uma trajetória em hélice ao redor do paciente. Fonte: Bushberg et al., 2011.

Um fator importante para a TC helicoidal é o pitch ou espaçamento - grau de sobreposição entre fatias adjacentes da TC - que descreve o avanço relativo da mesa de TC por rotação do gantry definido como (BUSHBERG; SEIBERT; LEIDHOLDT JR; BOONE, 2011):

$$
\text { Pitch }=\frac{F_{\text {mesa }}}{n T}
$$

onde $F_{m e s a}$ é a progressão da mesa por rotação do gantry, n é número de detectores e T é a espessura dos detectores, sendo $n T$ é a largura nominal do feixe colimado. Para a maioria dos tomógrafos o intervalo do pitch varia entre 0,75 e 1,5 . O pitch define as sobreposições ou lacunas do intervalo de varredura: um pitch menor que 1,0 resulta em overscanning do paciente, aumentando a sua dose de radiação absorvida. Já um pitch maior que 1,0 resulta em underscanning do paciente, entregando uma dose de radiação menor para o paciente.

A relação entre dose relativa e o pitch é dada por (BUSHBERG; SEIBERT; LEIDHOLDT JR; BOONE, 2011):

$$
\text { Dose } \propto \frac{1}{\text { pitch }} \text {. }
$$




\subsubsection{Tomografia Computadorizada de Múltiplos Detectores (MDCT) e Tomografia}

Computadorizada de Feixe Cônico

A tomografia computadorizada de múltiplos detectores (Multi-Detector Computed Tomography - MDCT), também conhecida como TC de múltiplos cortes (Multi-Slice Computed Tomography - MSCT), permitiu maior cobertura de volume com tempos de aquisição mais baixos em comparação a equipamentos com sistema de detector único (ULZHEIMER; FLOHR, 2009). Este equipamento faz uso da geometria da chamada "terceira geração" de tomógrafos (AAPM, 2008; BUSHBERG; SEIBERT; LEIDHOLDT JR; BOONE, 2011) aliada a tecnologia dos slip rings e a adição de várias matrizes de detectores ao longo do eixo z (AAPM, 2008).

O sistema de tomografia computadorizada de feixe cônico (Cone Beam CT - CBCT) é, essencialmente, um sistema MDCT com um grande número de detectores (BUSHBERG; SEIBERT; LEIDHOLDT JR; BOONE, 2011). A Figura 2.9 ilustra seções transversais de feixes de raios $\mathrm{X}$ e os arranjos de detectores para três modelos diferentes de tomógrafos.

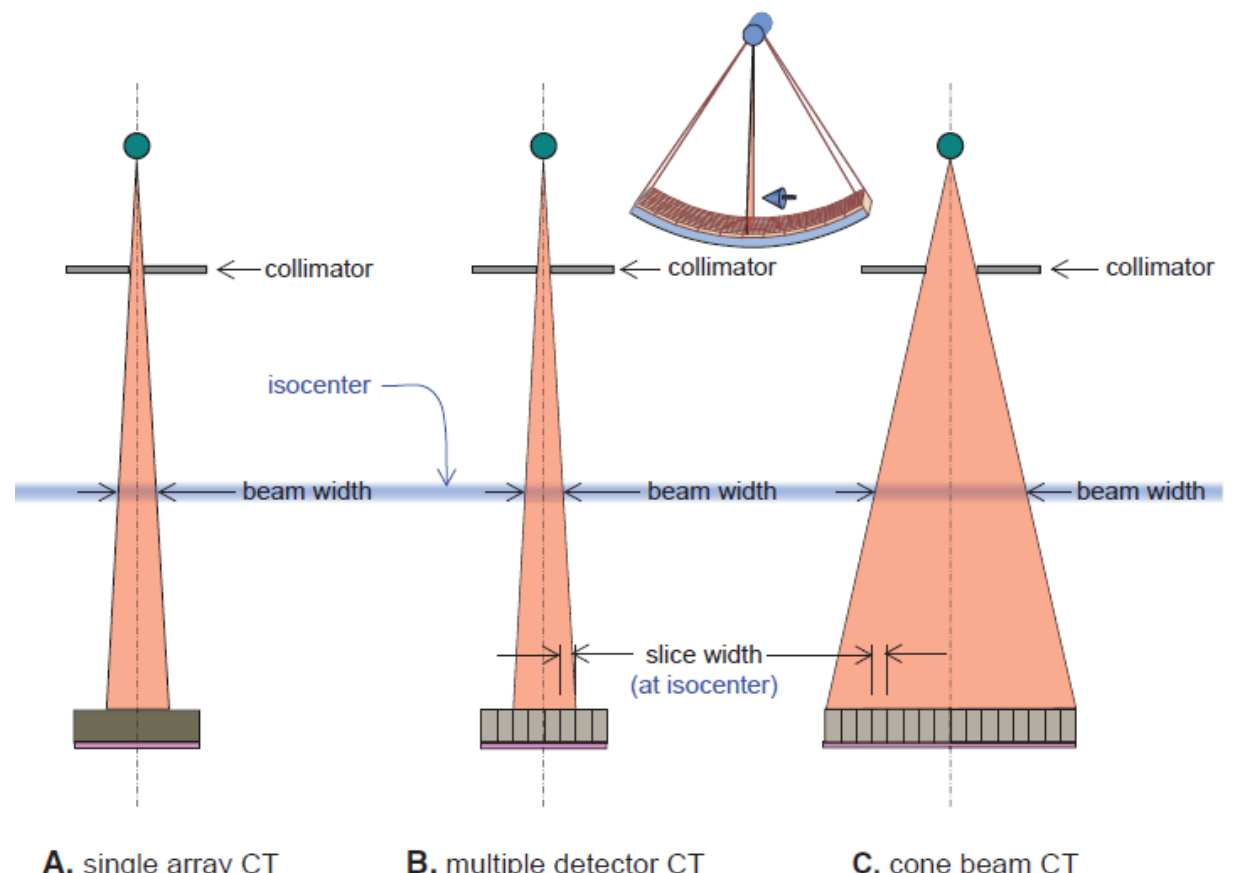

Figura 2.9 - Seções transversais de feixe de raios X e os respectivos arranjos de seus detectores para três modelos de TC: (a) único detector, (b) múltiplos detectores (MDCT) e (c) conjunto grande de múltiplos detectores (CBCT). Fonte: Bushberg et al., 2011.

\subsubsection{Tomografia Computadorizada de Dupla Energia}

O termo "TC de Dupla Energia" (Dual Energy CT - DECT) refere-se à aquisição de dados correspondentes a dois espectros de fótons diferentes e, portanto, também é referida como 
"TC Espectral" (Spectral CT) (PERISINAKIS, 2017). Neste tipo de TC, as medições de atenuação obtidas com o segundo espectro de raios X permitem a decomposição de uma mistura de dois ou três materiais em seus materiais constituintes (MCCOLLOUGH; LENG; YU; FLETCHER, 2015). Cinco diferentes abordagens de implementação para aquisição de dados DECT têm sido empregadas: aquisição consecutiva, dupla fonte, troca rápida de tensão no tubo, detector de camada dupla e filtragem de feixe dupla (PERISINAKIS, 2017).

A abordagem mais simples é a aquisição consecutiva, em que os dados de projeção de TC de baixa e alta energia são coletados consecutivamente, usando o modo de aquisição sequencial (axial) ou helicoidal (PERISINAKIS, 2017).

A TC de Dupla Fonte (Dual Source CT - DSCT) é um sistema de tomografia na qual duas fontes de raios X e dois sistemas de aquisição de dados são montados no mesmo gantry, posicionados ortogonalmente entre si (MCCOLLOUGH; LENG; YU; FLETCHER, 2015). Neste arranjo, o controle da tensão e da corrente do tubo de raios $\mathrm{X}$ é feito de maneira independente, pois cada fonte de raios $\mathrm{X}$ é equipada com seu próprio gerador de alta tensão.

A terceira técnica de aquisição de dados DECT consiste na troca rápida de tensão do tubo de raios $\mathrm{X}$, ao longo da rotação do conjunto fonte-detectores. Os dados de projeção são coletados duas vezes para aproximadamente a mesma posição da fonte de raios $\mathrm{X}$ ao longo do arco de rotação de $360^{\circ}$ (ou seja, uma para baixa e outra para alta tensão do tubo) (PERISINAKIS, 2017).

Em vez de utilizar dois feixes de TC com diferentes energias efetivas para obter dados de projeção de baixa e alta energia, os equipamentos DECT com detectores de camada dupla utilizam um único feixe de TC e um inovador sistema de detecção em dupla camada, em que os dados de projeção de baixa e alta energia são coletados pela camada superior e inferior do detector, respectivamente (PERISINAKIS, 2017).

Baseada no uso de filtros móveis de dois materiais para dividir o espectro de raios $\mathrm{X}$, (que é produzido por uma única fonte), a técnica de dupla filtragem separa o feixe incidente em duas partes ao longo do eixo z. O feixe de raios X é pré-filtrado por filtros de ouro e estanho e é dividido, respectivamente, em feixes de raios $\mathrm{X}$ de alta e baixa energia antes de chegar ao paciente (PERISINAKIS, 2017).

Tendo a capacidade única de diferenciar tecidos e fornecer melhor qualidade de imagem para a patologia investigada, a TC de Dupla Energia abriu novas perspectivas para o diagnóstico por imagem (PERISINAKIS, 2017). Atualmente, existem várias aplicações clínicas bem 
estabelecidas do DECT, como por exemplo, remoção de osso, quantificação de iodo, caracterização de cálculos renais e diagnóstico de gota.

\subsection{FORMAÇÃO DE IMAGENS}

O princípio da TC baseia-se na medição da distribuição espacial de uma grandeza física em diferentes direções, e calcular, a partir destes resultados, imagens sem superposição de estruturas anatômicas (KALENDER, 2011). Esta grandeza física é o coeficiente de atenuação linear, $\mu(x, y)$.

Para calcular a atenuação dos raios $\mathrm{X}$ da fonte até o detector, é necessário conhecer a sua intensidade de radiação primária ou sem atenuação $\left(I_{0}\right)$ e também a intensidade de radiação atenuada pelo paciente (I) (KALENDER, 2011). No caso mais simples de um feixe mono energético de raios $X$ atenuado por objeto homogêneo, a atenuação é descrita pela equação:

$$
I=I_{0} e^{-\mu d}
$$

Em que $\mu$ é o coeficiente de atenuação linear e $d$ é a espessura do objeto atenuador. A Figura 2.10 apresenta três diferentes casos de atenuação.

O primeiro caso é o mais simples, em que um objeto homogêneo é irradiado com um feixe mono energético de radiação (Figura 2.10, caso 1). A intensidade da radiação decai exponencialmente com a espessura do objeto atenuador e a atenuação é definida como o logaritmo natural da razão entre a intensidade primária $I_{0}$ e a intensidade atenuada $I$ ou apenas o produto entre a espessura do objeto atenuador $d$ e o coeficiente de atenuação linear $\mu$. Para um valor conhecido para a espessura de objeto atenuador, $\mu$ pode ser calculado diretamente.

No segundo caso, um objeto não-homogêneo é irradiado com feixe mono energético de radiação (Figura 2.10, caso 2). Neste caso, a atenuação ao longo da trajetória do feixe depende do valor local do coeficiente de atenuação linear $\mu_{i}$. A soma dos intervalos da trajetória deve ser realizada com pequenos incrementos $d_{i}$, podendo ser expressa como a integral sobre $\mu$ no decorrer da trajetória do feixe. A determinação dessas integrais de linha é exatamente o objetivo da tomografia computadorizada.

O caso 3 apresenta um caso mais complexo e genuíno: um objeto não-homogêneo irradiado por um feixe poli energético de radiação (Figura 2.10, caso 3). Neste caso também é necessário realizar a integração sobre todos os intervalos de energia, uma vez que o coeficiente de atenuação linear, bem como as intensidades de radiação primária e atenuadas, é fortemente 
dependente da energia. Este processo de integração é realizado automaticamente nos equipamentos atuais de TC (KALENDER, 2011).
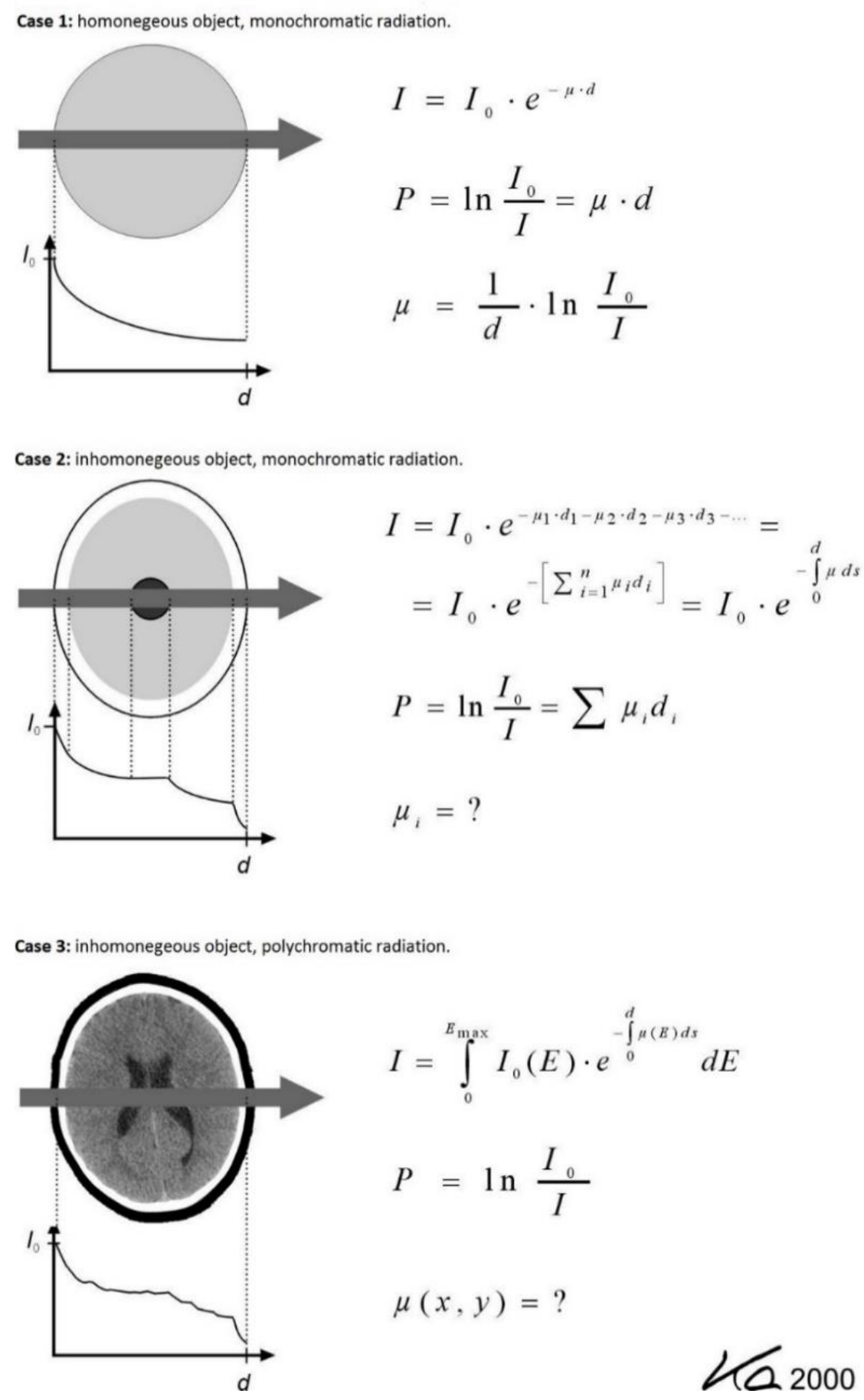

$$
\begin{aligned}
& I=\int_{0}^{E_{\max }} I_{0}(E) \cdot e^{-\int_{0}^{d \mu(E) d s} d E} \\
& P=\ln \frac{I_{0}}{I} \\
& \mu(x, y)=?
\end{aligned}
$$

Figura 2.10 - A intensidade de radiação atenuada. Ilustração de três casos de atenuação, considerando feixes de raios $\mathrm{X}$ mono energéticos e poli energéticos atenuados por objetos homogêneos e não homogêneos. Para objetos não homogêneos, a imagem tomográfica é necessária para determinar a distribuição $\mu(x, y)$. Fonte: Kalender (2011). 


\subsubsection{Número TC e Unidade Hounsfield}

Na modalidade de TC, os tons de cinza das imagens são de grande importância (BUSHBERG; SEIBERT; LEIDHOLDT JR; BOONE, 2011). Esses tons de cinza da TC são chamados de número TC ou valor TC (CT numbers ou CT values) e são determinados em unidades Hounsfield (Hounsfiel Units - HU) em homenagem ao engenheiro Godfrey N. Hounsfield, inventor do primeiro tomógrafo. O número TC é definido como (KALENDER, 2011):

$$
N u ́ m e r o T C=\frac{\mu_{T}-\mu_{\text {água }}}{\mu_{\text {água }}} \times 1000 H U
$$

em que $\mu_{T}$ é o coeficiente de atenuação linear para um tecido arbitrário e $\mu_{a ́ g u a}$ é o coeficiente de atenuação linear da água. O número TC adotado para o ar é -1000 e o número TC adotado para a água é 0.

\subsection{MODULAÇÃO DE CORRENTE DO TUBO (TCM)}

Os sistemas de TC atuais oferecem controle automático de exposição (Automatic Exposure Control - AEC) com modulação de corrente de tubo (Tube Current Modulation TCM) para reduzir a dose ao paciente, mantendo a qualidade da imagem (BARRETO; VERMA; QUAILS; OLGUIN et al., 2020; REINA, 2014). Obtida a partir de escanogramas, a modulação é baseada na atenuação do feixe de raios X nos tecidos do corpo, visando manter o nível de qualidade de imagem (MARTIN; SOOKPENG, 2016). A inclusão de funções para modular a corrente do tubo para compensar variações na atenuação dos tecidos corporais dos pacientes foi um grande desenvolvimento tecnológico para auxiliar na otimização de dose (MARTIN; SOOKPENG, 2016).

A modulação angular (plano x-y) compreende a variação da corrente do tubo para igualar o fluxo de fótons ao detector, à medida que o tubo de raios $\mathrm{X}$ gira em torno do paciente (MCCOLLOUGH; BRUESEWITZ; KOFLER JR, 2006). Neste caso, o operador escolhe um valor inicial para o produto corrente-tempo do tubo (mAs) e a corrente do tubo é modulada (normalmente diminuída) a partir do valor inicial durante uma rotação do gantry (MCCOLLOUGH; BRUESEWITZ; KOFLER JR, 2006). 
A modulação longitudinal (eixo $\mathrm{z}$ ) compreende a variação da dose de radiação entre regiões anatômicas variando a corrente do tubo ao longo do eixo z do paciente, cujo objetivo é a produção de níveis de ruído relativamente uniformes nas várias regiões da anatomia (MCCOLLOUGH; BRUESEWITZ; KOFLER JR, 2006). Em outras palavras, o sistema calcula a corrente do tubo necessária para adquirir imagens com um nível de ruído pré-selecionado. Assim, o operador deve selecionar o nível desejado de qualidade de imagem usando algum dos métodos específicos do fabricante (MCCOLLOUGH; BRUESEWITZ; KOFLER JR, 2006).

\subsection{DOSIMETRIA PARA TOMOGRAFIA COMPUTADORIZADA}

As grandezas dosimétricas Índice Volumétrico de Dose em Tomografia Computadorizada (Volume Computed Tomograghy Dose Index - $\mathrm{CTDI}_{\mathrm{vol}}$ ) e Produto DoseComprimento (Dose Length Product - DLP) são frequentemente usadas para representar as doses de radiação de uma tomografia computadorizada (AAPM, 2014). As definições destas grandezas serão descritas nas próximas seções.

2.6.1. Índice de Dose em Tomografia Computadorizada (CTDI) e Produto DoseComprimento (DLP)

As primeiras medições de dose e mapeamento de distribuição de dose em TC eram realizados com dosímetros termoluminescentes (DIXON, 2019). O conceito da grandeza dosimétrica CTDI foi introduzido pela primeira vez nos EUA em 1981, por Shope et al (1981) (SHOPE; GAGNE; JOHNSON, 1981) como uma métrica para refletir a quantidade de radiação ionizante produzida durante um exame de tomografia computadorizada (AAPM, 2019; KALENDER, 2014; MCCOLLOUGH; LENG; YU; CODY et al., 2011). Atualmente, existem algumas variações do conceito de CTDI: CTDI100, $\mathrm{CTDI}_{w}$ e $\mathrm{CTDI}_{\mathrm{vol}}$, sendo todos medidos em mGy. Particularmente, o CTDIvol pode ser útil, em conjunto com informações de tamanho do paciente e a região anatômica irradiada, na estimativa de dose do paciente. Contudo, os valores de CTDI não devem ser interpretados como estimativas de dose do paciente (MCCOLLOUGH; LENG; YU; CODY et al., 2011).

O CTDI é determinado através da medição da radiação liberada em uma única rotação da fonte de raios X ao redor da mesa de suporte (AAPM, 2019). Esta grandeza é medida com uma câmara de ionização do tipo lápis e com simuladores cilíndricos padrão de poli-metilmetacrilato (PMMA) de $32 \mathrm{~cm}$ de diâmetro (simulador de corpo) ou de $16 \mathrm{~cm}$ de diâmetro (simulador de cabeça). Estes cilindros possuem $15 \mathrm{~cm}$ de comprimento e são dotados de uma 
cavidade central e mais quatro cavidades periféricas para a inserção da câmara de ionização (Figura 2.11). A definição formal do CTDI é dada pela relação 2.5:

$$
C T D I=\frac{1}{N T} \int_{-\infty}^{+\infty} D(z) d z,
$$

em que $D(z)$ é o perfil de dose de radiação ao longo do eixo z, $N$ é o número de fatias, $T$ é a largura da fatia e $N T$ é a largura de todas as fatias.

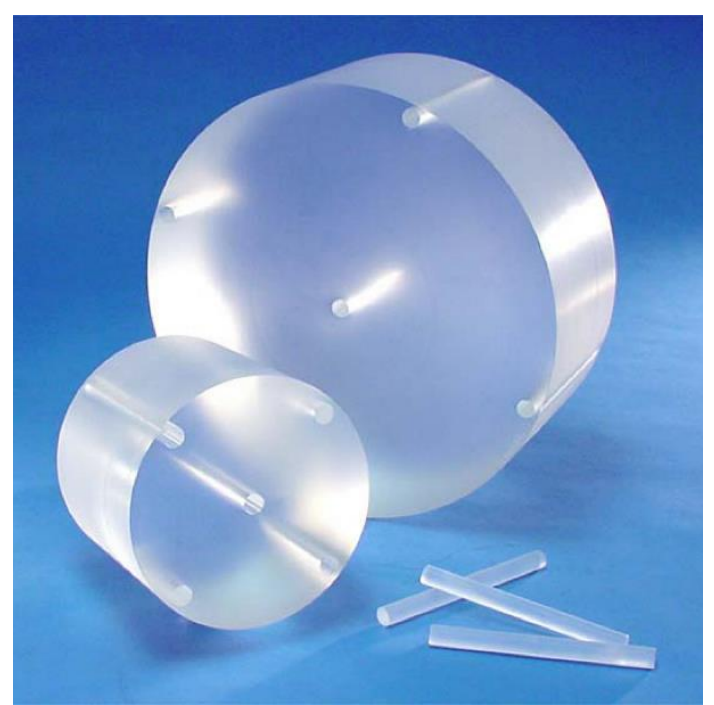

Figura 2.11 - Simuladores cilíndricos de PMMA utilizados para medição de CTDI. O cilindro menor (com $16 \mathrm{~cm}$ de diâmetro) é adotado como simulador de cabeça e o cilindro maior (com $32 \mathrm{~cm}$ de diâmetro) é adotado como simulador de corpo. Fonte: <http://www.universalmedicalinc.com/ct-dose-phantom.html〉.

$\mathrm{O} \mathrm{CTDI}_{100}$, introduzido em 1995 como um indicador mais prático de dose do paciente é baseado na medição com câmara de ionização do tipo lápis de $100 \mathrm{~mm}$ de comprimento (DIXON, 2019). Esta grandeza dosimétrica é medida e calculada através da integração do perfil de dose ao longo de $100 \mathrm{~mm}$ e os limites de integração da equação 2.5 são redefinidos de $50 \mathrm{~mm}$ até $+50 \mathrm{~mm}$. Seu baseado na leitura de kerma no ar realizada com a câmara de ionização, é realizado de acordo com a relação (AAPM, 2008):

$$
C T D I_{100}=\frac{f c \times L \times 100 \mathrm{~mm}}{N T}
$$

em que $f c$ é o fator de calibração para conversão da leitura em unidades de kerma no ar (mGy), $L$ é a leitura da câmara de ionização e $100 \mathrm{~mm}$ é o comprimento da integral ao longo do eixo z.

Como o $\mathrm{CTDI}_{100}$ possui valores diferentes para os eixos central e periférico, o desejo em se ter um valor único de CTDI para representar a "dose" em uma pesquisa nacional na Suécia originou uma dose "média ponderada" (DIXON, 2019). O CTDI ponderado (CTDI $\left.{ }_{w}\right)$ 
por sua vez, considera a inomogenidade das distribuições de dose e é calculado de acordo com a relação (KALENDER, 2014):

$$
C T D I_{w}=\frac{1}{3} C T D I_{100, c}+\frac{2}{3} C T D I_{100, p}
$$

em que o $C T D I_{100, c}$ é o $C T D I_{100}$ calculado a partir da medição com câmara de ionização no centro do cilindro de PMMA e o $C T D I_{100, p}$ é o $C T D I_{100}$ calculado como a média das medições com a câmara de ionização nos quatro orifícios da periferia do cilindro de PMMA.

Outra variação do CTDI é o CTDI volumétrico $\left(\mathrm{CTDI}_{\mathrm{vol}}\right)$, que considera o espaçamento helicoidal para aquisições de imagens helicoidais. É obtido através da razão entre o $\mathrm{CTDI}_{\mathrm{w}}$ e o pitch (para aquisições helicoidais) ou a translação da mesa dividida pela largura da colimação (para aquisições axiais):

$$
C T D I_{v o l}=\frac{1}{p i t c h} \times C T D I_{w}
$$

Usando o formalismo de CTDI, uma estimativa da dose absorvida integrada para um volume escaneado de comprimento L é fornecida pelo Produto Dose-Comprimento (Dose Length Product - DLP), definido para exames axiais (equação 2.9) e helicoidais (equação 2.10), respectivamente, como (AAPM, 2019):

$$
\begin{gathered}
D L P_{\text {Axial }}=C T D I_{v o l} \times \Delta d \times n \\
D L P_{\text {Helicoidal }}=C T D I_{v o l} \times L
\end{gathered}
$$

Em que $n$ é o número de rotações do exame axial, $\Delta$ d é a translação da mesa por rotação e L é o deslocamento total da mesa durante o exame helicoidal.

Embora o phantom de CTDI e sua metodologia de medição com câmara de ionização do tipo lápis se provaram muito úteis, sofrem de limitações que foram examinadas criticamente ao longo dos últimos anos (AAPM, 2020). Um estudo recente (GONZALES, 2019) propõe uma abordagem analítica sobre a descrição da distribuição da dose em simuladores cilíndricos submetidos a procedimentos de CT clínicos, a partir da qual é possível derivar descritores de dose mais precisos para os exames de TC atuais do que a métrica tradicional $\mathrm{CTDI}_{100}$. 


\subsubsection{Estimativa de Dose Específica por Tamanho (SSDE)}

O relatório 204 da Associação Americana de Físicos em Medicina (American Association of Physicists in Medicine - AAPM) introduziu o uso de uma grandeza que utiliza

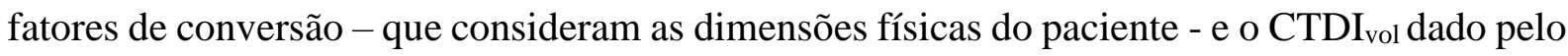
scanner na determinação da estimativa de dose específica por tamanho (Size Specific Dose Estimates - SSDE) da TC. A grandeza SSDE é calculada de acordo com (AAPM, 2019):

$$
S S D E=f_{W E D} \times C T D I_{v o l}
$$

Em que o fWED representa o fator de conversão que reflete o tamanho do paciente, para um dado diâmetro equivalente a água (water-equivalent diameter - WED).

O WED pode ser calculado usando a radiografia de TC (ou scout view) ou imagens axiais reconstruídas utilizando um FOV completo (AAPM, 2014; 2019).

\subsubsection{Níveis de Referência de Diagnóstico (DRL)}

O conceito de Níveis de Referência de Diagnóstico (Diagnostic Reference Levels DRL) foi introduzido pela primeira vez nos anos 90, proposto pela publicação 73 da Comissão Internacional de Proteção Radiológica (Commission on Radiological Protection - ICRP) (ICRP, 1996). Os DRLs são níveis de referência para imagens médicas obtidas com radiação ionizante e podem ser usados na identificação das doses administradas em determinados procedimentos, revelando se são excessivas ou insuficientes. A ICRP e a IAEA (International Atomic Energy Agency - IAEA) sugerem que os DRLs sejam usados como uma ferramenta prática para promover otimização (RIA; DAVIS; SOLOMON; WILSON et al., 2019). Eles se aplicam a grupos de pacientes e não devem ser usados para avaliar doses de radiação em pacientes individuais (DAUER; CHU; ZANZONICO, 2018). Um dado valor de DRL não deve ser interpretado como um limite de dose (ICRP, 2017).

Os valores de DRL são determinados para cada tipo específico de exame por imagem. No caso da TC, as grandezas dosimétricas adotadas como DRLs são o CTDI $_{\text {vol }}$ e o DLP (EUROPEAN SOCIETY OF RADIOLOGY, 2015). Se esses valores forem obtidos com phantoms, é essencial ter certeza de que o mesmo phantom está sendo usado, pois existem dois tipos padrão: 16 e 32 cm de diâmetro (DAUER; CHU; ZANZONICO, 2018). 
Algumas pesquisas europeias fornecem valores de DRLs pediátricos baseados em grupos etários e, recentemente, foram publicadas para TC recomendações de DRLs pediátricos baseados no peso do paciente (DAUER; CHU; ZANZONICO, 2018).

\subsubsection{Doses em TC}

Existem riscos e benefícios associados ao uso da tomografia computadorizada, tal qual qualquer tipo procedimento médico (DAUER; CHU; ZANZONICO, 2018). Embora a TC englobe doses maiores de radiação quando comparada a procedimentos convencionais de radiologia (BRENNER; HALL, 2007), a dose de radiação absorvida que um paciente recebe em um exame tomográfico de rotina é considerada com um risco muito baixo de dano, quando usada adequadamente para obter um diagnóstico (AAPM, 2019). A dose de radiação associada a um típico exame de TC é equivalente a dose de radiação recebida anualmente de fontes naturais de radiação - como radiações cósmicas (ANAM; HARYANTO; WIDITA; ARIF et al., 2017; MCCOLLOUGH; PRIMAK; BRAUN; KOFLER et al., 2009).

A melhor grandeza para estimativa de risco é a dose em órgão (AAPM, 2019; BRENNER; HALL, 2007). A dose absorvida é a quantidade de energia depositada pela radiação no tecido humano (JAMAL; SAYED; SYED, 2020) e é expressa em Grays (Gy). Embora as grandezas dosimétricas para TC sejam bem definidas, elas somente quantificam a radiação entregue pelo tomógrafo. A dose de radiação absorvida pelo paciente também depende do seu tamanho, o que torna a sua estimativa uma tarefa bastante complexa. Nos últimos anos, alguns tipos de abordagens têm sido adotadas, como medições diretas, utilizando diferentes tipos de dosímetros em phantoms antropomórficos (GIANSANTE; MARTINS; NERSISSIAN; KIERS et al., 2019) ou em objetos post-mortem (BARRETO; LAMOUREUX; OLGUIN; QUAILS et al., 2019; GRIGLOCK; SINCLAIR; MENCH; CORMACK et al., 2015; SINCLAIR; GRIGLOCK; MENCH; LAMOUREUX et al., 2015) e cálculos baseados em simulações de métodos Monte Carlo em combinação com phantoms computacionais (KRAMER; KHOURY; VIEIRA, 2008; LEE; KIM; BOLCH; MOROZ et al., 2015).

\subsubsection{Otimização de Doses em TC}

Não há dúvidas de que as imagens médicas são essenciais para o atendimento ao paciente (STRAUSS; KASTE, 2006) e que a aplicação da radiação ionizante nestes procedimentos é benéfica para centenas de milhões de pessoas a cada ano (WORLD HEALTH ORGANIZATION \& IAEA, 2014). Contudo, o uso da radiação ionizante na medicina deve 
ponderar cuidadosamente os benefícios oriundos da exposição e os riscos relacionados à radiação (WORLD HEALTH ORGANIZATION \& IAEA, 2014).

A tarefa de otimizar a dose de radiação e a qualidade de imagens em TC é uma das tarefas mais desafiadoras enfrentadas pela comunidade de imagens médicas (DAUER; CHU; ZANZONICO, 2018). O conceito de otimização implica em aumentar os benefícios para a saúde do paciente em consonância com a diminuição do risco de efeitos biológicos (JAMAL; SAYED; SYED, 2020). Este também é o princípio de ALARA (As Low As Reasonably Achievable ou tão baixo quanto razoavelmente exequível, em português) - um acrônimo utilizado em proteção radiológica, originalmente definido para exposição ocupacional e atualmente praticado em TC e em outros procedimentos médicos que utilizem radiação ionizante (KALENDER, 2014). Além dos requisitos de justificação médica, o processo contínuo de otimização é fundamental (HOJREH; WEBER; HOMOLKA, 2015). Para a TC, a otimização requer que as imagens tenham qualidade adequada para o diagnóstico do trabalho clínico em questão, ao passo que devem ser adquiridas com uma dose de radiação apropriada para o nível de risco indicado ao paciente e ao público em geral (STRAUSS; GOSKE; KASTE; BULAS et al., 2010).

A modalidade de TC é essencial para a avaliação de muitas patologias durante a infância, e, consequentemente, a sua aplicação em crianças cresceu ao redor do mundo (STRAUSS, 2014). Até os anos 2000, era rara a distinção entre os protocolos de TC adultos e pediátricos, sendo as técnicas de aquisição de imagem esporadicamente ajustadas com base no tamanho corporal (STRAUSS; SOMASUNDARAM; SENGUPTA; MARIN et al., 2019). Atualmente, existem campanhas de proteção radiológica como Image Gently (para pacientes pediátricos), Latin Safe e Image Wisely (para pacientes adultos) com recomendações para o uso da radiação ionizante em procedimentos médicos com o menor risco possível para todos os pacientes. Apesar das recomendações disponíveis, ainda existem oportunidades de melhoria na administração de doses pediátricas de TC (STRAUSS; SOMASUNDARAM; SENGUPTA; MARIN et al., 2019).

De acordo com a publicação da Agência Internacional de Energia Atômica (IAEA) de Ciências da Saúde Humana (HHS) 24 - Dosimetria em Radiologia Diagnóstica para Pacientes Pediátricos -, a dosimetria para pacientes pediátricos submetidos a procedimentos para radiologia diagnóstica requer cuidados especiais em relação aos métodos de dosimetria utilizados em pacientes adultos, dada a sua maior expectativa de vida (IAEA, 2014). Considerando os prováveis efeitos da radiação ionizante nos corpos jovens e em crescimento 
das crianças, tanto os protocolos de TC quanto a dose administrada no exame devem ser adaptados ao tamanho, idade e necessidades clínicas dos pacientes pediátricos, de acordo com o princípio de ALARA (COUNCIL, 2006; HOJREH; WEBER; HOMOLKA, 2015). Esta também é a recomendação da campanha Image Gently (GOSKE; APPLEGATE; BOYLAN; BUTLER et al., 2008).

\subsection{OBJETOS SIMULADORES}

Existem dois tipos de phantoms ou objetos simuladores: os destinados a calibração e controle de qualidade e os antropomórficos, feitos de materiais tecido-equivalentes.

Em Tomografia Computadorizada, phantoms são usados rotineiramente na determinação de CTDI e avaliação de desempenho do tomógrafo. Os phantoms destinados à medição de CTDI são cilindros de PMMA com aproximadamente $15 \mathrm{~cm}$ de comprimento e diâmetro variável, sendo $10 \mathrm{~cm}$ para os protocolos pediátricos da cabeça, $16 \mathrm{~cm}$ para os protocolos pediátricos do corpo e de cabeça adulto e $32 \mathrm{~cm}$ para os protocolos corporais adultos (VEDANTHAM, 2017). Os phantoms projetados para garantia de qualidade incluem vários módulos que permitem a determinação de parâmetros como a linearidade da escala HU, largura e perfil de sensibilidade da fatia, uniformidade espacial e ruído, resolução de alto e baixo contraste e função transferência de modulação (VEDANTHAM, 2017). Um exemplo importante de phantom de qualidade de imagem para TC introduzido para permitir a determinação dos principais parâmetros para avaliar quantitativamente a qualidade de imagem de TC é o Catphan (The Phantom Laboratory, EUA) (TOMAL; COSTA, 2017), que é utilizado para testes de controle de qualidade (GULLIKSRUD; STOKKE; MARTINSEN, 2014).

Os phantoms antropomórficos foram introduzidos na proteção contra radiação com o objetivo de simular as propriedades de absorção de radiação do tecido humano e também suas características anatômicas, como densidade de elétrons e as variações de número atômico efetivo (COSTA, 2014). Estes simuladores antropomórficos, construídos a partir de materiais tecido-equivalentes, têm sido muito utilizados para fornecer uma representação física das características anatômicas e de atenuação do corpo para estudos de dosimetria de radiação (WINSLOW; HYER; FISHER; TIEN et al., 2009).

Existem também os phantoms computacionais, que podem ser complexos ou simples, de acordo com o que eles irão representar, podendo simular qualquer coisa, desde uma simples placa a humanos anatomicamente precisos (BLIZNAKOVA, 2017). São descrições matemáticas ou modelos matriciais de órgãos ou tecidos do corpo ou do próprio corpo inteiro, 
que visam imitar com precisão uma determinada característica ou conjunto de características das partes representadas do corpo humano (BLIZNAKOVA, 2017).

\subsection{NATIONAL CANCER INSTITUTE DOSIMETRY SYSTEM FOR CT (NCICT)}

O método Monte Carlo (MC) destina-se à solução de problemas estocásticos e é fundamentado em distribuição de probabilidades. Sua aplicação na estimativa de dose absorvida em órgãos resultante de exames tomográficos é recorrente (AAPM, 2019). O método MC simula as interações dos raios $\mathrm{X}$ com os tecidos (como espalhamento Compton e interações fotoelétricas), que são adaptadas para estimar as doses em órgãos (AAPM, 2019).

O cálculo de dose em órgão via simulação de Monte Carlo é uma maneira sofisticada e confiável de se obter distribuições precisas de dose em órgão no corpo humano exposto à radiação proveniente de exames tomográficos (LEE; KIM; LONG; FISHER et al., 2011). No método de Monte Carlo, o paciente é simulado usando um modelo anatômico computacional e o tomógrafo é simulado por um modelo de fonte de raios X (LONG; LEE; TIEN; FISHER et al., 2013). Dois tipos de phantoms computacionais foram desenvolvidos para cálculos dosimétricos: phantoms estilizados (ou matemáticos), baseados em equações matemáticas usadas para descrever estruturas dos órgãos internos e as regiões externas do corpo, e phantoms voxelizados (ou tomográficos) desenvolvidos a partir de imagens médicas transversais, como de ressonância magnética e de tomografia computadorizada (LEE; LODWICK; WILLIAMS; BOLCH, 2008). Um novo tipo de phantom computacional é o phantom híbrido, que combina as melhores características dos phantoms voxelizados e dos phantoms estilizados: flexibilidade e realismo anatômico, respectivamente (LEE; LODWICK; WILLIAMS; BOLCH, 2008).

O NCICT é um software para cálculo de dose em órgãos para pacientes submetidos a tomografias computadorizadas. O software baseia-se em phantoms voxelizados adultos e pediátricos de referência propostas pela ICRP e em simulações Monte Carlo para o feixe de raios X do tomógrafo (LEE; KIM; BOLCH; MOROZ et al., 2015). O NCICT possui uma interface gráfica de usuário (Graphical User Interface - GUI) para inserção do gênero e faixa etária do paciente (recém-nascido, 1 ano, 5 anos, 10 anos, 15 anos ou adulto), do modelo e fabricante do tomógrafo e dos parâmetros de aquisição do exame, como $\mathrm{CTDI}_{\mathrm{vol}}$, tensão aplicada no tubo de raios $\mathrm{X}(\mathrm{kV})$, carga aplicada $(\mathrm{mAs})$ e o comprimento de varredura do exame. Caso o valor de $\mathrm{CTDI}_{\mathrm{vol}}$ não esteja disponível, uma reconstrução de $\mathrm{CTDI}_{\mathrm{vol}}$ é realizada, baseada num banco de dados de CTDI ponderado $\left(\mathrm{CTDI}_{\mathrm{w}}\right)$ normalizado (LEE; KIM; BOLCH; MOROZ et al., 2015; LEE; LAMART; LITTLE; LEE, 2014). O software também possui um 
módulo para cálculo de dose para exames realizados com modulação de corrente do tubo (TCM) e em sua versão mais recente (versão 3.0), é possível calcular a dose em órgãos para a gestante e feto a partir da oitava semana de gestação.

Dois estudos recentes utilizaram simulações do NCICT para validação de dose em órgãos obtidas experimentalmente com dosímetros termoluminescentes, encontrando diferenças percentuais entre doses experimentais e simuladas no intervalo de $\pm 20 \%$ (DABIN; MENCARELLI; MCMILLAN; ROMANYUKHA et al., 2016; GIANSANTE; MARTINS; NERSISSIAN; KIERS et al., 2019). Outro estudo publicado recentemente apresenta um método para cálculo de dose em órgãos para exames tomográficos abdominais, usando uma técnica de segmentação automatizada dedicada aos órgãos abdominais em combinação com simulação Monte Carlo de um tomógrafo clínico (LEE; LIU; GRIFFIN; FOLIO et al., 2020).

\subsection{QUALIDADE DE IMAGENS EM TC}

A qualidade de imagem em TC tem se mostrado um importante tópico de controle de qualidade nos últimos anos, principalmente devido à sua forte correlação com a dose do paciente e a escolha de parâmetros técnicos e de configuração do tomógrafo (TOMAL; COSTA, 2017).

Contraste, resolução espacial e ruído são métricas muito utilizadas na avaliação da qualidade da imagem médica bem como relações entre elas, resultando em parâmetros como Razão Sinal Ruído (RSR) e Razão Contraste Ruído (RCR). A resolução espacial descreve o nível de detalhe que pode ser visto em uma imagem e, em termos simples, refere-se a quão pequeno um objeto pode ser visto em um sistema de imagem específico - e essa seria a resolução espacial limitante (BUSHBERG; SEIBERT; LEIDHOLDT JR; BOONE, 2011). A Razão Sinal Ruído é uma medida de comparação entre o nível de um sinal desejado e o nível de ruído de fundo (SOOKPENG; BUTDEE, 2017), sendo uma das métricas mais significativas que descreve a conspicuidade de um objeto - quão bem será visto pelo observador típico (BUSHBERG; SEIBERT; LEIDHOLDT JR; BOONE, 2011). A Razão Contraste Ruído é uma medida que independe do tamanho do objeto do nível do sinal na presença de ruído, sendo particularmente útil para objetos simples (BUSHBERG; SEIBERT; LEIDHOLDT JR; BOONE, 2011).

Já o ruído da imagem refere-se a variações aleatórias no brilho da imagem que podem obscurecer estruturas de baixo contraste na imagem, que podem ser causadas por limitações técnicas do detector de raios $\mathrm{X}$ ou pela natureza aleatória da produção e detecção de raios $\mathrm{X}$ 
(CUNNINGHAM; NANO; ESCARTIN, 2017). O desvio padrão ( $\sigma$ ), a medição direta do Ruído, é calculado usando a relação (BUSHBERG; SEIBERT; LEIDHOLDT JR; BOONE, 2011):

$$
\sigma=\sqrt{\frac{\sum_{i=1}^{N}\left(H U_{i}-H U\right)^{2}}{N-1}}
$$

Em que $\mathrm{N}$ é o número de pixels, $\mathrm{HU}_{\mathrm{i}}$ é o número $\mathrm{TC}$ de cada pixel de uma região de interesse (Region of Interest - ROI) e HU é o valor médio do número TC nesta ROI.

\subsection{DOSIMETRIA OSL}

De acordo com a publicação AAPM TG 191 (KRY; ALVAREZ; CYGLER; DEWERD et al., 2020), a dosimetria de luminescência é a medida da dose absorvida de radiação ionizante baseada na emissão de fótons na faixa de comprimento de onda visível por um fósforo e pode referir-se à termoluminescência (TL), luminescência opticamente estimulada (OSL) ou outros tipos de processos de emissão de fótons, incluindo radiofotoluminescência, radioluminescência e cintilação.

O fenômeno OSL (Optically Stimulated Luminescence - OSL) é um tipo de fenômeno luminescente que consiste na emissão de luz por cristais semicondutores ou isolantes durante a aplicação de um estímulo luminoso. Para observação deste fenômeno luminescente, é necessário que o cristal tenha sido exposto, previamente, à radiação ionizante. A leitura do sinal OSL pode ser realizada através do estímulo do cristal com luz de intensidade constante e medindo-se a luminescência resultante (ANDREO; BURNS; NAHUM; SEUNTJENS et al., 2017).

Embora o desenvolvimento da tecnologia OSL tenha acontecido nas últimas duas décadas, o seu uso na dosimetria de radiação para aplicações médicas foi introduzido apenas recentemente (ANDREO; BURNS; NAHUM; SEUNTJENS et al., 2017). Os OSLDs são aplicáveis à dosimetria relativa, dosimetria in vivo ou qualquer outra aplicação em que tenham sido aplicáveis TDLs (ANDREO; BURNS; NAHUM; SEUNTJENS et al., 2017).

Suas propriedades podem ser explicadas pela teoria da banda de energia dos sólidos: cristais semicondutores ou isolantes quando absorvem alguma quantidade de radiação ionizante, têm seus elétrons excitados da banda de valência para a banda de condução. Neste 
processo, os elétrons deixam "buracos" na banda de valência. Entre as bandas de valência e condução existe uma região proibida (gap band), onde os pares elétron-buraco podem ficar presos em virtude dos defeitos da rede cristalina, caracterizando um estado metaestável do cristal. Os elétrons da banda de condução e os buracos na banda de valência são livres para se movimentarem através da rede cristalina, até que sejam capturados pelos níveis de energia localizados - que atuam como armadilhas - ou que se recombinem entre si (YUKIHARA; MCKEEVER, 2008). Para retomar o estado de equilíbrio, o material necessita de um estímulo - no caso do OSL, energia luminosa. Durante o processo de leitura, o estímulo luminoso liberta as cargas retidas (KRY; ALVAREZ; CYGLER; DEWERD et al., 2020). Os elétrons e buracos aprisionados são liberados da região proibida para a banda de condução, com certa probabilidade de recombinação entre eles, resultando na luminescência do material. A concentração de elétrons e buracos aprisionados está relacionada com a quantidade de energia absorvida pelo cristal durante o processo de excitação, ou seja, à dose absorvida de radiação (YUKIHARA; MCKEEVER, 2011). A Figura 2.12 apresenta os diferentes estágios do fenômeno luminescente opticamente estimulado.

(a) Excitation

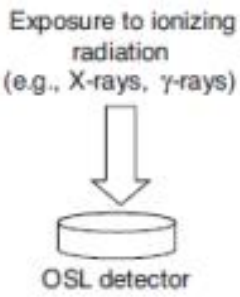

OSL detector (b) Latency

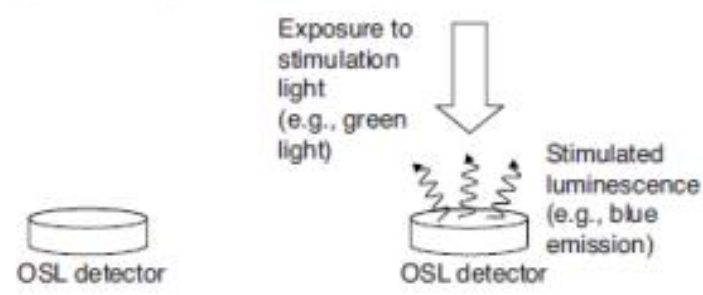

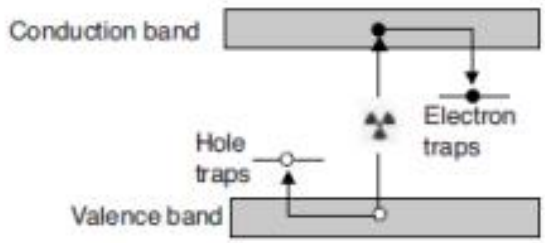
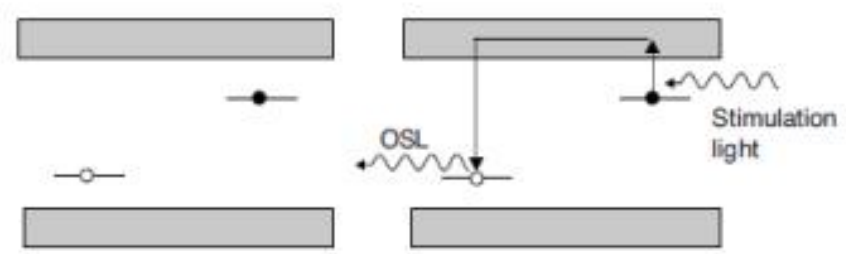

Figura 2.12 - Diferentes estágios do fenômeno OSL: (a) excitação do cristal OSL devido a exposição à radiação ionizante, criando elétrons livre e buracos; (b) período de latência, em que os elétrons e buracos estão presos nos defeitos da rede cristalina e (c) estímulo do detector com luz e a resultante recombinação dos pares elétron-buraco com a emissão de luz (OSL). Fonte: Yukihara \& McKeever (2011).

Num modelo simples para o fenômeno OSL, é demonstrado que a intensidade do OSL decai exponencialmente durante o período da estimulação. Neste modelo, $n$ é a concentração de elétrons aprisionados e $p$ a probabilidade por unidade de tempo que os elétrons aprisionados 
têm de serem liberados de volta à banda de condução sob estimulação óptica. De acordo com este modelo, $n$ mudará de acordo com a equação (YUKIHARA; MCKEEVER, 2011):

$$
\frac{d n}{d t}=-n p
$$

A solução para esta equação prova que a concentração que elétrons aprisionados decai exponencialmente com o tempo de estímulo:

$$
n(t)=n_{0} e^{-p t}
$$

Em que $n_{0}=n(0)$ é a concentração inicial de cargas aprisionadas. Se todos os elétrons estimulados têm recombinação imediata, a intensidade de luz emitida é proporcional a taxa de elétrons aprisionados, $\frac{d n}{d t}$, logo:

$$
I_{O S L}(t) \propto\left|\frac{d n}{d t}\right|=n_{0} p e^{-p t}
$$




\section{MATERIAIS E MÉTODOS}

Este trabalho, é parte de um projeto de pesquisa chamado "Avaliação e Otimização de Imagens Pediátricas" (Evaluation and Optimizations of Pediatric Imaging), coordenado pela IAEA. Neste projeto, foi iniciada a implementação de um processo de otimização de procedimentos radiológicos pediátricos no Instituto de Radiologia do Hospital das Clínicas da Faculdade de Medicina da USP (INRAD-FMUSP), em parceria com o Grupo de Dosimetria das Radiações e Física Médica do Instituto de Física da USP (GUERRA; NERSISSIAN; MELO; VASCONCELLOS et al., 2019). Neste processo de otimização, novos protocolos tomográficos pediátricos (otimizados) foram propostos, substituindo protocolos que eram realizados previamente ao processo de otimização (não otimizados).

Foram avaliados, neste trabalho, os protocolos não otimizados Tórax Infantil, Crânio 3D e Crânio Criança Axial, adotados previamente ao processo de otimização, e os protocolos otimizados Infantil/Tórax 1-10 anos, Crânio 3D Infantil e Infantil/Crânio 2-6 anos, adotados após o processo de otimização realizado na instituição. Nas próximas seções serão descritos os materiais utilizados e metodologias experimentais adotadas.

\subsection{MATERIAIS}

\subsubsection{Phantom Pediátrico ATOM modelo 705}

Neste trabalho, foi utilizado o phantom pediátrico ATOM modelo 705 produzido pela Computerized Imaging Reference System (CIRS, EUA), com $110 \mathrm{~cm}$ de altura e $19 \mathrm{~kg}$ de massa, equivalente a um paciente de cinco anos de idade (CIRS, 2013) (Figura 3.1). 


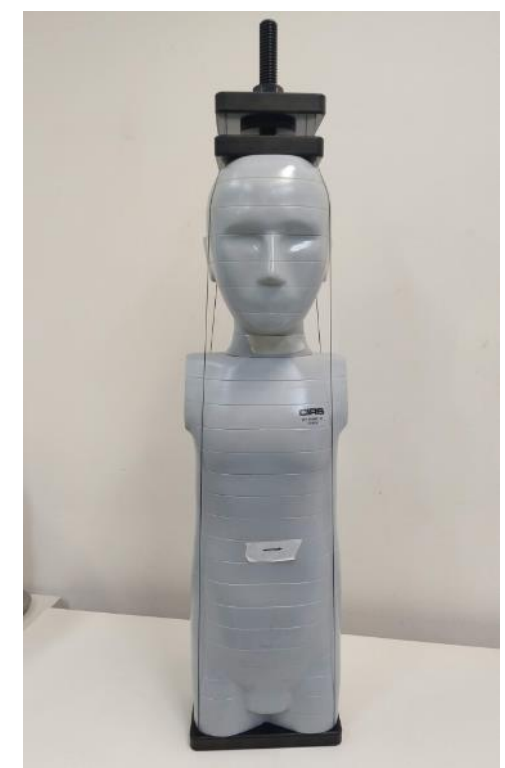

Figura 3.1 - Phantom antropomórfico pediátrico ATOM da CIRS, modelo 705 (CIRS, EUA).

Este phantom é composto de materiais tecido-equivalentes, apropriados para representar diversos tecidos do corpo humano como ossos, cérebro, cartilagens, pulmões, medula espinhal e tecidos moles. É dividido em 26 fatias (numeradas de 1 a 26) dotadas de orifícios/cavidades, onde é possível a introdução de dosímetros (CIRS, 2013), como ilustrado na Figura 3.2. A tireoide está localizada na fatia 8 e os pulmões estão distribuídos ao longo das fatias 9 a 15 do phantom.

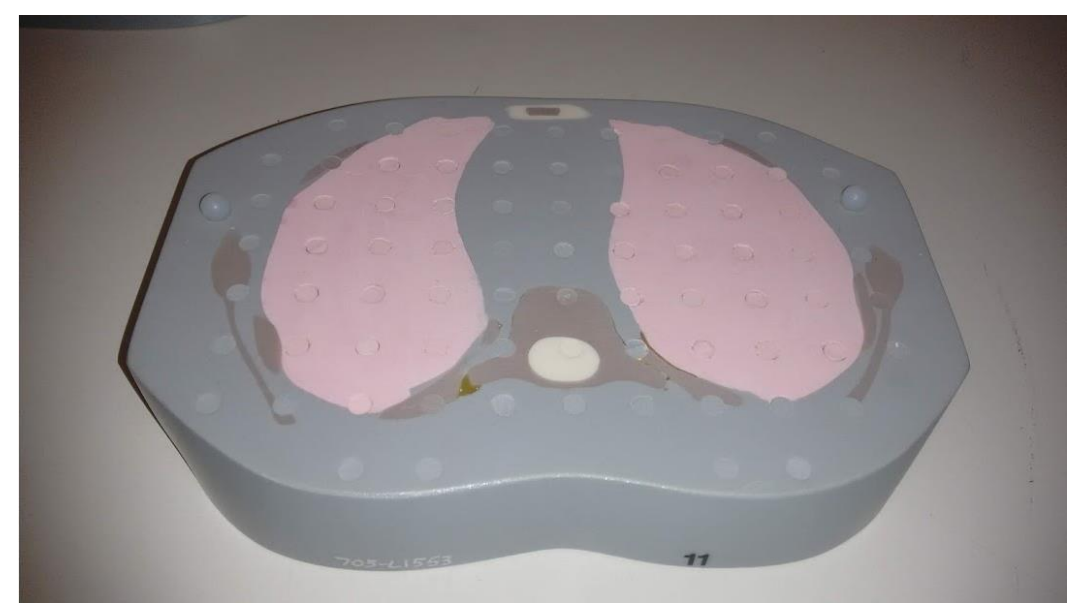

Figura 3.2 - Fatia 11 do phantom pediátrico ATOM modelo 705 (CIRS, EUA) dotada de cavidades para inserção de dosímetros. O material em cor-de-rosa representa os pulmões.

\subsubsection{Leitor Ris $\phi T L / O S L$}

Para ler a informação armazenada nos dosímetros após cada irradiação, foi utilizado o leitor Ris $\phi$ TL/OSL modelo DA-20 (DTU Nutech., Dinamarca), disponível no Grupo de 
Dosimetria das Radiações e Física Médica do IFUSP. O equipamento permite a inserção simultânea de até 48 dosímetros, que são lidos individualmente numa câmara conforme configuração previamente selecionada pelo usuário (DTU NUTECH, 2015). O leitor possui um sistema detector de luz, composto de tubo fotomultiplicador com filtros ópticos. O tubo fotomultiplicador é responsável por converter o sinal luminoso dos dosímetros em sinal elétrico. Os dados provenientes da leitura podem ser exportados como arquivos do tipo ASCII. O leitor e o carrossel para inserção dos dosímetros no equipamento estão ilustrados na Figura 3.3.
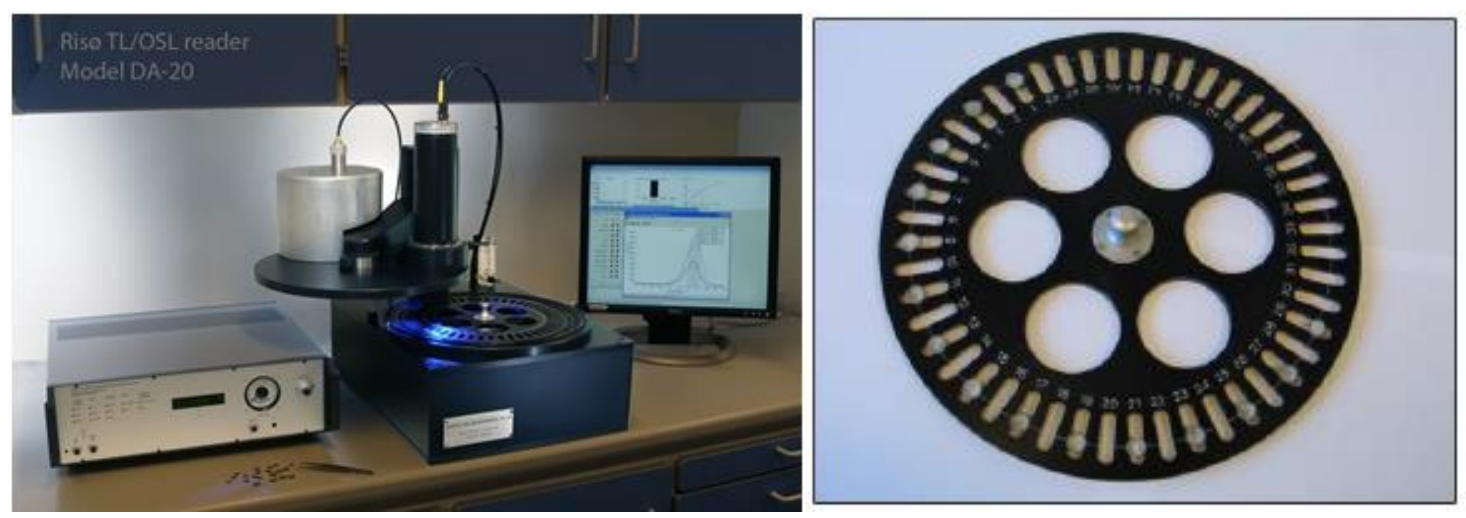

Figura 3.3 - À esquerda: Leitor Risø TL/OSL modelo DA-20 (DTU Nutech., Dinamarca). À direita: Carrossel com copinhos de aço inoxidável para o posicionamento de até 48 dosímetros do leitor Risø. Fonte: DTU Nutech, 2015 .

\subsubsection{Dosímetros por Luminescência Opticamente Estimulada}

A Luminescência Opticamente Estimulada do óxido de alumínio dopado com carbono $\left(\mathrm{Al}_{2} \mathrm{O}_{3}: \mathrm{C}\right)$ é amplamente utilizada na dosimetria pessoal (UMISEDO; YOSHIMURA; GASPARIAN; YUKIHARA, 2010) e o seu uso na dosimetria médica é embrionário, porém crescente (YUKIHARA; MCKEEVER, 2011). Dosímetros de luminescência opticamente estimulada (Optically Stimulated Luminescence Dosimeters - OSLDs) são dosímetros de estado sólido, utilizados para dosimetria de pacientes e para o monitoramento de exposição.

No presente trabalho, foi utilizada a fita OSL Landauer Luxel ${ }^{\mathrm{TM}}$ (Landauer, Inc., Glenwood, EUA) de óxido de alumínio dopado com carbono $\left(\mathrm{Al}_{2} \mathrm{O}_{3}: \mathrm{C}\right)$ disponível no Grupo de Dosimetria das Radiações e Física Médica do IFUSP. O cristal $\mathrm{Al}_{2} \mathrm{O}_{3}: \mathrm{C}$ é triturado em pó relativamente uniforme e fixado em uma fita plástica (KRY; ALVAREZ; CYGLER; DEWERD et al., 2020). O material possui $0,3 \mathrm{~mm}$ de espessura e pode ser cortado em diferentes formatos e tamanhos, de acordo com a necessidade do uso. Para todas as irradiações, os cristais foram fracionados em discos de $3 \mathrm{~mm}$ de diâmetro, conforme ilustrado na Figura 3.4. 


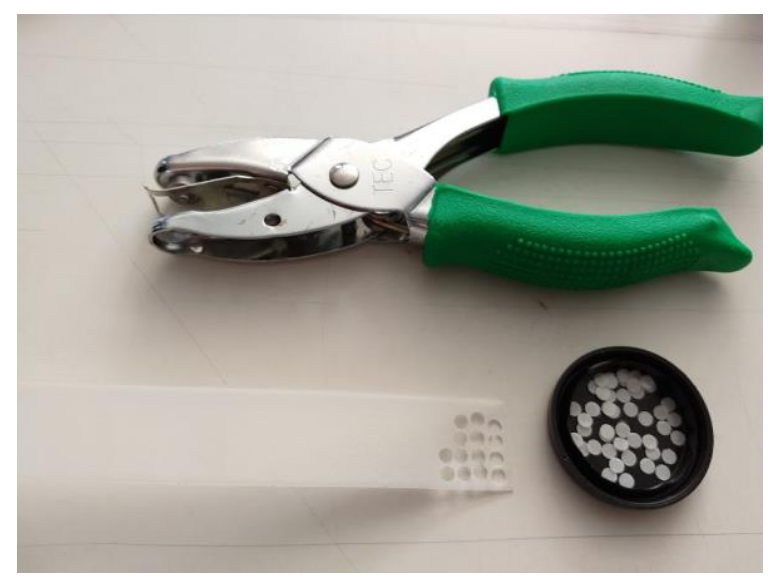

Figura 3.4 - Fita OSL Landauer Luxel ${ }^{\mathrm{TM}}$ (Landauer, Inc., Glenwood, EUA) de óxido de alumínio dopado com carbono $\left(\mathrm{Al}_{2} \mathrm{O}_{3}: \mathrm{C}\right)$ fracionada em discos de $3 \mathrm{~mm}$ de diâmetro e $0,3 \mathrm{~mm}$ de espessura.

Para conter os dosímetros OSL foram utilizados dois tipos de porta-dosímetros. No processo de calibração dos dosímetros OSL e para a avaliação da dose absorvida no cristalino do phantom, foram utilizados envelopes escuros de PVC. Para a avaliação de dose absorvida nos pulmões e na tireoide do phantom, foram usados porta-dosímetros cilíndricos de polioximetileno com 4,9 mm de diâmetro, para encaixar nas cavidades das fatias do phantom. Ambos os porta-dosímetros (Figura 3.5) foram fabricados na oficina mecânica do Instituto de Física da Universidade de São Paulo.

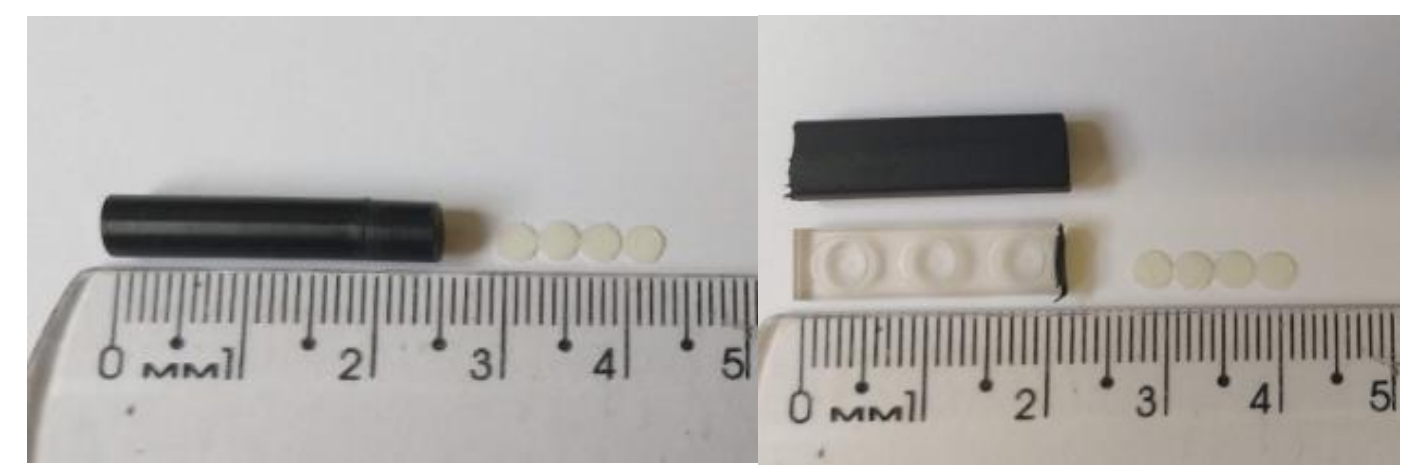

Figura 3.5 - Porta-dosímetros utilizados para conter os OSLDs durante as irradiações. À esquerda: porta-dosímetro cilíndrico utilizado para inserção dos OSLDs nas cavidades dos pulmões e tireoide do phantom. À direita: envelopes escuros de PVC utilizados para conter os OSLDs posicionados nos olhos do phantom e durante a irradiação para calibração dos dosímetros OSL.

\subsubsection{Equipamentos para Irradiação}

Todas as irradiações foram realizadas no tomógrafo Philips Brilliance 64 CT scanner (Philips, Holanda), instalado no INRAD-FMUSP. As medições de kerma no ar foram realizadas com uma câmara de ionização de $0,6 \mathrm{~cm}^{3}$ da Radcal modelo 10X6-0,6 CT (Radcal Corporation, 
EUA) acoplada a um eletrômetro Radcal modelo 9010 (Radcal Corporation, EUA). Este eletrômetro aplica a correção de temperatura e pressão automaticamente, sendo desnecessária a aplicação de um fator de correção para os valores apresentados no visor do aparelho.

\subsubsection{Phantom CATPHAN 500}

O phantom comercial de qualidade de imagem CATPHAN 500 (The Phantom Laboratory, EUA) foi utilizado para analisar a qualidade das imagens produzidas com os protocolos de TC avaliados neste trabalho. Este phantom (Figura 3.6) é composto por módulos ou seções de materiais adequados para as diversas métricas de controle de qualidade.

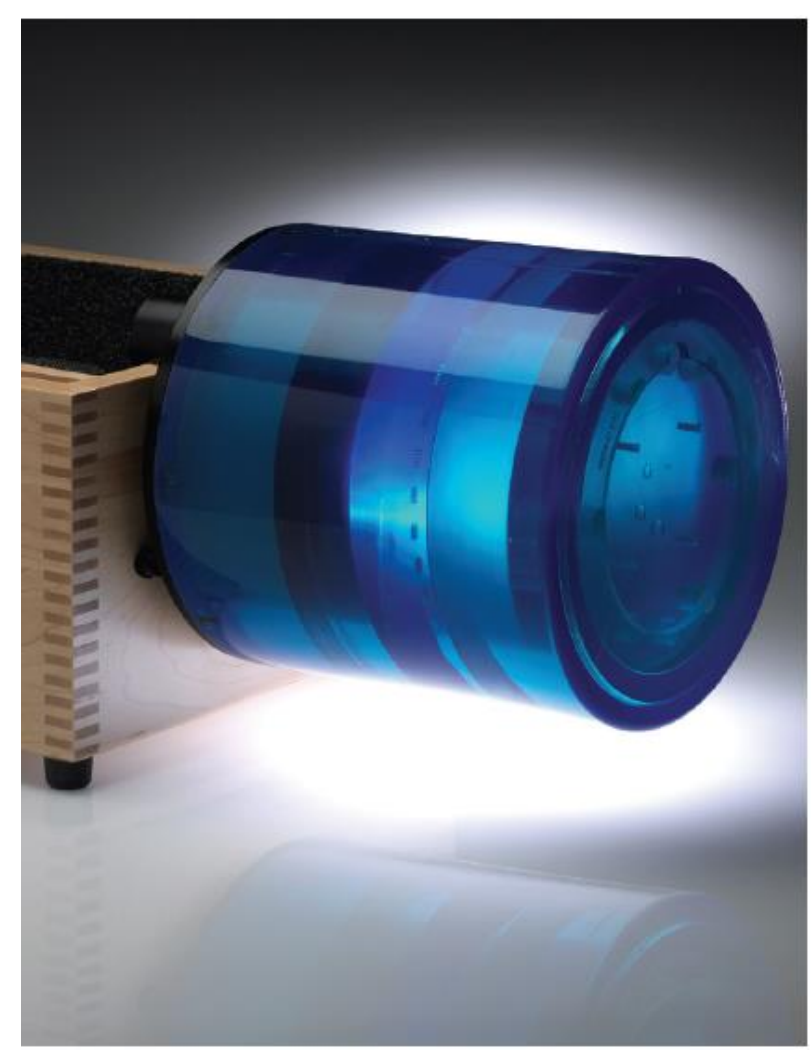

Figura 3.6 - Phantom comercial de qualidade de imagem CATPHAN 500 (The Phantom Laboratory, EUA). Fonte: The Phantom Laboratory, (2014).

Foram empregados os módulos CTP 486, CTP 515 e CTP 528. O módulo de uniformidade da imagem, CTP 486, é adequado para medições de uniformidade espacial, número TC médio e valor de ruído da imagem de um material com densidade próxima à água (20 HU) (THE PHANTOM LABORATORY, 2014). O módulo CTP 515 é o módulo de baixo contraste com alvos de contraste supra fatia e sub fatia. O módulo de alta resolução, CTP 528, possui 21 pares de linhas por cm para avaliação da resolução espacial da imagem. 


\subsection{MÉTODOS}

\subsubsection{Tratamento Óptico dos OSLDs}

Antes das irradiações realizadas neste trabalho, todos os dosímetros OSL foram submetidos a um tratamento óptico - conhecido como bleaching - para eliminar sinais residuais armazenados por radiação de fundo. O processo consiste na exposição dos dosímetros à luz branca fluorescente de tungstênio por um período de, aproximadamente, oito horas. Foi utilizado um conjunto de quatro lâmpadas brancas de tungstênio (ATEK Digilight, ATEK, Brasil) disponível no Grupo de Dosimetria das Radiações e Física Médica do IFUSP para iluminar os dosímetros OSL.

\subsubsection{Leitura dos Dosímetros OSL}

A leitura dos dosímetros OSL foi realizada no leitor automático Ris $\phi$ TL/OSL modelo DA-20 (DTU Nutech, Dinamarca). Neste processo, foi acoplado ao tubo fotomultiplicador um filtro passa banda de transmissão ultravioleta Hoya U-340, com 7,5 mm de espessura e $45 \mathrm{~mm}$ de diâmetro (DTU NUTECH, 2015). O resultado da leitura de cada dosímetro é apresentado como uma curva de contagens (número de fótons) por tempo (segundos), ilustrado na Figura 3.7. O sinal de cada dosímetro OSL pode ser obtido através da integração numérica da área sob esta curva. Este resultado é chamado de sinal OSL. Para todas as leituras, os dosímetros foram estimulados com luz azul por 60 segundos.

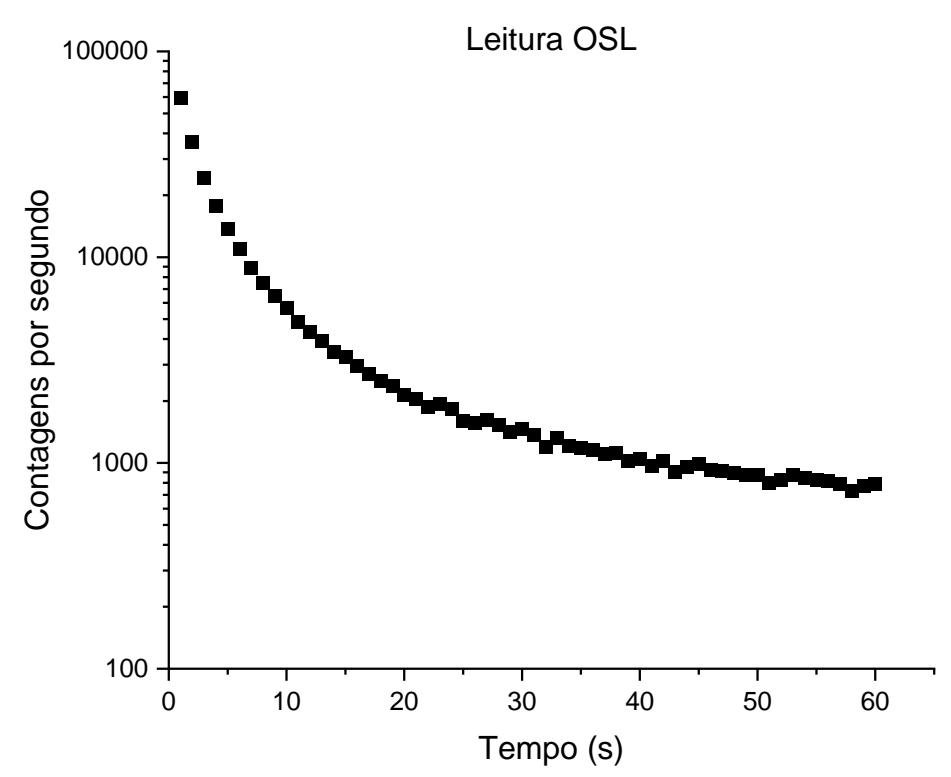

Figura 3.7 - Exemplo de uma curva de contagens obtida na leitura de um dosímetro OSL $\mathrm{Al}_{2} \mathrm{O}_{3}$ : $\mathrm{C}$ Landauer Luxel $^{\mathrm{TM}}$ (Landauer, Inc., Glenwood, EUA) após prévia irradiação. 


\subsubsection{Calibração dos Dosímetros}

A calibração dos dosímetros OSL para determinadas qualidades de feixe de raios $\mathrm{X}$ tem por objetivo relacionar o sinal do dosímetro (valor OSL) com uma grandeza física, como kerma no ar. A partir dos valores de kerma no ar, pode-se obter a dose absorvida no órgão.

A calibração dos dosímetros foi realizada com um tomógrafo Philips Brilliance 64 (Philips, Holanda) para $100 \mathrm{kVp}$ e $120 \mathrm{kVp}$, que correspondem aos valores utilizados em procedimentos de tomografia computadorizada para pacientes pediátricos do INRAD-FMUSP. No processo de calibração, a tensão aplicada no tubo é mantida fixa e muda-se o produto corrente-tempo (mAs ou carga aplicada) para a medição do kerma no ar com câmara de ionização. Em seguida, os dosímetros OSL são irradiados com os mesmos parâmetros que a câmara de ionização para posterior leitura do sinal.

Foram irradiados 5 grupos com 3 OSLDs para cada qualidade de feixe, posicionados no centro do gantry do tomógrafo. Um sexto grupo com 3 dosímetros OSL foi mantido na sala de controle para a estimativa da radiação de fundo. A radiação de fundo foi subtraída após a leitura dos grupos de dosímetros irradiados. O arranjo experimental está ilustrado na Figura 3.8.

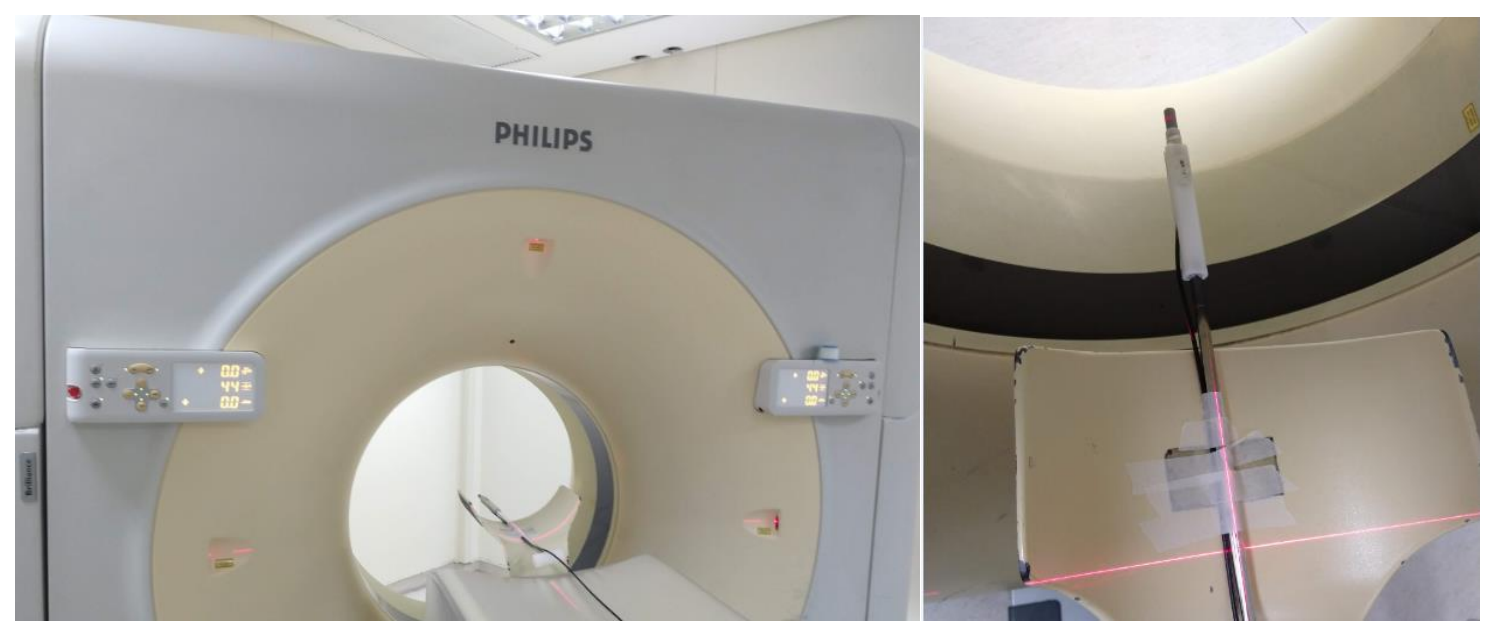

Figura 3.8 - Câmara de ionização de 0,6 $\mathrm{cm}^{3}$ modelo 10X6-0,6 alinhada no centro do gantry do tomógrafo Philips Brilliance 64 CT scanner (Philips, Holanda). Após a medição do kerma no ar, os conjuntos de dosímetros OSL foram posicionados com suporte acrílico na mesma posição da câmara de ionização.

Para a conversão da leitura registrada pela câmara de ionização em kerma no ar, os fatores de correção foram aplicados de acordo com as recomendações da publicação TRS 457 da International Atomic Energy Agency Code of Practice in Radiology (IAEA, 2007). Os fatores de correção para temperatura e pressão foram automaticamente aplicados pela câmara de 
ionização de $0,6 \mathrm{~cm}^{3}$. Os parâmetros técnicos utilizados para as calibrações são apresentados na Tabela 3.1.

\begin{tabular}{cc} 
Tabela $3.1-$ Parâmetros usados na construção das curvas de calibração \\
$\begin{array}{c}\text { Tensão aplicada no } \\
\text { tubo }(\mathbf{k V p})\end{array}$ & $\begin{array}{c}\text { Produto corrente- } \\
\text { tempo no tubo (mAs) }\end{array}$ \\
\hline & 30 \\
$\mathbf{1 0 0}$ & 120 \\
& 210 \\
& 300 \\
& 400 \\
\hline & 30 \\
& 120 \\
& 210 \\
& 300 \\
\end{tabular}

As curvas de calibração são apresentadas no Apêndice B.

\subsubsection{Estimativa do Volume Pulmonar do Phantom Pediátrico}

O volume do órgão é uma informação necessária para a estimativa da dose de radiação absorvida por ele. Como os pulmões do phantom utilizado neste trabalho estão distribuídos ao longo de algumas fatias (fatias 9 a 15), foi realizada a avaliação da fração volumétrica contida em cada uma destas fatias para a estimativa de dose absorvida pelo órgão.

A estimativa do volume pulmonar do phantom pediátrico ATOM, modelo 705 (CIRS, EUA) foi feita a partir de imagens tomográficas da região do tórax, com o auxílio da ferramenta de medição volumétrica do software IntelliSpace® PACS (Philips, Holanda), disponível no INRAD-FMUSP. Esta plataforma de visualização permite a manipulação das imagens e é utilizada pelos médicos para o laudo dos exames.

Para o cálculo do volume, as imagens da tomografia foram analisadas no modo MPR (Multi Planar Reformatting) do software, em que a visualização da região escaneada é apresentada em fatias, facilitando a observação dos detalhes das estruturas. A ferramenta de medição volumétrica opera de maneira semiautomática, na qual o usuário deve delinear a região de interesse na pilha de imagens. Entre as imagens que o usuário fez o contorno da região de 
interesse, o software faz uma interpolação automática baseada no delineamento das imagens anteriores.

A partir do delineamento da região de interesse na pilha de imagens, o software faz uma reconstrução 3D da estrutura, fornecendo o seu volume. O processo é ilustrado na Figura 3.9.

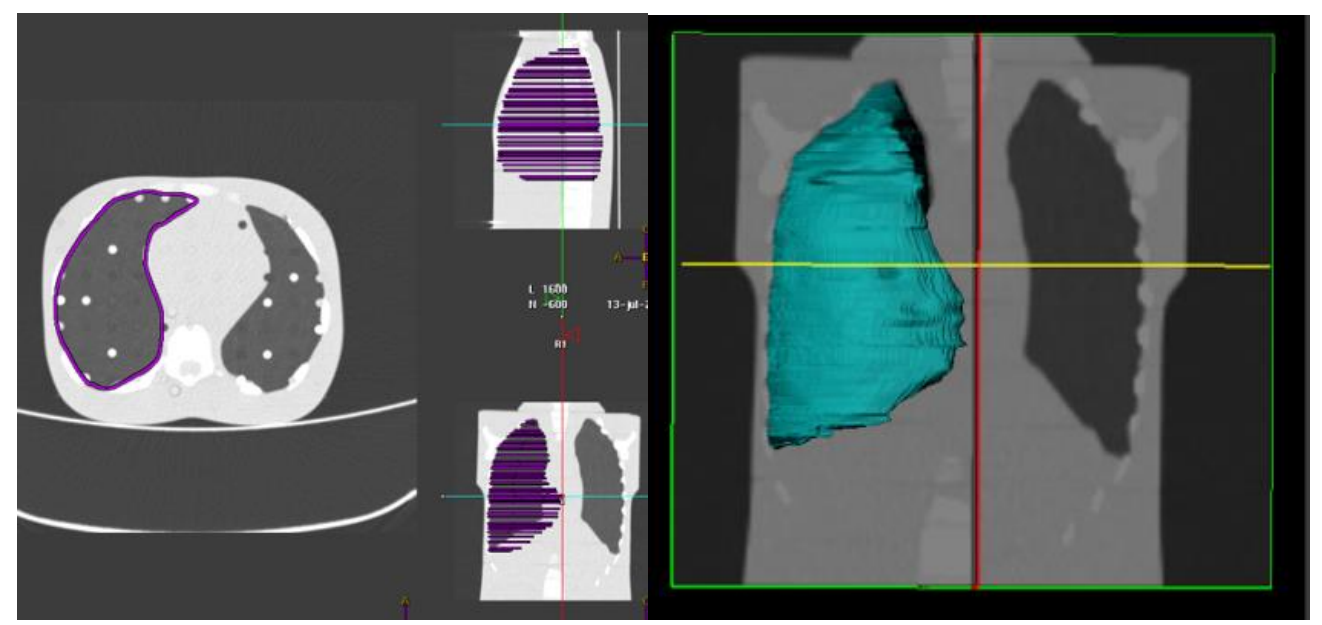

Figura 3.9 - À esquerda: imagens da tomografia de tórax do phantom em análise no software IntelliSpace ${ }^{\circledR}$ PACS (Philips, Holanda). As linhas em roxo representam o contorno feito pelo usuário. À direita: resultado da reconstrução volumétrica do pulmão direito do phantom pediátrico realizada pelo software.

\subsubsection{Irradiações do Phantom}

O simulador ATOM modelo 705, equivalente a um paciente de cinco anos, foi irradiado com alguns protocolos pediátricos para o estudo de dose absorvida em alguns de seus órgãos: pulmões, cristalino e tireoide (Figura 3.10). Foram avaliados três protocolos não otimizados, adotados previamente ao processo de otimização realizado no INRAD-FMUSP em parceria com o IFUSP, e três protocolos otimizados, sugeridos com o processo de otimização realizado na instituição (GUERRA; NERSISSIAN; MELO; VASCONCELLOS et al., 2019).

Foram replicados quatro protocolos de crânio - sendo dois não otimizados (Crânio 3D e Crânio Criança Axial) e dois otimizados (Crânio 3D Infantil e Infantil/Crânio 2-6 anos) - e dois protocolos de tórax, sendo um não otimizado (Tórax Infantil) e um otimizado (Infantil/Tórax 1-10 anos). Todas as irradiações foram realizadas com o tomógrafo Philips Brilliance 64 CT scanner (Philips, Holanda) instalado nas dependências do INRAD/FMUSP. Para todos os conjuntos de medições, uma curva de calibração foi construída e um grupo de dosímetros OSL foi mantido na sala de controle para quantificação da radiação de fundo, a qual foi devidamente subtraída das leituras dos dosímetros irradiados. 


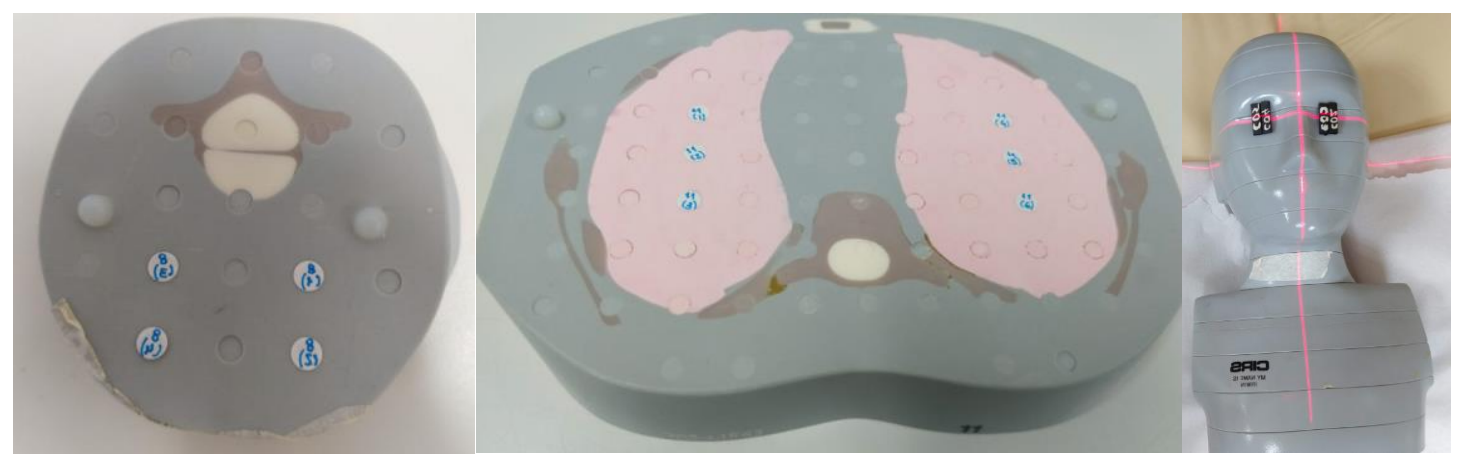

Figura 3.10 - Distribuição dos dosímetros OSL nas cavidades do phantom pediátrico para avaliação de dose absorvida. À esquerda: na região da tireoide (fatia 8) do phantom. Centro: na região pulmonar (fatia 11) do phantom. À direita: na região do cristalino do phantom.

\subsubsection{Protocolos de Crânio}

Foram avaliados dois protocolos de crânio helicoidais - Crânio 3D (não otimizado) e Crânio 3D/Infantil (otimizado) e dois protocolos de crânio axiais - Crânio Criança Axial (não otimizado) e Infantil/Crânio 2-6 anos (otimizado), como descrito na seção 3. Para avaliação da dose de radiação absorvida proveniente de cada um dos protocolos, foram utilizados 36 dosímetros OSL, distribuídos nos olhos (cristalino) e no pescoço (tireoide) do phantom. Foram dispostos dois pares de porta-dosímetros com três OSLDs cada nos olhos do phantom e quatro porta-dosímetros com seis OSLDs cada na tireoide. O phantom foi posicionado no isocentro do gantry do tomógrafo e irradiado do topo da cabeça até o final do pescoço (fatias 1 a 8), de modo que o cristalino dos olhos e toda a tireoide fossem irradiados pelo feixe de raios $\mathrm{X}$ primário do equipamento. Os parâmetros de aquisição utilizados na obtenção das imagens tomográficas de crânio são apresentados na Tabela 3.2.

Tabela 3.2 - Parâmetros de aquisição das imagens de tomografia de crânio realizadas no phantom pediátrico. Valores de $\mathrm{CTDI}_{\mathrm{vol}}$ e DLP exibidos pelo display do tomógrafo.

\begin{tabular}{ccccc}
\hline $\begin{array}{c}\text { Parâmetros do } \\
\text { Protocolo }\end{array}$ & $\begin{array}{c}\text { Crânio 3D } \\
\text { (Não Otimizado) }\end{array}$ & $\begin{array}{c}\text { Crânio 3D/ } \\
\text { Infantil } \\
\text { (Otimizado) }\end{array}$ & $\begin{array}{c}\text { Crânio Criança } \\
\text { Axial } \\
\text { (Não Otimizado) }\end{array}$ & $\begin{array}{c}\text { Infantil/Crânio } \\
\mathbf{2 - 6} \text { anos } \\
\text { (Otimizado) }\end{array}$ \\
\hline $\begin{array}{c}\text { Tensão no tubo } \\
\mathbf{( k V p )}\end{array}$ & 120 & 100 & 120 & 100 \\
$\begin{array}{c}\text { Produto corrente- } \\
\text { tempo (mAs) }\end{array}$ & 299 & 149 & 200 & 110 \\
$\quad \begin{array}{l}\text { Pitch } \\
\mathbf{N} \times \mathbf{T}(\mathbf{m m})\end{array}$ & 0,298 & 0,298 & - & - \\
& $64 \times 0,625$ & $64 \times 0,625$ & $16 \times 0,625$ & $16 \times 0,625$
\end{tabular}




\begin{tabular}{lcccc} 
Colimação $(\mathbf{m m})$ & 40 & 40 & 10 & 10 \\
Comprimento de & 228 & 229 & 230 & 230 \\
Varredura $(\mathbf{m m})$ & & 11,8 & 31,7 & 10,6 \\
CTDI $_{\text {vol }}(\mathbf{m G y})$ & 38,7 & 335,8 & 730,1 & 244,9 \\
DLP $(\mathbf{m G y . c m})$ & 1097,0 & & \\
\hline
\end{tabular}

\subsubsection{Protocolos de Tórax}

Neste trabalho, também foram avaliados dois protocolos de tórax, tipicamente realizados em pacientes pediátricos nesta faixa etária no INRAD/FMUSP: Tórax Infantil (não otimizado), realizado previamente o processo de otimização, e Infantil/Tórax 1-10 anos (otimizado), adotado após o processo de otimização. Foram utilizados 152 dosímetros OSL nas cavidades dos pulmões e da tireoide do phantom pediátrico ATOM, dispostos de acordo com a Tabela 3.3, para avaliação de dose absorvida resultante de cada protocolo. Os porta-dosímetros posicionados na tireoide do phantom foram preenchidos com seis OSLDs cada e os portadosímetros inseridos nas fatias dos pulmões continham quatro OSLDs cada. Novamente, o simulador foi posicionado no centro do gantry do tomógrafo e irradiado da metade do pescoço até a metade do seu abdômen, para que os pulmões e a tireoide fossem irradiados pelo feixe primário de raios $\mathrm{X}$. As imagens tomográficas de tórax foram adquiridas de acordo com as técnicas descritas na Tabela 3.4.

Tabela 3.3 - Distribuição dos porta-dosímetros nas fatias dos órgãos de interesse do phantom pediátrico ATOM para os protocolos de tórax avaliados.

\begin{tabular}{cccc}
\hline Fatia $(\boldsymbol{i})$ & Órgão & $\begin{array}{c}\text { Fração do órgão } \\
\text { contida na fatia }\left(\boldsymbol{f}_{\boldsymbol{i}}\right)\end{array}$ & $\begin{array}{c}\text { Quantidade de porta- } \\
\text { dosímetros }\end{array}$ \\
\hline 8 & Tireoide & 1,00 & 4 \\
\hline 9 & & 0,03 & 2 \\
10 & & 0,14 & 4 \\
11 & & 0,22 & 6 \\
12 & & 0,19 & 6 \\
13 & Pulmões & 0,21 & 6 \\
14 & & 0,17 & 6 \\
15 & & 0,03 & 2 \\
\hline
\end{tabular}

Tabela 3.4 - Parâmetros de aquisição das imagens de tomografia de tórax realizadas no phantom pediátrico. Valores de CTDI $_{\mathrm{vol}}$ e DLP exibidos pelo display do tomógrafo.

Parâmetros do Protocolo

\section{Tórax Infantil} (Não Otimizado)

\author{
Infantil/Tórax 1-10 \\ anos (Otimizado)
}

Tensão no tubo (kVp) $120 \quad 100$




\begin{tabular}{ccc} 
Produto corrente-tempo (mAs) & 55 & 110 \\
Pitch & 0,922 & 0,923 \\
N $\times$ T (mm) & $64 \times 0,625$ & $64 \times 0,625$ \\
Colimação (mm) & 40 & 40 \\
Comprimento de Varredura & 220,0 & 220,0 \\
$(\mathbf{m m})$ & 3,6 & 4,3 \\
CTDI & 105,3 & 126,1 \\
DLP (mGy.cm) & & \\
\hline
\end{tabular}

Para o protocolo Tórax Infantil, os valores de CTDI ${ }_{v o l}$ e DLP exibidos pelo display do tomógrafo eram, originalmente, 7,0 mGy e 202,5 mGy.cm, baseados no phantom cilíndrico de referência de $16 \mathrm{~cm}$ de diâmetro. No caso do protocolo novo Infantil/Tórax 1-10 anos, as grandezas baseiam-se no phantom cilíndrico de referência para corpo, com $32 \mathrm{~cm}$ de diâmetro. Com o processo de otimização implementado no INRAD em parceria com o IFUSP (GUERRA; NERSISSIAN; MELO; VASCONCELLOS et al., 2019), o protocolo Tórax Infantil foi substituído pelo novo protocolo Infantil/Tórax 1-10 anos, baseado no phantom cilíndrico de referência para corpo, com $32 \mathrm{~cm}$ de diâmetro, de acordo com a norma proposta pela IEC (International Electrotechnical Commission), que estabelece que o CTDI deve ser exibido para o phantom cilíndrico de $32 \mathrm{~cm}$ para todos exames corporais e exibido para o phantom cilíndrico de $16 \mathrm{~cm}$ para todos os exames de crânio, independentemente do tamanho/idade do paciente (VASSILEVA; REHANI; KOSTOVA-LEFTEROVA; AL-NAEMI et al., 2015). A título de comparação entre os protocolos Tórax Infantil e Infantil/Tórax 1-10 anos, foi aplicado um fator de correção de 0,52 (veja seção 3.2.7) nas grandezas dosimétricas.

\subsubsection{Estimativa de Dose Absorvida em Órgãos}

A estimativa de dose absorvida nos órgãos foi elaborada em algumas etapas. Primeiramente, os porta-dosímetros com os OSLDs foram inseridos nas cavidades dos órgãos de interesse do phantom ATOM, modelo 705 (CIRS, EUA) para que fossem irradiados com o tomógrafo Philips Brilliance 64 CT scanner (Philips, Holanda) de acordo com os protocolos previamente descritos. Após as irradiações, a informação armazenada nos dosímetros OSL foi avaliada com o leitor automático Ris $\phi$ TL/OSL modelo DA-20 (DTU Nutech., Dinamarca). Para todas as medições, um grupo de OSLDs foi deixado na sala de controle do tomógrafo para quantificar a radiação de fundo, que foi devidamente subtraída do conjunto de dados. 
Após o processo de leitura dos OSLDs, a curva de calibração foi utilizada para a conversão do sinal OSL de cada dosímetro na grandeza física kerma no ar $\left(K_{A r}\right)$. Em seguida, foi calculado o valor médio de kerma no ar para cada fatia $i$ do phantom, de acordo com a relação 3.1 (GIANSANTE, 2017; MARTINS, 2015; VUOLO, 2002), onde G é o número de grupos (porta dosímetros) inseridos na fatia $i$ do phantom, e a $\sigma_{\mathrm{n}}^{2}$ variância dos sinais OSLs do grupo $n$ de dosímetros:

$$
K_{A r}^{i}=\frac{\sum_{n=1}^{G}\left(K_{A r}^{n} / \sigma_{n}^{2}\right)}{\sum_{n=1}^{G}\left(1 / \sigma_{n}^{2}\right)}
$$

O kerma no ar precisa então ser convertido em dose média absorvida na fatia $i$ do órgão clínico de interesse, como na equação 3.2 (GIANSANTE, 2017; MARTINS, 2015; OKUNO; YOSHIMURA, 2010):

$$
D_{i}=K_{A r}^{i} \frac{\left(\mu_{e n} / \rho\right)_{\text {Órgão }}}{\left(\mu_{e n} / \rho\right)_{A r}}
$$

Na Equação 3.2, $\left(\mu_{e n} / \rho\right)$ Órgão e $\left(\mu_{e n} / \rho\right){ }_{A r}$ são os coeficientes mássicos de absorção para uma determinada energia efetiva. Para calculá-los, é necessário conhecer a energia efetiva do feixe de radiação, no caso deste trabalho, para os feixes de tensões $100 \mathrm{kV}$ e $120 \mathrm{kV}$. A energia efetiva $E_{e f}$ dos feixes poli energéticos é obtida através da associação com a energia efetiva de um feixe mono energético de mesma Camada Semi-Redutora (CSR). A obtenção da CSR para um feixe de radiação com energia efetiva $E_{e f}$ é feita de acordo com a relação:

$$
C S R=\frac{\ln (2)}{\mu_{A l}\left(E_{e f}\right)}
$$

Reescrevendo a equação acima e dividindo pela densidade do alumínio $\left(\rho_{A l}\right)$ em ambos os lados, obtemos a relação:

$$
\left(\frac{\mu}{\rho}\right)_{A l}=\frac{\ln (2)}{\operatorname{CSR} \times \rho_{A l}}
$$


Os valores de CSR para os feixes de raios X com tensões de $100 \mathrm{kV}$ e $120 \mathrm{kV}$ do equipamento Philips Brilliance 64 CT scanner (Philips, Holanda) são apresentados Tabela 3.5, juntamente com os coeficientes de atenuação mássicos calculados e suas correspondentes energias efetivas. A obtenção da energia efetiva para tais feixes foi realizada através da associação aos coeficientes de atenuação mássicos correspondentes no banco de dados do Instituto Nacional de Padrões e Tecnologia (NIST, EUA) (The National Institute of Standards and Technology - NIST) (NIST, 1998). A densidade do alumínio foi adotada como $\rho_{A l}=2,7 \mathrm{~g} / \mathrm{cm}^{3}$.

Tabela 3.5 - Valores calculados para os coeficientes de atenuação mássicos e suas respectivas energias efetivas, para os feixes de raios $\mathrm{X}$ de 100 e $120 \mathrm{kV}$.

\begin{tabular}{ccccc}
\hline $\begin{array}{c}\text { Tensão no Tubo } \\
\text { de Raios X } \\
{[\mathbf{k V}]}\end{array}$ & $\begin{array}{c}\text { Filtração } \\
\text { Externa } \\
{[\mathbf{m m ~ C u}]}\end{array}$ & $\begin{array}{c}\text { Primeira CSR } \\
{[\mathbf{m m ~ A l}]}\end{array}$ & $\begin{array}{c}\text { Coef. de } \\
\text { Atenuação } \\
\text { Mássico }\left[\mathbf{c m}^{2} / \mathbf{g}\right]\end{array}$ & $\begin{array}{c}\text { Energia Efetiva } \\
{[\mathbf{k e V}]}\end{array}$ \\
\hline 100 & 0,20 & 7,35 & 0,3494 & 51,6 \\
120 & 0,25 & 8,37 & 0,3068 & 56,0 \\
\hline
\end{tabular}

Os coeficientes de absorção mássicos para as energias efetivas $\left(E_{e f}(100 \mathrm{kV})=\right.$ $51,6 \mathrm{keV})$ e $\left(E_{e f}(120 \mathrm{kV})=56,0 \mathrm{keV}\right)$ dos tecidos dos órgãos avaliados e do ar podem ser obtidos com o auxílio das informações contidas no banco de dados do NIST (NIST). Neste banco de dados estão disponíveis os coeficientes de absorção mássicos $\left(\frac{\mu_{e n}}{\rho}\right)$ em função da energia do fóton, baseados na composição de cada composto/órgão proposta pelo ICRU Report 44 (ICRU, 1989).

Para encontrar os coeficientes de absorção mássicos específicos para as energias efetivas de $51,6 \mathrm{keV}$ e $56,0 \mathrm{keV}$, foi realizado um ajuste exponencial do tipo $(\mu / \rho)_{e n}=y_{0}+A_{1} e^{-\frac{E}{t 1}}$, onde $y_{0}, A_{1}$ e $t_{1}$ são parâmetros de ajuste, no intervalo de energias entre $20-60 \mathrm{keV}$ utilizando o software Origin ${ }^{\circledR} 2020$ (OriginLab Co., MA, EUA). Os resultados encontrados são apresentados na Tabela 3.6.

\footnotetext{
${ }^{\mathrm{b}}$ Cortesia: Denise Y. Nersissian (IFUSP).
} 
Tabela 3.6 - Coeficientes de absorção mássicos para as energias de 51,6 keV e 56,0 keV calculados para estimativa de dose absorvida nos órgãos.

\begin{tabular}{cccccc}
\hline $\begin{array}{c}\text { Energia } \\
\text { Efetiva }\end{array}$ & Cristalino & $\begin{array}{c}\text { Tecido } \\
\text { Pulmonar }\end{array}$ & Tireoide & $\begin{array}{c}\text { Ar } \\
\text { (nível do mar) }\end{array}$ \\
\hline $\mathbf{5 1 , 6 ~ k e V}$ & $\left(\frac{\boldsymbol{\mu}_{e n}}{\boldsymbol{\rho}}\right)\left[\mathbf{c m}^{2} / \mathbf{g}\right]$ & $0,038 \pm 0,004$ & $0,041 \pm 0,004$ & $0,045 \pm 0,006$ & $0,039 \pm 0,004$ \\
$(\mathbf{1 0 0 k V})$ & & & & & \\
$\mathbf{5 6 , 0} \mathbf{~ k e V}$ & $\left(\frac{\boldsymbol{\mu}_{e n}}{\boldsymbol{\rho}}\right)\left[\mathbf{c m}^{2} / \mathbf{g}\right]$ & $0,035 \pm 0,004$ & $0,039 \pm 0,004$ & $0,043 \pm 0,006$ & $0,036 \pm 0,004$ \\
$(\mathbf{1 2 0 k V})$ & & & & & \\
\hline
\end{tabular}

Por fim, a estimativa de dose absorvida nos órgãos do phantom pode ser obtida através da soma das doses médias absorvidas em cada fração $\left(\mathrm{f}_{\mathrm{i}}\right)$ do órgão correspondente, de acordo com a relação (GIANSANTE, 2017):

$$
\text { Dose }=\sum_{i} f_{i} \times D_{i}
$$

Todos os fatores considerados na estimativa das incertezas associadas aos valores de dose absorvida em órgão são descritos no Apêndice A.

\subsubsection{Análise de Parâmetros de Aquisição}

Foi realizado, em projeto anterior (GIANSANTE, 2017), um levantamento de dados retrospectivo no sistema PACS/RIS do INRAD-FMUSP para identificação de exames de TC pediátricos das regiões de crânio e tórax. Os pacientes foram divididos em grupos de quatro faixas etárias: $0-1$ ano, $1-5$ anos, $5-10$ anos e $10-16$ anos de idade e as grandezas dosimétricas de tomografia computadorizada $\mathrm{CTDI}_{\mathrm{vol}}$ e DLP foram coletadas. No presente trabalho, o levantamento de dados e a investigação das grandezas dosimétricas foram continuadas para o acompanhamento dos protocolos pré e pós implementação da otimização de procedimentos radiológicos pediátricos realizados na instituição (GUERRA; NERSISSIAN; MELO; VASCONCELLOS et al., 2019). Os dados comparativos apresentam os exames otimizados realizados no período de 2018-2020.

Valores medianos das grandezas dosimétricas foram determinados para cada faixa etária e então comparados a DRLs propostos por uma pesquisa britânica (SHRIMPTON; HILLIER; MEESON; GOLDING, 2014), uma pesquisa europeia (EUROPEAN SOCIETY OF RADIOLOGY, 2015) e por outra pesquisa internacional (VASSILEVA; REHANI; 
KOSTOVA-LEFTEROVA; AL-NAEMI et al., 2015). A pesquisa europeia considera o grupo de peso dos pacientes em vez da faixa etária (EUROPEAN SOCIETY OF RADIOLOGY, 2015). Os autores apresentam uma tabela com equivalência aproximada entre peso e faixas etárias, com o objetivo de comparar os DRLs baseados na faixa etária do paciente com o DRL no seu peso.

Os três trabalhos propõem DRLs para a grandeza CTDI $_{\text {vol }}$ baseados em phantoms cilíndricos de referência com $16 \mathrm{~cm}$ de diâmetro, para exames de cabeça, e em phantoms cilíndricos de referência com $32 \mathrm{~cm}$ de diâmetro, para exames de tórax. No presente estudo, alguns exames tomográficos de tórax de bebês (0-2 anos) apresentam valores de CTDI ${ }_{\mathrm{vol}}$ baseados em phantoms de $16 \mathrm{~cm}$. Para realizar a comparação com os DRLs sugeridos pelas pesquisas internacionais, as grandezas dosimétricas destes pacientes foram corrigidas por um fator de 0,52 , de acordo com um teste realizado pelo grupo de controle de qualidade do IFUSP no mesmo equipamento de $\mathrm{TC}^{\mathrm{c}}$.

\subsubsection{Avaliação Comparativa entre Doses Experimentais e Simuladas}

Para verificar a metodologia experimental adotada neste trabalho, foi utilizada a versão 3.0 do software para cálculo de dose em órgãos National Cancer Institute Dosimetry System for CT (NCICT) (LEE; KIM; BOLCH; MOROZ et al., 2015). A interface gráfica do software foi utilizada para seleção do fabricante e modelo do tomógrafo e para a inserção dos parâmetros de aquisição das imagens dos seis protocolos de TC pediátricos avaliados neste trabalho (Figura 3.11). Baseado nestas informações, o software NCICT calcula, por método Monte Carlo, a dose absorvida por alguns órgãos críticos durante a aquisição das imagens.

\footnotetext{
${ }^{\mathrm{c}}$ Cortesia: Denise Y. Nerssisian (IFUSP).
} 


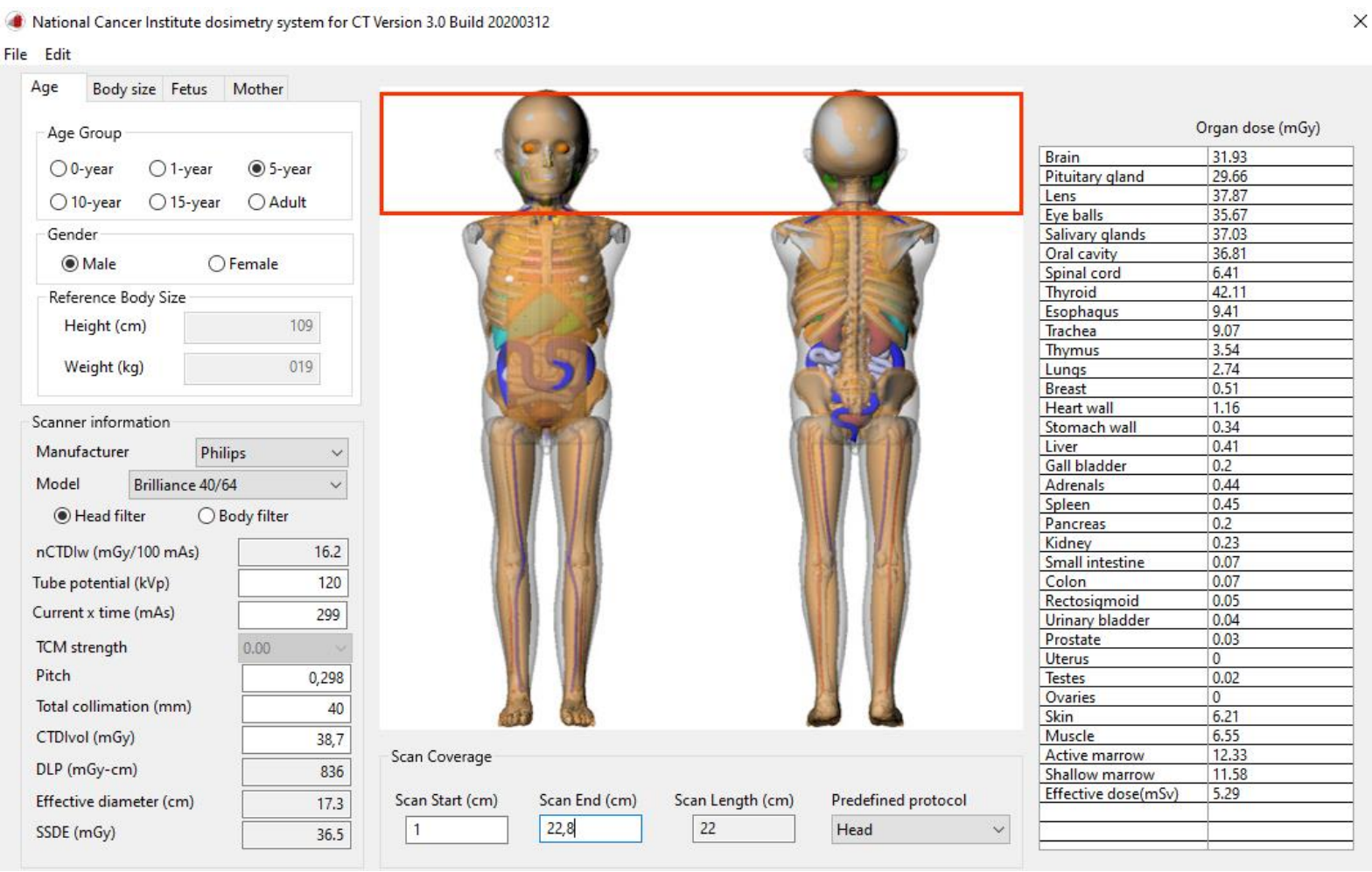

Figura 3.11 - Interface do software NCICT versão 3.0, utilizado para simular dose absorvida em órgãos críticos de phantoms de referência, proveniente de exames tomográficos, via método Monte Carlo.

A diferença percentual entre a dose absorvida calculada experimentalmente com os dosímetros OSL, $D_{\text {experimental }}$, e a dose absorvida calculada por simulação Monte Carlo, $D_{\text {simulação } M C}$, foi determinada de acordo com a relação (DABIN; MENCARELLI; MCMILLAN; ROMANYUKHA et al., 2016; GIANSANTE, 2017):

$$
\text { Diferença } \%=\left(\frac{D_{\text {simulação } M C}-D_{\text {experimental }}}{D_{\text {simulação } M C}}\right) \times 100
$$

\subsubsection{Avaliação Estatística}

A avaliação de Bland-Altman foi utilizada para analisar a concordância entre a metodologia experimental adotada neste trabalho e as simulações pelo método Monte Carlo realizadas com o software NCICT.

A análise de Bland-Altman foi introduzida em 1983 para avaliar a concordância entre duas medições quantitativas. Esta análise é uma maneira simples de avaliar um viés entre as diferenças médias e estimar um intervalo de concordância, dentro do qual caem $95 \%$ das diferenças entre o primeiro e o segundo método (BLAND; ALTMAN, 1999; GIAVARINA, 2015). A construção de limites de concordância é feita através da dose média (D) e do desvio 
padrão $\left(d_{p}\right)$ das duas medidas (GIAVARINA, 2015). O gráfico de Bland-Altman é um gráfico de dispersão, em que o eixo das ordenadas representa a diferença entre as medidas e o eixo das abscissas representa a média aritmética entre elas (HIRAKATA; CAMEY, 2009). Os dados podem ser analisados tanto como gráfico de diferenças de unidade quanto como gráfico de diferenças de porcentagem (GIAVARINA, 2015). Os limites de concordância são determinados através da relação (HIRAKATA; CAMEY, 2009):

$$
\mathrm{D} \pm 1,96 \times d_{p}
$$

\subsubsection{Análise da Qualidade das Imagens}

Para a análise de qualidade das imagens tomográficas, o phantom comercial de qualidade de imagem CATPHAN 500 (The Phantom Laboratory, EUA) foi irradiado no tomógrafo Philips Brilliance 64 CT scanner (Philips, Holanda) com os mesmos protocolos de TC pediátricos utilizados no phantom antropomórfico para estimativa de dose absorvida. As medições de ruído e de número TC em unidades Hounsfield foram feitas com o software ImageJ (National Institutes of Health, EUA) um programa de processamento de imagens. A qualidade das imagens foi avaliada em termos de Ruído, Razão Sinal Ruído (RSR) e Razão Contraste Ruído (RCR).

O módulo CTP 486 foi utilizado para determinar a Razão Sinal Ruído (RSR) e o Ruído das imagens. A determinação do Ruído foi baseada em medições de desvio padrão realizadas dentro de regiões de interesse (Region of Interest - ROI) circulares, posicionadas no fundo da imagem. O cálculo da RSR foi baseado na divisão do número TC médio pelo Ruído (desvio padrão do número TC).

O módulo de baixo contraste (CTP 515) foi utilizado para o cálculo da Razão Contraste Ruído (RCR) nas imagens. ROIs circulares de mesmo tamanho foram posicionadas no círculo de maior diâmetro (alvo supra slice com $15 \mathrm{~mm}$ de diâmetro e nível de contraste 1\%) e na região de fundo para medição do número CT médio e do Ruído. A RCR foi calculada de acordo com a relação:

$$
R C R=\frac{\text { Sinal }_{\text {círculo }}-\text { Sinal }_{\text {fundo }}}{\text { Ruído }}
$$


Para a avaliação qualitativa da resolução espacial das imagens, foi utilizado o módulo de alta resolução (CTP 528). Nesta avaliação, o observador busca encontrar nas imagens o último conjunto possível de pares de linhas visualmente separadas.

Por fim, o fator Q foi utilizado para descrever a relação entre dose e qualidade de imagem. Este parâmetro relaciona a grandeza $\mathrm{CTDI}_{\mathrm{vol}}$, o ruído, a resolução espacial e a largura da fatia em um único número, definida de acordo com a relação (VERDUN; RACINE; OTT; TAPIOVAARA et al., 2015):

$$
Q_{C T D I v o l}=\sqrt{\frac{f^{3}}{\sigma^{2} \times Z \times C T D I_{v o l}}}
$$

Em que f é a resolução espacial (em pares de linha por $\mathrm{cm}$ ), $\sigma$ é o ruído da imagem (em unidades Hounsfield HU) e z é a largura da fatia (em mm).

Para avaliação da qualidade das imagens tomográficas de crânio e tórax do ponto de vista clínico, as imagens realizadas com os protocolos otimizados foram analisadas por um médico radiologista ${ }^{\mathrm{d}}$ da instituição. $\mathrm{O}$ objetivo desta análise era a classificação das imagens em três categorias: 1- imagem não diagnóstica, 2 - imagem adequada ou 3 - imagem excelente, para o acompanhamento do processo de otimização implementado no INRAD-FMUSP.

\footnotetext{
d Dr. Marcio Sawamura é médico radiologista do Instituto de Radiologia da Faculdade de Medicina da Universidade de São Paulo (INRAD-FMUSP) e colaborou com o presente trabalho.
} 


\section{RESULTADOS}

\subsection{ANÁLISE DE PARÂMETROS DE AQUISIÇÃO}

Foi realizado no sistema PACS/RIS do INRAD-FMUSP um levantamento retrospectivo para análise de grandezas dosimétricas para tomografia computadorizada - DLP e CTDI vol $_{\text {- de }}$ exames pediátricos. Foram analisados exames tomográficos de crânio e tórax, de acordo com a metodologia descrita na seção 3.2.7, para o acompanhamento dos protocolos implementados com o projeto de otimização de procedimentos radiológicos pediátricos na instituição. A coleta dos exames otimizados foi realizada ao longo dos anos 2018-2020.

\section{Exames tomográficos de crânio}

Foram analisados dados de 80 exames tomográficos pediátricos realizados antes da implementação do processo de otimização dos protocolos e de 119 exames tomográficos pediátricos otimizados, distribuídos entre as quatro faixas etárias dos pacientes.

Valores medianos de $\mathrm{CTDI}_{\mathrm{vol}}$ encontrados neste trabalho e os DRLs propostos pelos trabalhos internacionais são apresentados na Tabela 4.1.

Tabela 4.1 - Valores medianos da grandeza CTDI $_{\mathrm{vol}}$ para os exames tomográficos de crânio coletados e os DRLs propostos por três trabalhos internacionais. Valores entre parêntesis representam o intervalo interquartil.

\begin{tabular}{cccccc}
\hline \multicolumn{7}{c}{ CTDI $_{\text {vol }}(\mathbf{m G y})$} \\
\hline $\begin{array}{c}\text { Faixa Etária } \\
\text { (anos) }\end{array}$ & $\begin{array}{c}\text { Este Trabalho } \\
\text { (Não Otimizado) }\end{array}$ & $\begin{array}{c}\text { Este Trabalho } \\
\text { (Otimizado) }\end{array}$ & $\begin{array}{c}\text { Vassileva et al. } \\
(\mathbf{2 0 1 5})\end{array}$ & $\begin{array}{c}\text { Europa } \\
(\mathbf{2 0 1 5})\end{array}$ & $\begin{array}{c}\text { Reino } \\
\text { Unido } \\
(\mathbf{2 0 1 4})\end{array}$ \\
\hline $0-1$ & $26(15)$ & $12(7)$ & 26 & 25 & 25 \\
$1-5$ & $26(15)$ & $11(2)$ & 36 & 25 & 40 \\
$5-10$ & $35(13)$ & $24(12)$ & 43 & 38 & 60 \\
$10-16$ & $43(5)$ & $12(12)$ & 53 & 53 & - \\
\hline
\end{tabular}

Os resultados comparativos são apresentados na forma de gráficos box-plots (Figura 4.1). Cada caixa (box) contém 50\% dos dados (primeiro quartil $25 \%$ - terceiro quartil $75 \%$ ) e uma linha horizontal que representa o valor da mediana, com seus limites inferior e superior nas extremidades. 

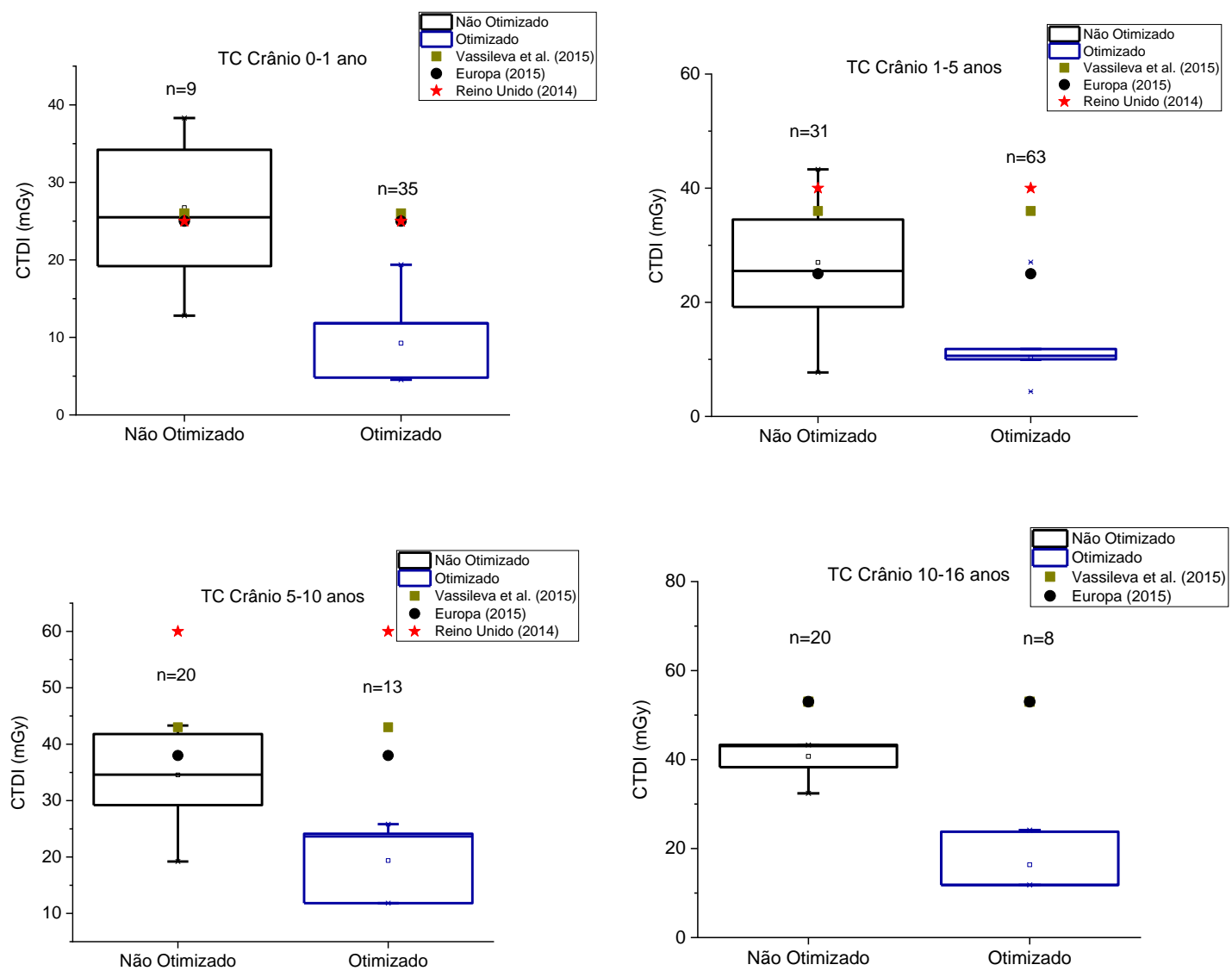

Figura 4.1 - Box-plots comparativos da grandeza dosimétrica CTDI $_{\mathrm{vol}}$ para os exames de crânio avaliados antes e após o processo de otimização dos protocolos pediátricos para as quatro faixas etárias analisadas.

Valores medianos de DLPs encontrados neste trabalho os DRLs propostos pelos trabalhos internacionais são apresentados na Tabela 4.2.

Tabela 4.2 - Valores medianos da grandeza DLP para os exames tomográficos de crânio coletados e os DRLs propostos por três trabalhos internacionais. Valores entre parêntesis representam o intervalo interquartil.

\begin{tabular}{cccccc}
\hline \multicolumn{7}{c}{ DLP (mGy.cm) } \\
\hline $\begin{array}{c}\text { Faixa Etária } \\
\text { (anos) }\end{array}$ & $\begin{array}{c}\text { Este Trabalho } \\
\text { (Não Otimizado) }\end{array}$ & $\begin{array}{c}\text { Este Trabalho } \\
\text { (Otimizado) }\end{array}$ & $\begin{array}{c}\text { Vassileva et } \\
\text { al. (2015) }\end{array}$ & $\begin{array}{c}\text { Europa } \\
(\mathbf{2 0 1 5})\end{array}$ & $\begin{array}{c}\text { Reino } \\
\text { Unido } \\
(\mathbf{2 0 1 4})\end{array}$ \\
\hline $0-1$ & $527(207)$ & $231(178)$ & 440 & 300 & 350 \\
$1-5$ & $527(149)$ & $191(98)$ & 540 & 370 & 650 \\
$5-10$ & $552(148)$ & $410(150)$ & 690 & 505 & 860 \\
$10-16$ & $649(87)$ & $288(150)$ & 840 & 700 & - \\
\hline
\end{tabular}


Os resultados comparativos são apresentados na forma de gráficos box-plots (Figura 4.2).
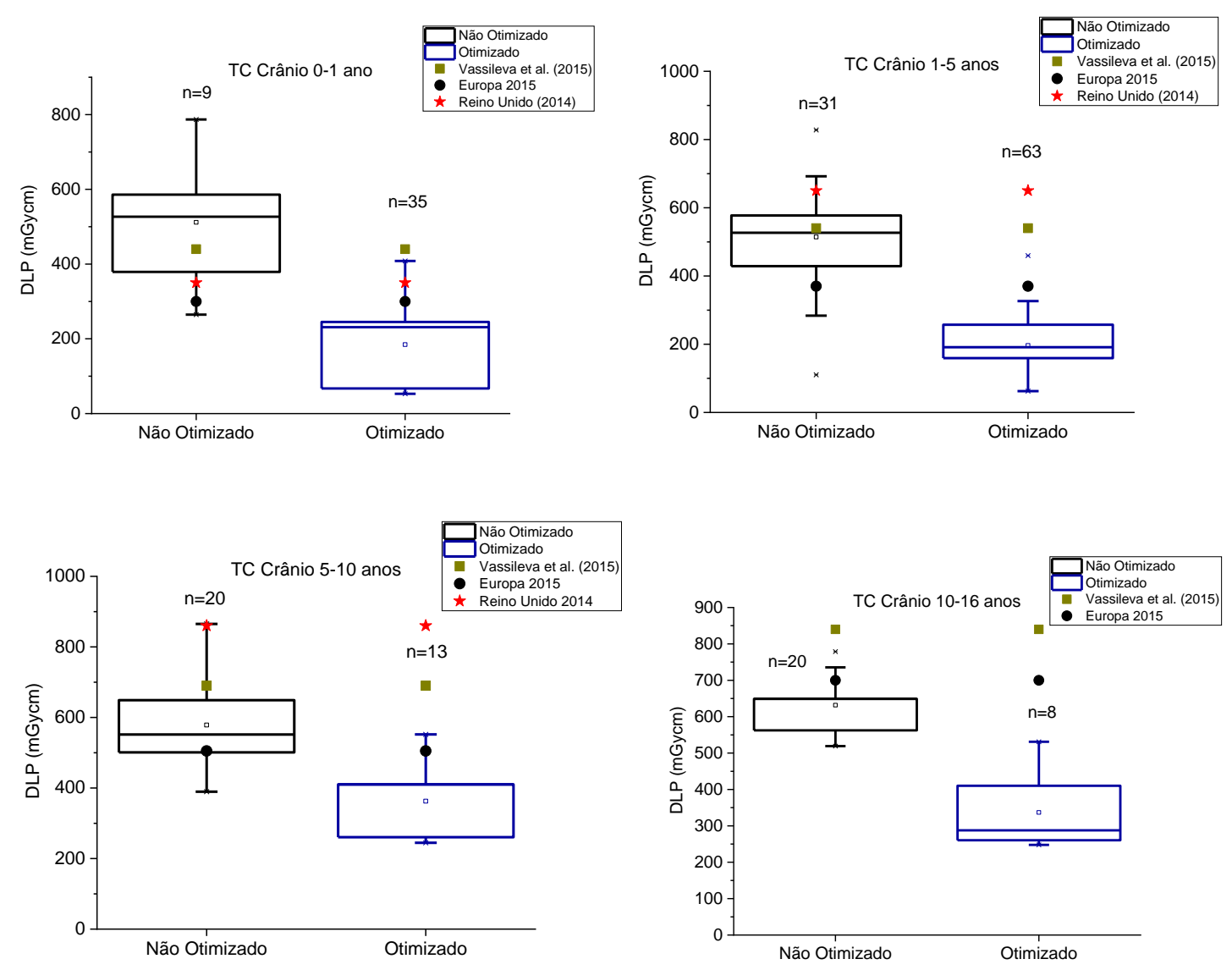

Figura 4.2 - Box-plots comparativos da grandeza dosimétrica DLP para os exames de crânio avaliados antes e após o processo de otimização dos protocolos pediátricos para as quatro faixas etárias analisadas.

Nestes protocolos, observa-se a diminuição das grandezas dosimétricas coletadas com a otimização. Esta tendência será refletida nas doses de radiação provenientes destes exames, como será mostrado na seção 4.4.

2. Exames tomográficos de tórax

Um total de 47 exames tomográficos pediátricos não otimizados - realizados previamente ao processo de otimização - e de 36 exames tomográficos pediátricos otimizados foram analisados. Novamente, são apresentados os valores medianos de $\mathrm{CTDI}_{\mathrm{vol}}$ encontrados neste trabalho e os DRLs propostos pelas pesquisas adotadas como referência (Tabela 4.3). Os resultados comparativos são apresentados na forma de gráficos box-plots (Figura 4.3). 
Tabela 4.3 - Valores medianos da grandeza CTDI $_{\text {vol }}$ para os exames tomográficos de tórax coletados e os DRLs propostos por três trabalhos internacionais. Valores entre parêntesis representam o intervalo interquartil.

\section{$\mathrm{CTDI}_{\mathrm{vol}}(\mathrm{mGy})$}

\begin{tabular}{cccccc}
\hline $\begin{array}{c}\text { Faixa Etária } \\
(\text { anos) }\end{array}$ & $\begin{array}{c}\text { Este Trabalho } \\
\text { (Não Otimizado) }\end{array}$ & $\begin{array}{c}\text { Este Trabalho } \\
\text { (Otimizado) }\end{array}$ & $\begin{array}{c}\text { Vassileva et al. } \\
(\mathbf{2 0 1 5})\end{array}$ & $\begin{array}{c}\text { Europa } \\
(\mathbf{2 0 1 5})\end{array}$ & $\begin{array}{c}\text { Reino } \\
\text { Unido } \\
(\mathbf{2 0 1 4})\end{array}$ \\
\hline $0-1$ & $2,7(0,9)$ & $3,2(0,5)$ & 5,2 & 2,7 & 6,0 \\
$1-5$ & $2,9(2,3)$ & $4,3(0)$ & 6,0 & 3,3 & 6,5 \\
$5-10$ & $4,5(0,7)$ & $4,3(0)$ & 6,8 & 5,6 & 10,0 \\
$10-16$ & $4,6(1,2)$ & $5,9(0)$ & 7,3 & 5,7 & - \\
\hline
\end{tabular}
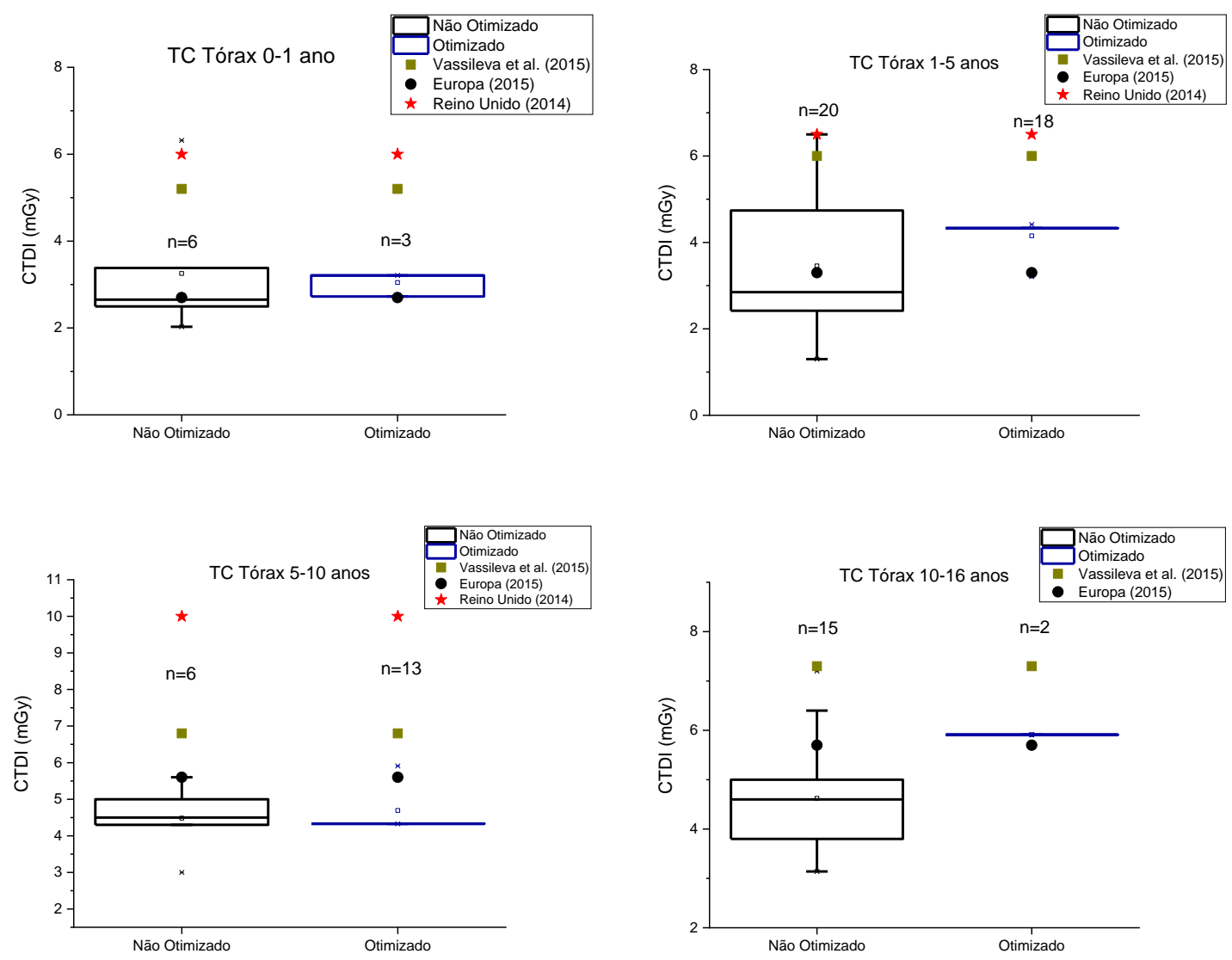

Figura 4.3 - Box-plots comparativos da grandeza dosimétrica CTDI $_{\text {vol }}$ para os exames de tórax avaliados antes e após o processo de otimização dos protocolos pediátricos para as quatro faixas etárias analisadas. 
Valores medianos de DLPs encontrados neste trabalho os DRLs propostos pelos trabalhos internacionais são apresentados na Tabela 4.4 e os resultados comparativos, apresentados na forma de gráficos box-plots na Figura 4.4.

Tabela 4.4 - Valores medianos da grandeza DLP para os exames tomográficos de tórax coletados e os DRLs propostos por três trabalhos internacionais. Valores entre parêntesis representam o intervalo interquartil.

DLP (mGy.cm)

\begin{tabular}{cccccc}
\hline $\begin{array}{c}\text { Faixa Etária } \\
\text { (anos) }\end{array}$ & $\begin{array}{c}\text { Este Trabalho } \\
\text { (Não Otimizado) }\end{array}$ & $\begin{array}{c}\text { Este Trabalho } \\
\text { (Otimizado) }\end{array}$ & $\begin{array}{c}\text { Vassileva et } \\
\text { al. (2015) }\end{array}$ & $\begin{array}{c}\text { Europa } \\
(\mathbf{2 0 1 5})\end{array}$ & $\begin{array}{c}\text { Reino } \\
\text { Unido } \\
(\mathbf{2 0 1 4})\end{array}$ \\
\hline $0-1$ & $59(12)$ & $67(24)$ & 130 & 45 & 100 \\
$1-5$ & $74(64)$ & $124(25)$ & 140 & 80 & 115 \\
$5-10$ & $138(52)$ & $139(25)$ & 170 & 115 & 185 \\
$10-16$ & $162(63)$ & $195(33)$ & 300 & 180 & - \\
\hline
\end{tabular}



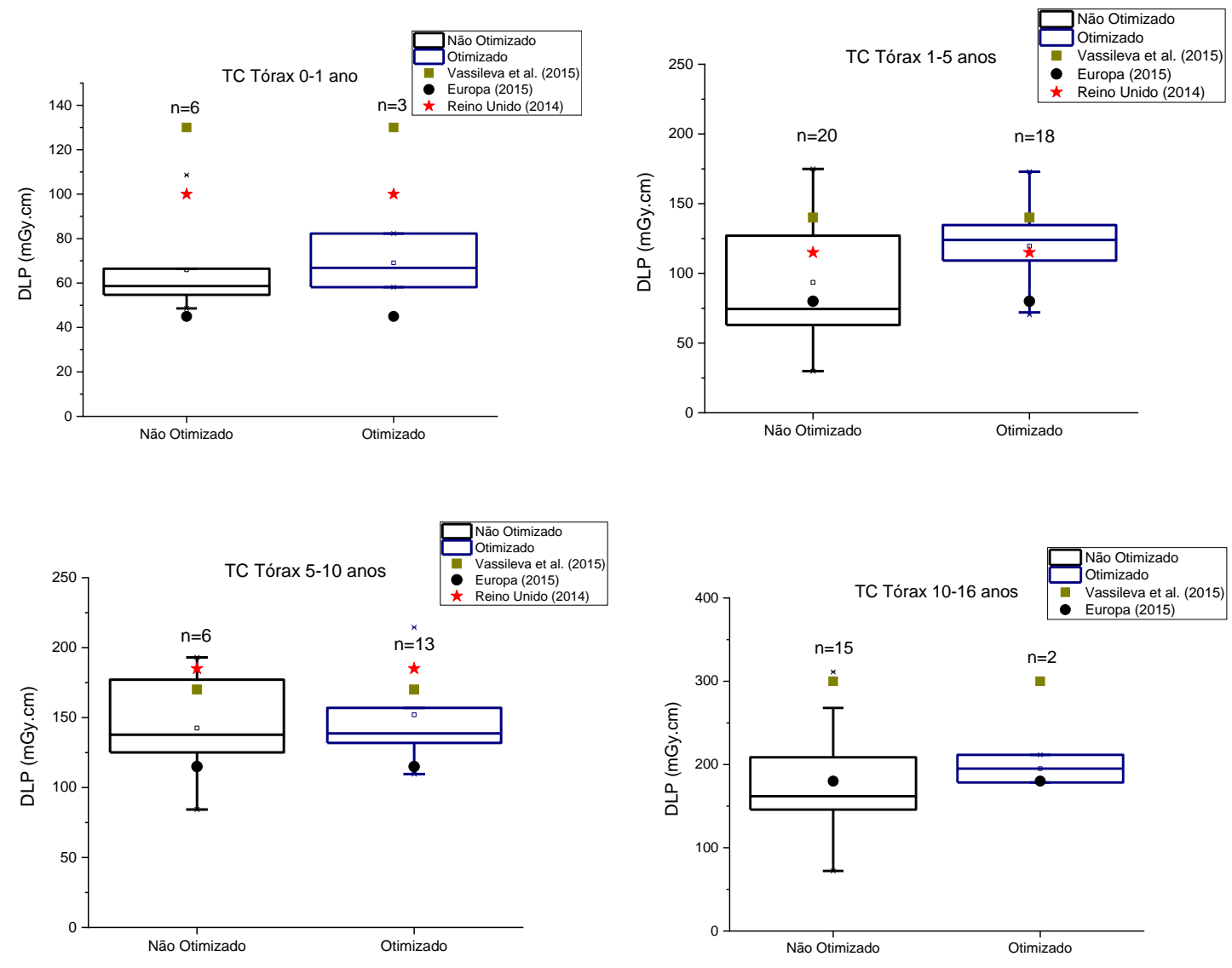

Figura 4.4 - Box-plots comparativos da grandeza dosimétrica DLP para os exames de crânio avaliados antes e após o processo de otimização dos protocolos pediátricos para as quatro faixas etárias analisadas.

Com a otimização dos protocolos de tórax, nota-se um ligeiro aumento das grandezas dosimétricas coletadas. Embora esta tendência também se confirme nos resultados de dose absorvida, os novos protocolos de tórax apresentam imagens com ruído levemente menor, como será mostrado nas próximas seções. Nota-se, também, um grupo pequeno de pacientes em algumas faixas etárias. Este comportamento ocorre, pois, o INRAD é um hospital geral e não exclusivamente pediátrico, em que a maioria dos pacientes atendidos é adulta.

\subsection{ANÁLISE DA VARIAÇÃO DA QUALIDADE DAS IMAGENS}

O phantom comercial de qualidade de imagem CATPHAN 500 (The Phantom Laboratory, EUA) foi irradiado no tomógrafo Philips Brilliance 64 CT scanner (Philips, Holanda) com os mesmos parâmetros e protocolos de TC pediátricos utilizados para estimativa de dose absorvida nos órgãos do phantom antropomórfico. Para analisar a qualidade dessas imagens tomográficas, foram determinados o Ruído, a Razão Sinal Ruído (RSR) e a Razão 
Contraste Ruído (RCR), de acordo com a metodologia descrita na seção 3.2.10. Os resultados são apresentados na Tabela 4.5 e Tabela 4.6 para as imagens de crânio e na Tabela 4.7 para as imagens de tórax. Na avaliação qualitativa da resolução espacial entre as imagens antigas e otimizadas, realizada com módulo de alta resolução (CTP 528), não foi observada alteração do último conjunto de pares de linhas separadas visível.

Tabela 4.5 - Parâmetros de qualidade de imagem calculados para os protocolos de TC de crânio helicoidais avaliados.

\begin{tabular}{cccc}
\hline & $\begin{array}{c}\text { Crânio 3D } \\
\text { (Não Otimizado) }\end{array}$ & $\begin{array}{c}\text { Crânio 3D/Infantil } \\
\text { (Otimizado) }\end{array}$ & $\begin{array}{c}\text { Diferença Percentual } \\
(\%)\end{array}$ \\
\hline Tensão (kV) & 120 & 100 & -17 \\
Carga (mAs) & 299 & 149 & -50 \\
Razão Sinal Ruído & $2,86 \pm 0,01$ & $0,59 \pm 0,001$ & -79 \\
$\begin{array}{c}\text { (RSR) } \\
\text { Razão Contraste } \\
\text { Ruído (RCR) } \\
\text { Ruído (HU) }\end{array}$ & $1,65 \pm 0,09$ & $0,77 \pm 0,09$ & -53 \\
Pares de linhas & $6,70 \pm 0,02$ & $13,76 \pm 0,03$ & +105 \\
visíveis & 6 & 6 & 0 \\
\hline
\end{tabular}

Tabela 4.6 - Parâmetros de qualidade de imagem calculados para os protocolos de TC de crânio axiais avaliados.

\begin{tabular}{cccc}
\hline & $\begin{array}{c}\text { Crânio Criança } \\
\text { Axial (Não } \\
\text { Otimizado) }\end{array}$ & $\begin{array}{c}\text { Infantil/Crânio 2-6 } \\
\text { anos } \\
\text { (Otimizado) }\end{array}$ & $\begin{array}{c}\text { Diferença Percentual } \\
(\%)\end{array}$ \\
\hline Tensão (kV) & 120 & 100 & -17 \\
Carga (mAs) & 200 & 110 & -45 \\
Razão Sinal Ruído & $2,93 \pm 0,02$ & $0,88 \pm 0,01$ & -70 \\
$\begin{array}{c}\text { (RSR) } \\
\text { Razão Contraste } \\
\text { Ruído (RCR) } \\
\text { Ruído (HU) }\end{array}$ & $1,61 \pm 0,23$ & $1,45 \pm 0,06$ & -10 \\
Pares de linhas & $6,63 \pm 0,02$ & $8,37 \pm 0,02$ & +26 \\
visíveis & 6 & 6 & 0 \\
\hline
\end{tabular}


Tabela 4.7 - Parâmetros de qualidade de imagem calculados para os protocolos de TC de tórax avaliados.

\begin{tabular}{|c|c|c|c|}
\hline & $\begin{array}{c}\text { Tórax Infantil } \\
\text { (Não Otimizado) }\end{array}$ & $\begin{array}{c}\begin{array}{c}\text { Infantil/Tórax 1-10 } \\
\text { anos } \\
\text { (Otimizado) }\end{array} \\
\end{array}$ & $\begin{array}{c}\text { Diferença Percentual } \\
(\%)\end{array}$ \\
\hline Tensão (kV) & 120 & 100 & -17 \\
\hline Carga (mAs) & 55 & 110 & +50 \\
\hline $\begin{array}{l}\text { Razão Sinal } \\
\text { Ruído (RSR) }\end{array}$ & $0,29 \pm 0,001$ & $0,14 \pm 0,001$ & -52 \\
\hline $\begin{array}{l}\text { Razão Contraste } \\
\text { Ruído (RCR) }\end{array}$ & $0,16 \pm 0,02$ & $0,15 \pm 0,05$ & -6 \\
\hline Ruído (HU) & $52,41 \pm 0,09$ & $48,43 \pm 0,11$ & -8 \\
\hline $\begin{array}{c}\text { Pares de linhas } \\
\text { visíveis }\end{array}$ & 7 & 7 & 0 \\
\hline
\end{tabular}

A otimização dos protocolos de crânio foi responsável por um aumento considerável no ruído das imagens e, no caso dos protocolos de tórax, por uma diminuição mais discreta. As outras métricas avaliadas sofreram pouca redução com os novos protocolos.

Os valores encontrados para o fator $\mathrm{Q}$, calculados de acordo com a metodologia apresentada na seção 3.2.10 são apresentadas na Tabela 4.8 e na Tabela 4.9 para protocolos de crânio e na Tabela 4.10 para protocolos de tórax.

Tabela 4.8 - Fatores Q

\begin{tabular}{lccc}
\hline & $\begin{array}{c}\text { Crânio 3D } \\
\text { (Não Otimizado) }\end{array}$ & $\begin{array}{c}\text { Crânio 3D/Infantil } \\
\text { (Otimizado) }\end{array}$ & $\begin{array}{c}\text { Diferença Percentual } \\
(\%)\end{array}$ \\
\hline Q $_{\text {CTDIvol }}$ & $0,353 \pm 0,001$ & $0,311 \pm 0,001$ & -12 \\
CTDI $_{\text {vol }}$ (mGy) & 38,7 & 11,8 & -70 \\
DLP (mGy.cm) & 1097,0 & 335,8 & -69 \\
\hline
\end{tabular}

Tabela 4.9 - Fatores Q QTDI calculados para os protocolos de crânio axiais avaliados.

\begin{tabular}{lccc}
\hline & $\begin{array}{c}\text { Crânio Criança Axial } \\
\text { (Não Otimizado) }\end{array}$ & $\begin{array}{c}\text { Infantil/Crânio 2-6 anos } \\
\text { (Otimizado) }\end{array}$ & $\begin{array}{c}\text { Diferença } \\
\text { Percentual (\%) }\end{array}$ \\
\hline Q $_{\text {CTDIvol }}$ & $0,249 \pm 0,001$ & $0,241 \pm 0,001$ & -3 \\
CTDI $_{\text {vol }}$ (mGy) & 31,7 & 10,6 & -67 \\
DLP (mGy.cm) $^{\text {(mG) }}$ & 730,1 & 244,9 & -66 \\
\hline
\end{tabular}


Tabela 4.10 - Fatores $\mathrm{Q}_{\mathrm{CTDI}}$ calculados para os protocolos de tórax avaliados.

\begin{tabular}{lccc}
\hline & $\begin{array}{c}\text { Tórax Infantil } \\
\text { (Não Otimizado) }\end{array}$ & $\begin{array}{c}\text { Infantil/Tórax 1-10 anos } \\
\text { (Otimizado) }\end{array}$ & $\begin{array}{c}\text { Diferença } \\
\text { Percentual (\%) }\end{array}$ \\
\hline Q $_{\text {CTDIvol }}$ & $0,186 \pm 0,001$ & $0,184 \pm 0,001$ & -1 \\
CTDI $_{\text {vol }}(\mathbf{m G y})$ & 3,6 & 4,3 & +19 \\
DLP $(\mathbf{m G y . c m})$ & 105,3 & 126,1 & +20 \\
\hline
\end{tabular}

Nota-se que a otimização destes protocolos causou, em geral, reduções discretas nos fatores Q, especialmente no caso dos protocolos de tórax, sugerindo que a otimização foi pouco onerosa em relação à qualidade das imagens tomográficas.

Sob o ponto de vista clínico, as imagens não experimentaram perda de qualidade para o diagnóstico: foram classificadas, em sua maioria, como adequadas para o diagnóstico (classificação 2), com nenhuma imagem avaliada como não diagnóstica (classificação 1).

\subsection{ESTIMATIVA DO VOLUME PULMONAR DO PHANTOM PEDIÁTRICO}

Para realizar a estimativa da dose de radiação absorvida por um órgão durante um exame de tomografia, é necessária a informação do seu volume. Conforme apresentado no item 3.2.4, o cálculo das frações de volume pulmonar contidas nas fatias do phantom pediátrico ATOM da CIRS modelo 705 foi realizado com o software IntelliSpace® PACS (Philips, Holanda). Os pulmões deste simulador estão distribuídos ao longo das fatias 9 a 15 . No caso da tireoide, todo o volume do órgão está contido na fatia 8 do phantom. Os resultados são apresentados na Tabela 4.11. O volume pulmonar total encontrado para o phantom foi de $1035 \pm 34 \mathrm{~cm}^{3}$. Os valores de incerteza são baseados no desvio padrão da média de três medições.

Tabela 4.11- Frações volumétricas dos órgãos avaliados contidas nas fatias do phantom pediátrico.

\begin{tabular}{ccc}
\hline Fatia $(\boldsymbol{i})$ & Órgão & $\boldsymbol{f}_{\boldsymbol{i}}$ \\
\hline & Cristalino (direito) & 0,50 \\
& Cristalino (esquerdo) & 0,50 \\
\hline 8 & Tireoide & 1,00 \\
\hline 9 & & $0,03 \pm 0,01$ \\
10 & & $0,14 \pm 0,02$ \\
11 & Pulmões & $0,22 \pm 0,03$ \\
12 & & $0,19 \pm 0,02$ \\
13 & & $0,21 \pm 0,02$ \\
14 & & $0,17 \pm 0,02$ \\
15 & & $0,03 \pm 0,01$ \\
\hline
\end{tabular}




\subsection{ESTIMATIVA DE DOSE EM ÓRGÃOS}

No presente trabalho, foram avaliados seis protocolos pediátricos de tomografia computadorizada com o phantom para estimativa da dose de radiação absorvida por alguns órgãos de interesse, de acordo com a metodologia descrita nas seções anteriores. Dosímetros OSL foram posicionados no cristalino e nas cavidades da tireoide, para estimativa de dose resultantes de protocolos de crânio. Para estimativa de dose proveniente de protocolos de tórax, os dosímetros foram inseridos nas cavidades da tireoide e dos pulmões. Em cada conjunto de medições, uma curva de calibração foi construída (Apêndice B). As incertezas do sinal OSL foram baseadas no desvio padrão médio da leitura dos dosímetros (Apêndice A). O nível de confiança considerado foi de $68,3 \%(k=1)$.

\subsubsection{Protocolos de Crânio}

Dois protocolos de crânio helicoidais foram avaliados: o protocolo Crânio 3D, adotado antes do processo de otimização, e o protocolo Crânio 3D Infantil, adotado após o processo de otimização. Os resultados encontrados para a dose absorvida na tireoide e no cristalino são apresentados na Tabela 4.12. Para ambos os protocolos, foi utilizado um conjunto de 36 dosímetros OSL distribuídos em 8 porta-dosímetros e uma curva de calibração foi construída para cada procedimento.

Tabela 4.12 - Curvas de calibração, parâmetros dosimétricos do exame e dose absorvida no cristalino e na tireoide para os protocolos de crânio helicoidais avaliados.

\begin{tabular}{|c|c|c|c|c|}
\hline \multicolumn{5}{|c|}{ Protocolos de Crânio Helicoidais } \\
\hline Curva de & Crânio 3D & \multicolumn{3}{|c|}{$K_{a r}[m G y]=(4,7 \pm 0,3) \times 10^{-5}($ Sinal OSL $)$} \\
\hline Calibração & Crânio 3D Infantil & \multicolumn{3}{|c|}{$K_{a r}[m G y]=(4,3 \pm 0,3) \times 10^{-5}($ Sinal OSL $)$} \\
\hline \multicolumn{2}{|c|}{ Nome Protocolo } & $\begin{array}{c}\text { Crânio 3D } \\
\text { (Não Otimizado) }\end{array}$ & $\begin{array}{c}\text { Crânio 3D Infantil } \\
\text { (Otimizado) }\end{array}$ & $\begin{array}{c}\text { Diferença } \\
(\%)\end{array}$ \\
\hline Grandeza & $\mathrm{CTDI}_{\mathrm{vol}}(\mathrm{mGy})$ & 38,7 & 11,8 & -70 \\
\hline Dosimétrica & DLP (mGy.cm) & 1097,0 & 335,8 & -69 \\
\hline \multirow{2}{*}{ Cristalino } & Dose em Órgão (mGy) & $32,3 \pm 2,3$ & $9,2 \pm 1,2$ & -72 \\
\hline & Dose/CTDI ${ }_{\mathrm{vol}}$ & $0,8 \pm 0,1$ & $0,8 \pm 0,1$ & 0 \\
\hline \multirow{2}{*}{ Tireoide } & Dose em Órgão (mGy) & $47,5 \pm 8,5$ & $13,7 \pm 2,4$ & -71 \\
\hline & Dose/CTDI ${ }_{\mathrm{vol}}$ & $1,2 \pm 0,2$ & $1,2 \pm 0,2$ & 0 \\
\hline
\end{tabular}


Também foram avaliados dois protocolos de crânio axiais: o protocolo Crânio Criança Axial, adotado antes do processo de otimização, e o protocolo Infantil/Crânio 2-6 anos, adotado após o processo de otimização. Os resultados encontrados para a dose absorvida no cristalino e na tireoide são apresentados na Tabela 4.13.

Tabela 4.13 - Curvas de calibração, parâmetros dosimétricos do exame e dose absorvida no cristalino e na tireoide para os protocolos de crânio axiais avaliados.

\section{Protocolos de Crânio Axiais}

\begin{tabular}{|c|c|c|c|c|}
\hline $\begin{array}{c}\text { Curva de } \\
\text { Calibração }\end{array}$ & $\begin{array}{l}\text { Crânio Criança Axial } \\
\text { Infantil/Crânio 2-6 anos }\end{array}$ & $\begin{array}{l}K_{a r}[m G y]= \\
K_{a r}[m G y]=\end{array}$ & $\begin{array}{l}(7,5 \pm 0,5) \times 10^{-5}(\text { Sinal } \\
(6,7 \pm 0,5) \times 10^{-5}(\text { Sinal }\end{array}$ & $\begin{array}{l}S L) \\
S L)\end{array}$ \\
\hline \multicolumn{2}{|c|}{ Nome Protocolo } & $\begin{array}{c}\text { Crânio Criança Axial } \\
\text { (Não Otimizado) }\end{array}$ & $\begin{array}{c}\text { Infantil/Crânio 2-6 anos } \\
\text { (Otimizado) }\end{array}$ & $\begin{array}{c}\text { Diferença } \\
(\%)\end{array}$ \\
\hline \multirow{2}{*}{$\begin{array}{c}\text { Grandeza } \\
\text { Dosimétrica }\end{array}$} & $\mathrm{CTDI}_{\mathrm{vol}}(\mathrm{mGy})$ & 31,7 & 10,6 & -67 \\
\hline & DLP (mGy.cm) & 730,1 & 244,9 & -66 \\
\hline \multirow{2}{*}{ Cristalino } & Dose em Órgão (mGy) & $24,8 \pm 2,1$ & $7,6 \pm 1,2$ & -69 \\
\hline & Dose/CTDI ${ }_{\text {vol }}$ & $0,8 \pm 0,1$ & $0,7 \pm 0,1$ & -13 \\
\hline \multirow{2}{*}{ Tireoide } & Dose em Órgão (mGy) & $33,9 \pm 6,1$ & $13,1 \pm 2,3$ & -61 \\
\hline & Dose/CTDI ${ }_{\mathrm{vol}}$ & $1,1 \pm 0,2$ & $1,2 \pm 0,2$ & +9 \\
\hline
\end{tabular}

\subsubsection{Protocolos de Tórax}

Para a avaliação de dose absorvida na tireoide e nos pulmões, o phantom pediátrico foi irradiado com dois protocolos de tórax: Tórax Infantil, adotado antes do processo de otimização, e Infantil/Tórax 1-10 anos, adotado após o processo de otimização. Em ambos os casos, foi utilizado um conjunto de 152 dosímetros OSL distribuídos em 36 porta-dosímetros nas cavidades dos órgãos do phantom. Uma curva de calibração foi construída para cada procedimento. Os resultados obtidos são apresentados na Tabela 4.14. 
Tabela 4.14 - Curvas de calibração, parâmetros dosimétricos do exame e dose absorvida na tireoide nos pulmões para os protocolos de tórax avaliados.

\begin{tabular}{|c|c|c|c|c|}
\hline \multicolumn{5}{|c|}{ Protocolos de Tórax } \\
\hline Curva de & Tórax Infantil & \multicolumn{3}{|c|}{$K_{a r}[m G y]=(4,8 \pm 0,2) \times 10^{-5}($ Sinal $O S L)$} \\
\hline Calibração & Infantil/Tórax 1-10 anos & \multicolumn{3}{|c|}{$K_{a r}[m G y]=(4,7 \pm 0,4) \times 10^{-5}($ Sinal OSL $)$} \\
\hline \multicolumn{2}{|c|}{ Nome Protocolo } & $\begin{array}{c}\text { Tórax Infantil } \\
\text { (Não Otimizado) }\end{array}$ & $\begin{array}{c}\text { Infantil/Tórax 1-10 anos } \\
\text { (Otimizado) }\end{array}$ & $\begin{array}{c}\text { Diferença } \\
(\%)\end{array}$ \\
\hline Grandeza & $\mathrm{CTDI}_{\mathrm{vol}}(\mathrm{mGy})$ & 3,6 & 4,3 & +19 \\
\hline Dosimétrica & DLP (mGy.cm) & 105,3 & 126,1 & +20 \\
\hline \multirow{2}{*}{ Tireoide } & Dose em Órgão (mGy) & $8,3 \pm 1,5$ & $10,0 \pm 1,8$ & +20 \\
\hline & Dose/CTDI ${ }_{\mathrm{vol}}$ & $2,3 \pm 0,4$ & $2,3 \pm 0,4$ & 0 \\
\hline \multirow{2}{*}{ Pulmões } & Dose em Órgão (mGy) & $6,9 \pm 0,6$ & $8,2 \pm 0,7$ & +19 \\
\hline & Dose/CTDI $_{\mathrm{vol}}$ & $1,9 \pm 0,2$ & $1,9 \pm 0,2$ & 0 \\
\hline
\end{tabular}

\subsection{AVALIAÇÃO COMPARATIVA ENTRE DOSES EXPERIMENTAIS E SIMULADAS}

Para verificar a metodologia experimental adotada neste trabalho, as doses em órgãos obtidas experimentalmente foram comparadas às doses em órgãos simuladas com o software NCICT. As simulações com o NCICT foram realizadas baseadas nos mesmos parâmetros de cada protocolo reproduzido com o phantom antropomórfico no tomógrafo Philips Brilliance 64 CT scanner (Philips, Holanda).

Os resultados comparativos para os protocolos de crânio helicoidais são apresentados na Tabela 4.15 e os de crânio axiais são apresentados na Tabela 4.16. A Tabela 4.17 apresenta os resultados comparativos para os protocolos de tórax.

Tabela 4.15 - Resultados comparativos de dose absorvida provenientes dos protocolos de crânio helicoidais avaliados e suas respectivas diferenças percentuais com valores simulados.

\begin{tabular}{ccccccc}
\hline & \multicolumn{2}{c}{ Crânio 3D } \\
& \multicolumn{2}{c}{ (Não Otimizado) } & & \multicolumn{3}{c}{$\begin{array}{c}\text { Crânio 3D/Infantil } \\
\text { (Otimizado) }\end{array}$} \\
\hline \multirow{2}{*}{ Órgão } & $\begin{array}{c}\text { Dose } \\
\text { Experimental } \\
(\mathbf{m G y})\end{array}$ & $\begin{array}{c}\text { Dose } \\
\text { Simulada } \\
(\mathbf{m G y})\end{array}$ & $\begin{array}{c}\text { Diferença } \\
(\boldsymbol{\%})\end{array}$ & $\begin{array}{c}\text { Dose } \\
\text { Experimental }\end{array}$ & $\begin{array}{c}\text { Dose } \\
\text { Simulada }\end{array}$ & $\begin{array}{c}\text { Diferença } \\
(\mathbf{m G y})\end{array}$ \\
\hline Cristalino & $32,3 \pm 2,3$ & 37,9 & 15 & $9,2 \pm 1,2$ & 10,8 & 15 \\
Tireoide & $47,5 \pm 8,5$ & 42,1 & -13 & $13,7 \pm 2,4$ & 12,2 & -7 \\
\hline
\end{tabular}


Tabela 4.16 - Resultados comparativos de dose absorvida provenientes dos protocolos de crânio axial avaliados e suas respectivas diferenças percentuais com valores simulados.

\begin{tabular}{|c|c|c|c|c|c|c|}
\hline \multirow[b]{2}{*}{ Órgão } & \multicolumn{3}{|c|}{$\begin{array}{c}\text { Crânio Criança Axial } \\
\text { (Não Otimizado) }\end{array}$} & \multicolumn{3}{|c|}{$\begin{array}{c}\text { Infantil/Crânio 2-6 anos } \\
\text { (Otimizado) }\end{array}$} \\
\hline & $\begin{array}{c}\text { Dose } \\
\text { Experimental } \\
(\mathrm{mGy})\end{array}$ & $\begin{array}{c}\text { Dose } \\
\text { Simulada } \\
(\mathrm{mGy})\end{array}$ & $\begin{array}{c}\text { Diferença } \\
(\%)\end{array}$ & $\begin{array}{c}\text { Dose Experimental } \\
(\mathrm{mGy})\end{array}$ & $\begin{array}{c}\text { Dose } \\
\text { Simulada } \\
(\mathrm{mGy})\end{array}$ & $\begin{array}{c}\text { Diferença } \\
(\%)\end{array}$ \\
\hline Cristalino & $24,8 \pm 2,1$ & 30,9 & 20 & $7,6 \pm 1,2$ & 9,9 & 23 \\
\hline Tireoide & $33,9 \pm 6,1$ & 41,0 & 17 & $13,1 \pm 2,3$ & 13,3 & 1 \\
\hline
\end{tabular}

Tabela 4.17 - Resultados comparativos de dose absorvida provenientes dos protocolos de tórax avaliados e suas respectivas diferenças percentuais com valores simulados.

\begin{tabular}{|c|c|c|c|c|c|c|}
\hline & \multicolumn{3}{|c|}{ Tórax Infantil } & \multicolumn{3}{|c|}{ Infantil/Tórax 1-10 anos } \\
\hline Órgão & $\begin{array}{c}\text { Dose } \\
\text { Experimental } \\
(\mathbf{m G y})\end{array}$ & $\begin{array}{c}\text { Dose } \\
\text { Simulada } \\
(\mathrm{mGy})\end{array}$ & $\begin{array}{c}\text { Diferença } \\
(\%)\end{array}$ & $\begin{array}{c}\text { Dose } \\
\text { Experimental } \\
(\mathrm{mGy})\end{array}$ & $\begin{array}{c}\text { Dose } \\
\text { Simulada } \\
(\mathbf{m G y})\end{array}$ & $\begin{array}{c}\text { Diferença } \\
(\%)\end{array}$ \\
\hline Pulmões & $6,9 \pm 0,6$ & 7,0 & 1 & $8,2 \pm 0,7$ & 7,9 & -3 \\
\hline Tireoide & $8,3 \pm 1,5$ & 7,5 & -10 & $10,0 \pm 1,8$ & 8,6 & -17 \\
\hline
\end{tabular}

\subsubsection{Avaliação Estatística}

A análise estatística de Bland-Altman foi adotada para avaliar a concordância entre as doses experimentais e as simuladas com o software NCICT. As diferenças percentuais são apresentadas na Figura 4.5 e foram calculadas de acordo com a metodologia descrita na seção 3.2.9. O maior valor percentual encontrado foi de $23 \%$, correspondente à dose de radiação absorvida pelo cristalino durante a aquisição do protocolo de crânio axial Infantil/Crânio 2-6 anos. Os desvios percentuais calculados entre as doses experimentais e simuladas encontramse dentro dos limites de concordância estabelecidos. 


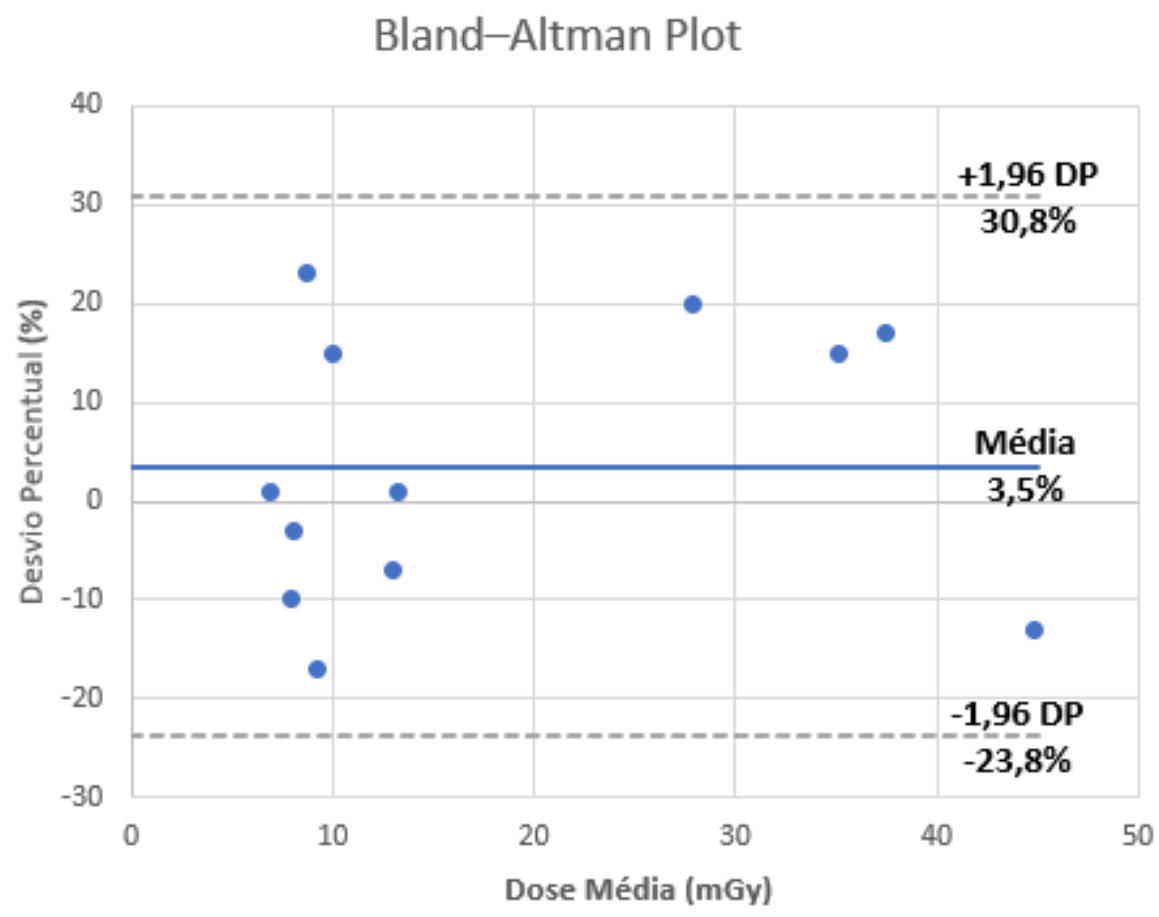

Figura 4.5 - Gráfico de Bland-Altman das diferenças percentuais em relação à média das doses em órgãos obtidas com o software NCICT e as medições com OSLDs. A média das diferenças percentuais é apresentada na linha azul $(3,5 \%)$ e os limites de concordância são apresentados em linhas tracejadas. 


\section{DISCUSSÃO}

O presente trabalho adotou uma metodologia experimental baseada na dosimetria opticamente estimulada em conjunto com um objeto simulador antropomórfico pediátrico para a estimativa de dose absorvida em órgãos. Foram avaliados seis protocolos tomográficos pediátricos de TC: quatro protocolos de crânio, sendo dois helicoidais e dois axiais, e dois protocolos de tórax. Os resultados encontrados foram comparados a valores simulados com o software NCICT e com resultados disponíveis na literatura. Adicionalmente, a coleta e análise de parâmetros dosimétricos de exames tomográficos pediátricos de crânio e tórax realizados no INRAD-FMUSP, iniciada em projeto anterior (GIANSANTE, 2017), foi continuada neste projeto.

\subsection{ANÁLISE DE PARÂMETROS DE AQUISIÇÃO}

Foram coletadas grandezas dosimétricas de exames tomográficos pediátricos de crânio e tórax, de acordo com metodologia previamente descrita, para análise e acompanhamento de novos protocolos implementados no INRAD-FMUSP, visando a otimização da dose de radiação em exames pediátricos. Esses dados foram comparados a três níveis de referência de diagnóstico, os DRLs propostos por uma pesquisa britânica (SHRIMPTON; HILLIER; MEESON; GOLDING, 2014), uma pesquisa europeia (EUROPEAN SOCIETY OF RADIOLOGY, 2015) e por outra pesquisa internacional (VASSILEVA; REHANI; KOSTOVA-LEFTEROVA; AL-NAEMI et al., 2015).

Com a otimização dos exames tomográficos de crânio, foi verificada uma diminuição significativa das grandezas dosimétricas CTDI $\mathrm{vol}_{\mathrm{e}}$ e DLP em todas as faixas etárias avaliadas (Tabela 4.1 e Tabela 4.2), com medianas abaixo dos DRLs propostos pelos três trabalhos internacionais. Este comportamento refletiu também na diminuição da dose entregue ao paciente, como foi verificado com a substituição do protocolo Crânio 3D pelo protocolo otimizado Crânio 3D Infantil.

No caso dos exames de tórax, nota-se um aumento discreto das grandezas dosimétricas CTDI $_{\text {vol }}$ e DLP com a otimização destes protocolos. As medianas encontradas neste trabalho ficam ligeiramente acima de todos os valores propostos como DRLs pela pesquisa europeia (com exceção do CTDI ${ }_{\text {vol }}$ para pacientes de 5-10 anos) e do DLP proposto como DRL pela pesquisa britânica para pacientes de 1-5 anos.

É recomendado pela sociedade europeia de radiologia que o valor mediano de uma grandeza seja determinado com um mínimo de 10 pacientes. Cabe destacar que no caso dos 
exames tomográficos de crânio os valores de mediana foram calculados com nove pacientes na primeira faixa etária (0-1 ano de idade) em exames não otimizados e com oito pacientes na última faixa etária (10-16 anos de idade) em exames não otimizados, dada a incidência maior deste tipo de exame em crianças. No caso dos exames tomográficos de tórax, algumas faixas etárias apresentam estatísticas ainda mais baixas, como é o caso dos grupos etários de 0-1 ano e de 10-16 anos para TC de tórax otimizadas, com apenas três e dois pacientes, respectivamente. Este comportamento é reflexo do tipo de população atendida no INRAD-FMUSP, que é um hospital geral, e não exclusivamente pediátrico e, desta forma, não devem ser considerados como estatisticamente validados.

Um estudo recente (STRAUSS; SOMASUNDARAM; SENGUPTA; MARIN et al., 2019) constatou que as doses em exames tomográficos realizados em instalações dedicadas a exames de adultos podem ser até duas vezes maiores que as doses praticadas em instalações tomográficas dedicadas a exames pediátricos para o mesmo tamanho de paciente.

Cabe destacar que um dos objetivos deste estudo comparativo é o acompanhamento dos protocolos implementados na instituição, especialmente os otimizados, com a utilização do conceito de DRLs como ferramenta de otimização e promoção de boas práticas. Este método mostrou-se eficiente para a supervisão dos novos protocolos, resultando em doses menores para protocolos pediátricos de crânio.

\subsection{ANÁLISE DA QUALIDADE DAS IMAGENS}

Para analisar a qualidade das imagens tomográficas avaliadas neste trabalho, foram adotados os parâmetros quantitativos Ruído, a Razão Sinal Ruído (RSR) e a Razão Contraste Ruído (RCR), apresentados na seção 4.2. Adicionalmente, foram calculados os fatores Q para as grandezas $\mathrm{CTDI}_{\mathrm{vol}}$ de cada protocolo avaliado. As imagens tomográficas também foram avaliadas sob o ponto de vista clínico por um médico radiologista da instituição.

A otimização dos protocolos tomográficos de crânio possibilitou a redução significativa da dose absorvida nos órgãos avaliados. Em contrapartida, nota-se o aumento do ruído da imagem: $105 \%$ no protocolo helicoidal e $26 \%$ no protocolo axial e redução dos parâmetros RSR e RCR. Houve também redução discreta dos fatores Q. As imagens de crânio dos novos protocolos avaliadas pelo médico radiologista foram capazes de produzir imagens clínicas de qualidade suficiente para o diagnóstico médico.

Já a otimização do protocolo tomográfico de tórax provocou um aumento discreto na dose absorvida nos órgãos avaliados, com leve melhora no ruído da imagem e redução dos 
parâmetros RCR e RSR e nos fatores Q calculados. Novamente, as imagens adquiridas com os novos protocolos foram avaliadas como suficientes para o diagnóstico pelo médico radiologista da instituição.

De modo geral, a otimização dos protocolos de TC pediátricos de crânio e tórax gerou imagens sem prejuízos para o diagnóstico médico.

\subsection{ESTIMATIVA DO VOLUME PULMONAR DO PHANTOM PEDIÁTRICO}

O volume ou a fração volumétrica do órgão contida nas fatias do phantom ATOM da CIRS é fundamental na estimativa de dose absorvida pelo órgão durante a aquisição das imagens de TC. A determinação do volume pulmonar contido nas fatias 9 a 15 do phantom pediátrico ATOM da CIRS foi realizada através da análise de imagens tomográficas de tórax com o software IntelliSpace ${ }^{\circledR}$ PACS (Philips, Holanda), de acordo com a metodologia previamente descrita neste trabalho (seção 3.2.4). Os resultados são apresentados na seção 4.3. O volume pulmonar total encontrado para o phantom pediátrico é de $1035 \pm 34 \mathrm{~cm}^{3}$. De acordo com a publicação 89 da ICRP (ICRP, 2002), o volume pulmonar esperado de uma criança padrão de cinco anos de idade é de um litro $\left(1000 \mathrm{~cm}^{3}\right)$.

Os resultados alcançados com essa metodologia são também são equivalentes aos resultados de Giansante (GIANSANTE, 2017), que desenvolveu uma técnica de segmentação de imagens tomográficas para determinação do volume pulmonar contido nas fatias do mesmo phantom utilizado neste trabalho, o ATOM da CIRS modelo 705. O volume pulmonar total calculado por Giansante (GIANSANTE; SAWAMURA; TOMAL; COSTA, 2016) foi de 1040 $\mathrm{cm}^{3}$.

\subsection{ESTIMATIVA DE DOSE EM ÓRGÃOS}

O estudo das doses de radiação administradas em exames de TC é um assunto de extrema importância entre médicos, pesquisadores e fabricantes, especialmente para pacientes pediátricos. Este trabalho apresenta uma metodologia experimental para a estimativa de dose em órgãos de um phantom antropomórfico pediátrico submetido a seis protocolos de tomografia computadorizada, com o uso de dosímetros por luminescência opticamente estimulada de óxido de alumínio dopado com carbono $\left(\mathrm{Al}_{2} \mathrm{O}_{3}: \mathrm{C}\right)$. 


\subsubsection{Protocolos de Crânio}

Para a avaliação de dose absorvida resultante dos protocolos de crânio, o phantom ATOM da CIRS foi irradiado do topo da cabeça até o final do pescoço (fatias 1 a 8 ) nos quatro protocolos avaliados, para que o cristalino e a tireoide fossem irradiados pelo feixe primário de radiação.

O protocolo helicoidal Crânio 3D embora seja, inicialmente, um protocolo designado a pacientes adultos, também era frequentemente utilizado em crianças no INRAD-FMUSP. Durante a otimização dos procedimentos radiológicos pediátricos realizados na instituição, o protocolo helicoidal Crânio 3D/Infantil foi proposto para pacientes pediátricos, substituindo o antigo protocolo Crânio 3D. Estes foram os protocolos helicoidais escolhidos para avaliação de dose absorvida pelo cristalino e pela tireoide.

Para o protocolo Crânio 3D, os valores de $\mathrm{CTDI}_{\mathrm{vol}}$ e DLP exibidos pelo equipamento foram de 38,7 mGy e 1097,0 mGy.cm, respectivamente, num comprimento de varredura de $22,8 \mathrm{~cm}$. Provenientes do exame, as doses estimadas foram de 32,3 $\pm 2,3 \mathrm{mGy}$ para o cristalino e de 47,5 $\pm 8,5 \mathrm{mGy}$ para a tireoide. As grandezas dosimétricas apresentadas no display do tomógrafo para o protocolo Crânio 3D/Infantil foram de 11,8 mGy e 335,8 mGy.cm para CTDI $_{\text {vol }}$ e DLP, respectivamente, no exame com $22,9 \mathrm{~cm}$ de varredura. Como resultado desta TC, as doses estimadas foram de 9,2 \pm 1,2 mGy absorvidas pelo cristalino e 13,7 $\pm 2,4 \mathrm{mGy}$ absorvidas pela tireoide.

No estudo de dose em protocolos de crânio axiais, foram escolhidos os protocolos Crânio Criança Axial, utilizado antes do processo de otimização, e o protocolo Infantil/Crânio 2-6 anos implementado para crianças com a otimização de protocolos pediátricos no INRADFMUSP. No protocolo Crânio Axial Criança, os valores de CTDI ${ }_{\text {vol }}$ e DLP apresentados pelo display do tomógrafo são de 31,7 mGy e 730,1 mGy.cm, respectivamente para o escaneamento de $23 \mathrm{~cm}$. As doses absorvidas pelo cristalino e tireoide foram estimadas, respectivamente, em 24,8 \pm 2,1 mGy e 33,9 \pm 6,1 mGy. O protocolo otimizado Infantil/Crânio 2-6 anos apresentou valores de 10,6 mGy e 244,9 $\mathrm{mGy} \mathrm{cm}$ para $\mathrm{CTDI}_{\mathrm{vol}}$ e DLP, respectivamente, para o exame com $23 \mathrm{~cm}$ de varredura. As doses absorvidas foram estimadas em 7,6 $\pm 1,2 \mathrm{mGy}$ e 13,1 $\pm 2,3 \mathrm{mGy}$ para o cristalino e tireoide, respectivamente.

A otimização do protocolo helicoidal provocou uma redução de $71 \%$ na dose absorvida da tireoide e de $72 \%$ na dose absorvida pelo cristalino. No caso do protocolo axial, a redução foi de $61 \%$ na dose da tireoide e de $69 \%$ na dose do cristalino. 
O cristalino é um dos órgãos mais sensíveis à radiação ionizante e considerado de risco durante procedimentos de TC de crânio (SOOKPENG; BUTDEE, 2017). A inclinação do gantry (gantry tilt) durante a aquisição da tomografia de crânio é um dos métodos recomendados para se reduzir a dose para os olhos. De acordo com estudo realizado por Sookpeng \& Butdee (2017), a inclinação do gantry em ângulos de $5^{\circ}, 10^{\circ}$ e $15^{\circ}$, diminuiu a dose para o cristalino em até $40 \%$, em comparação ao exame realizado sem a inclinação do gantry com as mesmas configurações.

Giansante (2017) utilizou TLDs e OSLDs nas cavidades de um phantom antropomórfico equivalente a um paciente de cinco anos (CIRS, EUA) para medição de dose absorvida pelo cristalino e tireoide durante a aquisição de um exame tomográfico de crânio. Como consequência da irradiação de ambos os órgãos pelo feixe primário de radiação, a tireoide absorveu uma dose ainda maior que o cristalino, de modo semelhante aos resultados deste trabalho.

Os resultados encontrados neste trabalho ressaltam a importância da escolha adequada de protocolo, apropriado ao tamanho e faixa etária do paciente, em conjunto com o posicionamento correto do mesmo, para que somente a região de interesse clínico seja irradiada, poupando órgãos adjacentes de receberem mais radiação que o necessário para o exame.

\subsubsection{Protocolos de Tórax}

Para a avaliação de dose absorvida em procedimentos de tórax, os protocolos pediátricos Tórax Infantil e Infantil/Tórax 1-10 anos foram escolhidos. O primeiro protocolo era utilizado antes do processo de otimização em pacientes pediátricos na faixa etária de 2-5 anos. Já o segundo protocolo é mais recente e foi sugerido para crianças da faixa etária de 1-10 anos no decorrer da otimização de procedimentos radiológicos pediátricos do INRAD-FMUSP, desenvolvido em parceria com o IFUSP. Nos dois protocolos, o phantom foi irradiado da metade do pescoço até a metade do abdômen, para que tanto a tireoide quanto os pulmões fossem irradiados pelo feixe de raios $\mathrm{X}$ primário do tomógrafo.

Os valores de $\mathrm{CTDI}_{\mathrm{vol}}$ e DLP exibidos pelo equipamento para o protocolo Tórax Infantil foram de 3,6 mGy e 105,3 mGy.cm, respectivamente, numa varredura de $22 \mathrm{~cm}$. Como resultado, as doses absorvidas foram estimadas em 8,3 $\pm 1,5 \mathrm{mGy}$ pela tireoide e 6,9 \pm 0,6 mGy pelos pulmões do phantom ATOM da CIRS. Na aquisição das imagens com o protocolo Infantil/Tórax 1-10 anos, o display do tomógrafo indicou um CTDI $_{\mathrm{vol}}$ de 4,3 mGy e um DLP de 
126,1 mGy.cm para o escaneamento de $22 \mathrm{~cm}$. Consequentemente, as doses absorvidas foram estimadas em 10,0 \pm 1,8 mGy pela tireoide e em 8,2 \pm 0,7 mGy pelos pulmões do phantom.

A otimização do protocolo de tórax provocou um aumento de $20 \%$ na dose absorvida da tireoide e de $19 \%$ na dose absorvida pelos pulmões. Novamente, estes resultados destacam a importância do posicionamento correto do paciente para a realização do exame, com seu respectivo comprimento de varredura adequado, para que a tireoide não receba uma quantidade de radiação comparável à dose absorvida pelos pulmões.

Num estudo conduzido por Kalender e colegas (2014), os autores desenvolveram modelos de phantoms de corpo inteiro, baseados na combinação de imagens tomográficas adquiridas com três phantoms físicos - um phantom adulto (RANDO Phantoms Laboratory, EUA) e dois phantoms pediátricos, de um e cinco anos de idade (CIRS, EUA) - com modelos de phantoms computacionais (phantoms ICRP e ORNL, respectivamente) para representarem pacientes em simulações do método Monte Carlo. Os autores simularam as doses absorvidas por dez órgãos de interesse, resultantes de tomografias de tórax, com o software ImpactMC (CT Imaging $\mathrm{GmbH}$, Alemanha). Os resultados simulados foram validados com medições diretas, feitas com dosímetros termoluminescentes posicionados nas cavidades dos órgãos dos phantoms físicos. A partir do phantom de corpo inteiro desenvolvido para simular um paciente de cinco anos, os autores determinaram que a dose de radiação absorvida pelos pulmões numa TC de tórax é de 7,05 mGy, para um exame simulado com $120 \mathrm{kV}$ de tensão e 50 mAs de carga, que é semelhante ao protocolo Tórax Infantil avaliado neste trabalho. Neste caso, a dose absorvida pela tireoide, que foi deixada de fora da região escaneada, é de 4,30 mGy. Os resultados simulados baseados nos phantoms de corpo inteiro desenvolvidos ficaram dentro do intervalo de $10 \%$ das medições com TLDs (KALENDER; SALTYBAEVA; KOLDITZ; HUPFER et al., 2014).

Giansante e colegas (2019) calcularam a dose absorvida pelos pulmões em tomografias computadorizadas de tórax utilizando dosímetros termoluminescentes em dois phantoms antropomórficos (um adulto e um pediátrico, de cinco anos), avaliando seis protocolos adultos e quatro protocolos pediátricos. No caso dos protocolos pediátricos, a tireoide do phantom foi (parcialmente) irradiada pelo feixe primário de raios X para avaliação de dose absorvida. Nas irradiações com corrente constante no tubo de raios $\mathrm{X}$, as estimativas de dose absorvida pela tireoide e pulmões foram comparáveis, similares aos resultados encontrados neste trabalho.

Além da escolha adequada de comprimento de varredura do exame, o posicionamento do paciente no centro do gantry do tomógrafo também é de extrema importância. Barreto e 
colegas (2019) mostraram que a centralização incorreta do paciente afeta as doses em órgãos. Os autores utilizaram dosímetros por luminescência opticamente estimulada para medir as doses em órgãos de três indivíduos adultos post-mortem submetidos a exames tomográficos. Foram avaliadas nove posições verticais diferentes da mesa de suporte ao paciente, com desvio máximo de quatro centímetros. Correlações significativas foram encontradas entre o deslocamento vertical da mesa de suporte do paciente e as doses de cinco dos oito órgãos avaliados, incluindo pulmão, cólon, útero, ovário e pele, demonstrando um aumento na dose absorvida com o aumento do deslocamento vertical da mesa (BARRETO; LAMOUREUX; OLGUIN; QUAILS et al., 2019).

\subsection{AVALIAÇÃO COMPARATIVA ENTRE DOSES EXPERIMENTAIS E SIMULADAS}

Para verificação e comparação da metodologia experimental desenvolvida neste trabalho, simulações de método Monte Carlo foram adotadas, como descrito na seção 3.2.8.

Nos protocolos de crânio, os desvios percentuais entre as simulações MC e os resultados experimentais estão em concordância (Tabela 4.15 e Tabela 4.16), com desvio máximo de 23\%, obtido para o cristalino na aquisição do protocolo Infantil/Crânio 2-6 anos. Tal desvio pode ser atribuído ao posicionamento dos dosímetros OSL no phantom pediátrico e as eventuais diferenças anatômicas entre o phantom físico e o phantom computacional adotado pelo NCICT. Outro ponto relevante é o fato dos dosímetros OSL terem sido fixados na superfície do cristalino para a avaliação da dose absorvida, enquanto a simulação de MC considera o volume interno do órgão para sua estimativa de dose, o que pode explicar tais diferenças percentuais. Os resultados experimentais de dose resultantes dos protocolos de tórax avaliados também mostraram boa concordância com os resultados simulados com o software NCICT, com desvios percentuais de até $17 \%$ na dose absorvida pela tireoide do phantom, resultante do protocolo Infantil/Tórax 1-10 anos (Tabela 4.17).

Todos os desvios percentuais entre as doses experimentais e simuladas estão dentro dos limites de concordância estabelecidos pela avaliação estatística de Bland-Altman, com desvio médio de 3,5\%. Este comportamento mostra que a metodologia experimental adotada neste trabalho é eficiente para a estimativa de dose em órgãos.

Num estudo recente, Dabin e colegas (2016) realizaram medições de dose em órgãos em um phantom antropomórfico de cinco anos de idade para cinco diferentes tomógrafos de quatro fabricantes. Os autores utilizaram dosímetros termoluminescentes para medir as doses 
absorvidas em 22 órgãos, resultantes de exames tomográficos de crânio ao tronco (head-totorso). Os resultados experimentais foram comparados a valores calculados com o software NCICT. Em geral, as diferenças entre as doses medidas experimentalmente e as doses simuladas ficaram dentro no intervalo de $\pm 20 \%$ (DABIN; MENCARELLI; MCMILLAN; ROMANYUKHA et al., 2016). Estes resultados são semelhantes aos resultados encontrados neste trabalho.

O estudo conduzido por Giansante e colegas (2019) também comparou seus resultados experimentais de dose absorvida pelos pulmões em tomografias computadorizadas de tórax obtidos com dosímetros termoluminescentes e phantoms antropomórficos - a valores simulados com o NCICT, obtendo diferenças percentuais dentro do intervalo de $\pm 20 \%$. 


\section{CONCLUSÕES}

O presente trabalho utilizou uma abordagem experimental para a estimativa da dose de radiação absorvida por um phantom antropomórfico pediátrico resultante de exames tomográficos de crânio e tórax. Nesta metodologia, foram utilizados dosímetros por luminescência opticamente estimulada de óxido de alumínio dopado com carbono $\left(\mathrm{Al}_{2} \mathrm{O}_{3}: \mathrm{C}\right)$ no cristalino, tireoide e pulmões do phantom. Foram avaliados quatro protocolos pediátricos de crânio (dois não otimizados e dois novos e otimizados) e dois protocolos pediátricos de tórax (um não otimizado e um novo e otimizado). Os resultados mostraram que a otimização dos protocolos de crânio foi capaz de reduzir em até $72 \%$ a dose absorvida nos órgãos avaliados. A otimização do protocolo de tórax aumentou em cerca de $20 \%$ a dose absorvida nos pulmões e tireoide do phantom, com uma discreta melhora no ruído da imagem. Para cada protocolo foi calculado o fator $\mathrm{Q}$, que relaciona dose e qualidade da imagem. A pequena variação do fator $\mathrm{Q}$ entre os protocolos não otimizados e otimizados, associada à avaliação das imagens sob o ponto de vista clínico por um médico radiologista da instituição, revela que a otimização dos protocolos pediátricos não prejudicou a qualidade das imagens tomográficas. Com base nestes resultados, destaca-se a importância do posicionamento correto do paciente para poupar os órgãos adjacentes à região escaneada, e da escolha de protocolo apropriada ao tamanho e faixa etária do paciente, em especial dos pacientes pediátricos, dada a sua maior expectativa de vida em relação aos pacientes adultos.

Análises comparativas foram realizadas entre os resultados experimentais e simulados com o software NCICT, mostrando boa concordância. As diferenças percentuais encontram-se dentro dos limites de concordância estabelecidos pela análise estatística de Bland-Altman e ficaram, em geral, dentro do intervalo de $\pm 20 \%$.

Adicionalmente, dados de exames tomográficos pediátricos foram coletados de um dos tomógrafos do Instituto de Radiologia da Faculdade de Medicina da Universidade de São Paulo. A coleta destes dados e a comparação das grandezas CTDI ${ }_{v o l}$ e DLP com valores de DRLs internacionais mostrou-se eficaz para o acompanhamento da otimização dos protocolos realizada na instituição e para a promoção de boas práticas.

Por fim, são apresentadas algumas sugestões para futuras investigações.

- Implementação dos protocolos otimizados de TC pediátricos em outros tomógrafos da instituição;

- Avaliação de métodos e ferramentas para otimização de protocolos de TC adultos realizados na instituição; 
- Realização de um novo ciclo de otimização para os exames tomográficos de tórax, na tentativa de redução das doses; 


\section{REFERÊNCIAS}

AAPM. The Measurement, Reporting, and Management of Radiation Dose in CT. AAPM Task Group 23 of the Diagnostic Imaging Council CT Committee (AAPM Report $\mathrm{N}^{\circ}$ 96). American Association of Physicists in Medicine 2008.

AAPM. Use of Water Equivalent Diameter for Calculating Patient Size and Size-Specific Dose Estimates (SSDE) in CT. The Report of AAPM Task Group 220 (AAPM Report $\mathrm{N}^{\circ} 220$ ). American Association of Physicists in Medicine 2014.

AAPM. Estimating Patient Organ Dose with Computed Tomography: A Review of Present Methodology and Required DICOM Information. A Joint Report of AAPM Task Group 246 and the European Federation of Organizations for Medical Physics (EFOMP) (AAPM Report $\mathrm{N}^{\circ} 246$ ). American Association of Physicists in Medicine 2019.

AAPM. The Design and Use of the ICRU/AAPM CT Radiation Dosimetry Phantom: An Implementation of AAPM Report 111. AAPM Task Group 200 (AAPM Report N²00). American Association of Physicists in Medicine 2020.

ABDULKADIR, M. K.; RAHIM, N. A. Y. M.; MAZLAN, N. S.; DAUD, N. M. et al. Dose optimisation in paediatric CT examination: Assessment on current scanning protocols associated with radiation dose. Radiation Physics and Chemistry, 171, p. 108740, 2020.

AL MAHROOQI, K. M. S.; NG, C. K. C.; SUN, Z. Pediatric computed tomography dose optimization strategies: A literature review. Journal of medical imaging and radiation sciences, 46, n. 2, p. 241-249, 2015.

ANAM, C.; HARYANTO, F.; WIDITA, R.; ARIF, I. et al. The evaluation of the effective diameter (D eff) calculation and its impact on the size-specific dose estimate (SSDE). Atom Indonesia, 43, n. 1, p. 55-60, 2017.

ANDREO, P.; BURNS, D. T.; NAHUM, A. E.; SEUNTJENS, J. et al. Fundamentals of ionizing radiation dosimetry. John Wiley \& Sons, 2017. 3527409211.

BARRETO, I.; LAMOUREUX, R.; OLGUIN, C.; QUAILS, N. et al. Impact of patient centering in CT on organ dose and the effect of using a positioning compensation system: Evidence from OSLD measurements in postmortem subjects. Journal of applied clinical medical physics, 20, n. 6, p. 141-151, 2019.

BARRETO, I.; VERMA, N.; QUAILS, N.; OLGUIN, C. et al. Patient size matters: Effect of tube current modulation on size-specific dose estimates (SSDE) and image quality in low-dose lung cancer screening CT. Journal of Applied Clinical Medical Physics, 21, n. 4, p. 87-94, 2020.

BEHLING, R. Modern Diagnostic X-Ray Sources: Technology, Manufacturing, Reliability. CRC Press, 2015. 1482241331.

BEHLING, R.; GRÜNER, F. Diagnostic X-ray sources—present and future. Nuclear Instruments and Methods in Physics Research Section A: Accelerators, Spectrometers, Detectors and Associated Equipment, 878, p. 50-57, 2018. 
BERGER, N.; MARCON, M.; SALTYBAEVA, N.; KALENDER, W. A. et al. Dedicated breast computed tomography with a photon-counting detector: initial results of clinical in vivo imaging. Investigative radiology, 54, n. 7 , p. 409-418, 2019.

BLAND, J. M.; ALTMAN, D. G. Measuring agreement in method comparison studies. Statistical methods in medical research, 8, n. 2, p. 135-160, 1999.

BLIZNAKOVA, K. Software Phantoms for X-ray Radiography and Tomography. In: Handbook of X-ray Imaging: CRC Press, 2017. p. 1159-1184.

BRENNER, D. J.; ELLISTON, C. D.; HALL, E. J.; BERDON, W. E. Estimated risks of radiation-induced fatal cancer from pediatric CT. American journal of roentgenology, 176, n. 2, p. 289-296, 2001.

BRENNER, D. J.; HALL, E. J. Computed tomography — an increasing source of radiation exposure. New England Journal of Medicine, 357, n. 22, p. 2277-2284, 2007.

BUShBERG, J. T.; SEIBERT, J. A.; LEIDHOLDT JR, E. M.; BOONE, J. M. The Essential Physics of Medical Imaging. $3^{\text {rd }}$ ed. Lippincott Williams \& Wilkins., 2011.

BUZUG, T. M. Computed Tomography: From Photon Statistics to Modern Cone-Beam CT. Springer Science \&amp; Business Media, 2008. 3540394087.

CIRS. The ATOM Dosimetry Verification Phantoms Brochure. 2013. Disponível em: http://www.cirsinc.com/wp-content/uploads/2019/04/701-706-DS-120418.pdf. Acesso em: 19 de agosto de 2020.

COSTA, P. R. Computer Tomography Phantom Applications. In: The Phantoms of Medical and Health Physics: Springer, 2014. p. 123-142.

COUNCIL, N. R. Health risks from exposure to low levels of ionizing radiation: BEIR VII phase 2. National Academies Press, 2006. 030909156X.

CUNNINGHAM, I. A.; NANO, T. F.; ESCARTIN, T. Image Quality. Handbook of X-ray Imaging: Physics and Technology, p. 261, 2017.

DABIN, J.; MENCARELLI, A.; MCMILLAN, D.; ROMANYUKHA, A. et al. Validation of calculation algorithms for organ doses in CT by measurements on a 5 year old paediatric phantom. Physics in Medicine \& Biology, 61, n. 11, p. 4168, 2016.

DANCE, D.; CHRISTOFIDES, S.; MAIDMENT, A.; MCLEAN, I. et al. Diagnostic radiology physics: A handbook for teachers and students. Endorsed by: American Association of Physicists in Medicine, Asia-Oceania Federation of Organizations for Medical Physics, European Federation of Organisations for Medical Physics. International Atomic Energy Agency (IAEA): IAEA, 2014.

DAUER, L. T.; CHU, B. P.; ZANZONICO, P. B. Dose, benefit, and risk in medical imaging. CRC Press, 2018. 0429814739. 
DIXON, R. L. The Physics of CT Dosimetry: CTDI and Beyond. CRC Press, 2019. 0429665490.

DTU NUTECH. Guide to the Risø TL/OSL Reader. 2015. Disponível em: http://www.usu.edu/geo/luminlab/Reader.pdf. Acesso em: 19 de agosto de 2020.

EUROPEAN SOCIETY OF RADIOLOGY. European Guidelines on DRLs for Paediatric Imaging. Final complete draft for PiDRLWorkshop. PiDRL European Diagnostic Reference Levels for paediatric imaging, 2015. Disponível em: https://www.sirm.org/download/2011. Acesso em: 04 de agosto de 2020.

EUROSAFE. EuroSafe Imaging. 2014. Disponível em: https://www.myesr.org/quality-safety/eurosafe-imaging. Acesso em: 04 de agosto de 2020.

FOSBINDER, R.; ORTH, D. Essentials of radiologic science. Lippincott Williams \& Wilkins, 2011. $078177554 \mathrm{X}$.

GIANSANTE, L. Avaliação de doses em órgãos em procedimentos de tomografia computadorizada utilizando dosímetros TL e OSL. (Dissertação de Mestrado). Universidade de São Paulo, São Paulo SP, Brasil 2017.

GIANSANTE, L.; MARTINS, J. C.; NERSISSIAN, D. Y.; KIERS, K. C. et al. Organ doses evaluation for chest computed tomography procedures with TL dosimeters: Comparison with Monte Carlo simulations. Journal of applied clinical medical physics, 20, n. 1, p. 308-320, 2019.

GIANSANTE, L.; SAWAMURA, M. M.; TOMAL, A.; COSTA, P. R. Aplicação de Métodos de Segmentação de Imagens para Mapeamento dos Órgãos de um Phantom Antropomórfico Pediátrico. In: Jornada Paulista de Radiologia, 2016, São Paulo SP, Brasil.

GIAVARINA, D. Understanding bland altman analysis. Biochemia medica: Biochemia medica, 25, n. 2, p. 141 $151,2015$.

GONZALES, A. H. L. Simulação e validação de perfis de dose e seu uso para estimativa de grandezas dosimétricas para tomografia computadorizada. (Tese de Doutorado). Universidade de São Paulo, São Paulo SP, Brasil 2019.

GOSKE, M. J.; APPLEGATE, K. E.; BOYLAN, J.; BUTLER, P. F. et al. The Image Gently campaign: working together to change practice. American Journal of Roentgenology, 190, n. 2, p. 273-274, 2008.

GRIGLOCK, T. M.; SINCLAIR, L.; MENCH, A.; CORMACK, B. et al. Determining organ doses from CT with Direct measurements in postmortem subjects: part 1-methodology and validation. Radiology, 277, n. 2, p. 463470, 2015.

GUERRA, V. H.; NERSISSIAN, D. Y.; MELO, C. S.; VASCONCELLOS, C. E. C. et al. Pediatric computed tomography dose optimization in a general hospital. Revista Brasileira de Física Médica, 13, n. 1, p. 138-144, 2019. 
GULLIKSRUD, K.; STOKKE, C.; MARTINSEN, A. C. T. How to measure CT image quality: variations in CTnumbers, uniformity and low contrast resolution for a CT quality assurance phantom. Physica Medica, 30, n. 4, p. 521-526, 2014.

HIRAKATA, V. N.; CAMEY, S. A. Análise de concordância entre métodos de Bland-Altman. Clinical \& Biomedical Research, 29, n. 3, p. 261-268, 2009.

HOJREH, A.; WEBER, M.; HOMOLKA, P. Effect of staff training on radiation dose in pediatric CT. European journal of radiology, 84, n. 8, p. 1574-1578, 2015.

HOYE, J.; SHARMA, S.; ZHANG, Y.; FU, W. et al. Organ doses from CT localizer radiographs: Development, validation, and application of a Monte Carlo estimation technique. Medical Physics, 46, n. 11, p. 5262-5272, 2019.

HSIEH, J. Computed tomography : principles, design, artifacts, and recent advances. 2nd ed. ed. Hoboken, N.J.: Wiley Interscience ; Bellingham, Wash. : SPIE Press, 2009. 9780819475336 (SPIE : hbk.) : 198.50

0819475335 (SPIE : hbk.) : 198.50

9780470563533 (Wiley-Interscience :hbk.) : 170.50

0470563532 (Wiley-Interscience : hbk.) : 170.50.

IAEA. Dosimetry in Diagnostic Radiology: An International Code of Practice (Technical Report Series $N^{\circ} 457$ ). International Atomic Energy Agency 2007.

IAEA. Coordinated Research Projects-About Us. 2013. Disponível em: http://cra.iaea.org/cra/about-us.html. Acesso em: 04 de agosto de 2020.

IAEA. Dosimetry in Diagnostic Radiology for Paediatric Patients (IAEA Human Health Series $N^{\circ}$ 24). International Atomic Energy Agency 2014.

ICRP. Radiological protection and safety in medicine. ICRP Publication 73. Annals of the ICRP, 26, n. 2, 1996.

ICRP. Basic Anatomical and Physiological Data for Use in Radiological Protection Reference Values. ICRP Publication 89. Annals of the ICRP, 32, 2002.

ICRP. Diagnostic reference levels in medical imaging. ICRP Publication 135. Ann. ICRP, 46, n. 1, 2017.

ICRU. Tissue Substitutes in Radiation Dosimetry and Measurement (ICRU Report $\mathrm{N}^{\circ}$ 44). International Commission on Radiation Units and Measurements. 1989.

IMAGE GENTLY. Image Gently and CT Scans. 2014. Disponível em: https://www.imagegently.org/Procedures/Computed-Tomography. Acesso em: 04 de agosto de 2020.

IMAGE WISELY. Image Wisely: Computed Tomography. 2010-20. Disponível em: https://www.imagewisely.org/Imaging-Modalities/Computed-Tomography. Acesso em: 04 de agosto de 2020. 
JAMAL, N. H.; SAYED, I. S.; SYED, W. S. Estimation of organ absorbed dose in pediatric chest X-ray examination: A phantom study. Radiation Physics and Chemistry, 166, p. 108472, 2020.

KALENDER, W. A. X-ray computed tomography. Physics in Medicine \& Biology, 51, n. 13, p. R29, 2006.

KALENDER, W. A. Computed tomography: fundamentals, system technology, image quality, applications. John Wiley \& Sons, 2011. 3895786446.

KALENDER, W. A. Dose in x-ray computed tomography. Physics in Medicine \& Biology, 59, n. 3, p. R129, 2014.

KALENDER, W. A.; SALTYBAEVA, N.; KOLDITZ, D.; HUPFER, M. et al. Generating and using patientspecific whole-body models for organ dose estimates in CT with increased accuracy: feasibility and validation. Physica Medica, 30, n. 8, p. 925-933, 2014.

KRAMER, R.; KHOURY, H.; VIEIRA, J. CALDose_X - a software tool for the assessment of organ and tissue absorbed doses, effective dose and cancer risks in diagnostic radiology. Physics in Medicine \& Biology, 53, n. 22 , p. 6437, 2008 .

KRY, S. F.; ALVAREZ, P.; CYGLER, J. E.; DEWERD, L. A. et al. AAPM TG 191: Clinical use of luminescent dosimeters: TLDs and OSLDs. Medical physics, 47, n. 2, p. e19-e51, 2020.

LATIN SAFE. Latin Safe Pediatria. 2015. Disponível em: http://latinsafe.org/. Acesso em: 04 de agosto de 2020.

LEE, C.; KIM, K. P.; BOLCH, W. E.; MOROZ, B. E. et al. NCICT: a computational solution to estimate organ doses for pediatric and adult patients undergoing CT scans. Journal of Radiological Protection, 35, n. 4, p. 891909, 2015

LEE, C.; KIM, K. P.; LONG, D.; FISHER, R. et al. Organ doses for reference adult male and female undergoing computed tomography estimated by Monte Carlo simulations. Medical physics, 38, n. 3, p. 1196-1206, 2011.

LEE, C.; LIU, J.; GRIFFIN, K. T.; FOLIO, L. R. et al. Adult patient-specific CT organ dose estimations using automated segmentations and Monte Carlo simulations. Biomedical Physics \& Engineering Express, 2020.

LEE, C.; LODWICK, D.; WILLIAMS, J. L.; BOLCH, W. E. Hybrid computational phantoms of the 15-year male and female adolescent: applications to CT organ dosimetry for patients of variable morphometry. Medical physics, 35, n. 6Part1, p. 2366-2382, 2008.

LEE, E.; LAMART, S.; LITTLE, M. P.; LEE, C. Database of normalised computed tomography dose index for retrospective CT dosimetry. Journal of Radiological Protection, 34, n. 2, p. 363, 2014.

LELL, M. M.; KACHELRIEß, M. Recent and upcoming technological developments in computed tomography: high speed, low dose, deep learning, multienergy. Investigative Radiology, 55, n. 1, p. 8-19, 2020. 
LELL, M. M.; WILDBERGER, J. E.; ALKADHI, H.; DAMILAKIS, J. et al. Evolution in computed tomography: the battle for speed and dose. Investigative radiology, 50, n. 9, p. 629-644, 2015.

LONG, D. J.; LEE, C.; TIEN, C.; FISHER, R. et al. Monte Carlo simulations of adult and pediatric computed tomography exams: validation studies of organ doses with physical phantoms. Medical physics, 40, n. 1, p. 013901, 2013.

MARTIN, C.; SOOKPENG, S. Setting up computed tomography automatic tube current modulation systems. Journal of Radiological Protection, 36, n. 3, p. R74, 2016.

MARTINS, J. Estimativa de dose nos pulmões para procedimentos de tomografia computadorizada. (Dissertação de Mestrado). Universidade de São Paulo, São Paulo SP, Brasil 2015.

MCCOLLOUGH, C. H.; BRUESEWITZ, M. R.; KOFLER JR, J. M. CT dose reduction and dose management tools: overview of available options. Radiographics, 26, n. 2, p. 503-512, 2006.

MCCOLLOUGH, C. H.; LENG, S.; YU, L.; CODY, D. D. et al. CT dose index and patient dose: they are not the same thing. Radiology, 259, n. 2, p. 311-316, 2011.

MCCOLLOUGH, C. H.; LENG, S.; YU, L.; FLETCHER, J. G. Dual-and multi-energy CT: principles, technical approaches, and clinical applications. Radiology, 276, n. 3, p. 637-653, 2015.

MCCOLLOUGH, C. H.; PRIMAK, A. N.; BRAUN, N.; KOFLER, J. et al. Strategies for reducing radiation dose in CT. Radiologic Clinics, 47, n. 1, p. 27-40, 2009.

NIST. XCOM: X Ray Mass Attenuation Coefficient. Disponível em: https://physics.nist.gov/PhysRefData/XrayMassCoef/tab4.html. Acesso em: 05 de agosto de 2020.

NIST. XCOM: Photon Cross Sections Database. 1998. Disponível em: https://physics.nist.gov/PhysRefData/Xcom/html/xcom1.html. Acesso em: 04 de agosto de 2020.

NOTO, D.; FUNAMA, Y.; KITAJIMA, M.; UTSUNOMIYA, D. et al. Optimizing radiation dose by varying age at pediatric temporal bone CT. Journal of applied clinical medical physics, 16, n. 1, p. 311-318, 2015.

OKUNO, E.; YOSHIMURA, E. Física das Radiações. Oficina de Textos, 2010.

PERISINAKIS, K. Dual-Energy X-ray Computed Tomography. In: Handbook of X-ray Imaging: CRC Press, 2017. p. 805-816.

PRINSEN, P.; TRATTNER, S.; WIEGERT, J.; GERLAND, E. L. et al. High correlation between radiation dose estimates for 256-slice CT obtained by highly parallelized hybrid Monte Carlo computation and solid-state metaloxide semiconductor field-effect transistor measurements in physical anthropomorphic phantoms. Medical Physics, 46, n. 11, p. 5216-5226, 2019. 
REINA, T. R. Avaliação de sistemas de controle automático de exposição em tomografia computadorizada. (Dissertação de Mestrado). Universidade de São Paulo, São Paulo SP, Brasil 2014.

RIA, F.; DAVIS, J. T.; SOLOMON, J. B.; WILSON, J. M. et al. Expanding the concept of diagnostic reference levels to noise and dose reference levels in CT. American Journal of Roentgenology, 213, n. 4, p. 889-894, 2019.

SHOPE, T. B.; GAGNE, R. M.; JOHNSON, G. C. A method for describing the doses delivered by transmission X-ray computed tomography. Medical physics, 8, n. 4, p. 488-495, 1981.

SHRIMPTON, P.; HILLIER, M.; MEESON, S.; GOLDING, S. Doses from computed tomography (CT) examinations in the UK-2011 review. Public Health England Report PHE-CRCE-013. 2014.

SINCLAIR, L.; GRIGLOCK, T. M.; MENCH, A.; LAMOUREUX, R. et al. Determining organ doses from CT with direct measurements in postmortem subjects: part 2-correlations with patient-specific parameters. Radiology, 277, n. 2, p. 471-476, 2015.

SOOKPENG, S.; BUTDEE, C. Signal-to-noise ratio and dose to the lens of the eye for computed tomography examination of the brain using an automatic tube current modulation system. Emergency radiology, 24, n. 3, p. 233-239, 2017.

STRAUSS, K. J. Dose indices: everybody wants a number. Pediatric Radiology, 44, n. 3, p. 450-459, 2014// 2014.

STRAUSS, K. J.; GOSKE, M. J.; KASTE, S. C.; BULAS, D. et al. Image gently: ten steps you can take to optimize image quality and lower CT dose for pediatric patients. American Journal of Roentgenology, 194, n. 4, p. 868$873,2010$.

STRAUSS, K. J.; KASTE, S. C. The ALARA (as low as reasonably achievable) concept in pediatric interventional and fluoroscopic imaging: striving to keep radiation doses as low as possible during fluoroscopy of pediatric patients - a white paper executive summary. Radiology, 240, n. 3, p. 621-622, 2006.

STRAUSS, K. J.; SOMASUNDARAM, E.; SENGUPTA, D.; MARIN, J. R. et al. Radiation dose for pediatric CT: comparison of pediatric versus adult imaging facilities. Radiology, 291, n. 1, p. 158-167, 2019.

TANG, X.; XIE, H. X-ray Computed Tomography for Diagnostic Imaging_From Single-Slice to Multi-Slice. In: Handbook of X-ray Imaging: CRC Press, 2017. p. 637-668.

THE PHANTOM LABORATORY. Catphan ${ }^{\circledR} \mathbf{5 0 0}$ and $\mathbf{6 0 0}$ Manual. 2014. Disponível em: https://www.uio.no/studier/emner/matnat/fys/nedlagte-emner/FYS4760/h07/Catphan500-600manual.pdf. Acesso em: 04 de agosto de 2020.

TOMAL, A.; COSTA, P. R. Phantoms for image quality and dose assessment. In: Handbook of X-ray Imaging: CRC Press, 2017. p. 1135-1158. 
ULZHEIMER, S.; FLOHR, T. Multislice CT: current technology and future developments. In: Multislice CT: Springer, 2009. p. 3-23.

UMISEDO, N. K.; YOSHIMURA, E. M.; GASPARIAN, P. B.; YUKIHARA, E. Comparison between blue and green stimulated luminescence of Al2O3: C. Radiation Measurements, 45, n. 2, p. 151-156, 2010.

VASSILEVA, J.; REHANI, M.; KOSTOVA-LEFTEROVA, D.; AL-NAEMI, H. M. et al. A study to establish international diagnostic reference levels for paediatric computed tomography. Radiation protection dosimetry, 165, n. 1-4, p. 70-80, 2015.

VEDANTHAM, S. Tissue Substitute Materials for Diagnostic X-ray Imaging. In: Handbook of X-ray Imaging: CRC Press, 2017. p. 1107-1134.

VERDUN, F.; RACINE, D.; OTT, J.; TAPIOVAARA, M. et al. Image quality in CT: From physical measurements to model observers. Physica Medica, 31, n. 8, p. 823-843, 2015.

VUOLO, J. H. Fundamentos da teoria de erros. Edgard Blücher Ltda, 2002.

WAGNER, F.; BIZE, J.; RACINE, D.; LE COULTRE, R. et al. Derivation of new diagnostic reference levels for neuro-paediatric computed tomography examinations in Switzerland. Journal of radiological protection, 38, n. 3, p. 1013, 2018.

WINSLOW, J. F.; HYER, D. E.; FISHER, R. F.; TIEN, C. J. et al. Construction of anthropomorphic phantoms for use in dosimetry studies. Journal of Applied Clinical Medical Physics, 10, n. 3, p. 195-204, 2009.

WORLD HEALTH ORGANIZATION \& IAEA. Bonn call-for-action-joint position statement by the IAEA and WHO. WHO Geneva 2014.

YUKIHARA, E.; MCKEEVER, S. Optically stimulated luminescence (OSL) dosimetry in medicine. Physics in Medicine \& Biology, 53, n. 20, p. R351, 2008.

YUKIHARA, E. G.; MCKEEVER, S. W. Optically stimulated luminescence: fundamentals and applications. John Wiley \& Sons, 2011. 0470977213. 


\section{APÊNDICE A}

A Figura A1 apresenta, na forma de um diagrama de Ishikawa, todos os fatores considerados na estimativa de incerteza associada ao cálculo de dose absorvida. O nível de confiança considerado foi de $68,3 \%(k=1)$.

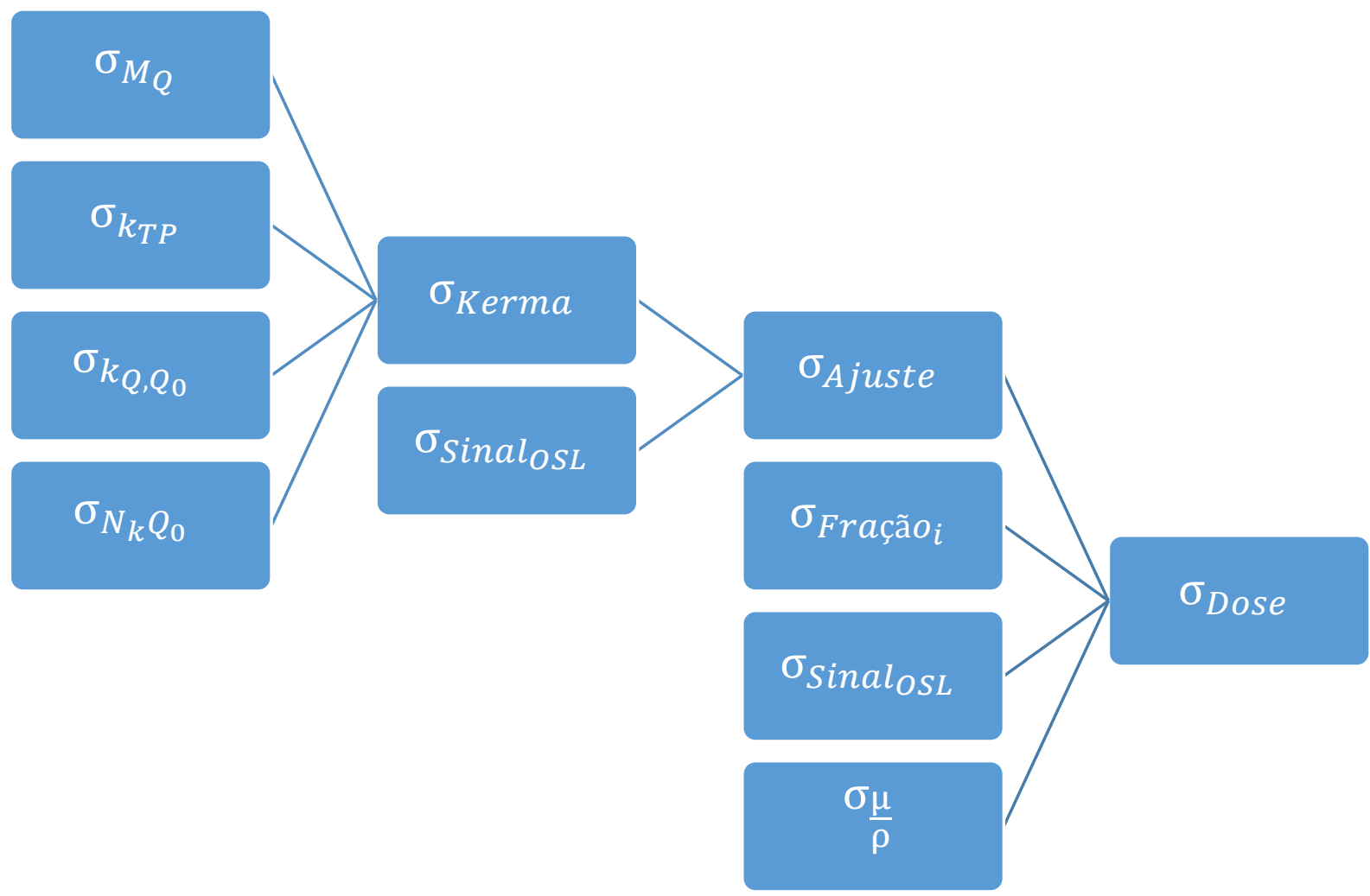

Figura A.1 - Diagrama de Ishikawa ilustrando todos os fatores considerados na estimativa da incerteza associada aos valores de dose absorvida pelos pulmões, tireoide e cristalino dos olhos do phantom pediátrico.

Em que:

- $\sigma_{\text {Sinal }_{O S L}}$ é a incerteza associada ao sinal do dosímetro OSL, baseada no desvio padrão médio da leitura dos dosímetros;

- $\sigma_{A j u s t e}$ é a incerteza associada ao ajuste da curva de calibração construída para relacionar o sinal do dosímetro OSL com o Kerma medido no ar com câmera de ionização;

- $\sigma_{F^{\prime} a c_{a} o_{i}}$ é a incerteza associada à fração do órgão contida na fatia $i$ do phantom; 
- $\sigma_{\frac{\mu}{\rho}}$ é a incerteza associada aos coeficientes de absorção mássicos para as energias efetivas consideradas;

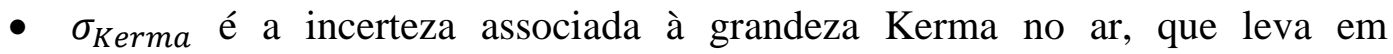
consideração a incertezas da câmara de ionização $\left(\sigma_{M_{Q}}\right)$, do coeficiente de calibração e do fator de correção para um feixe de radiação $\left(\sigma_{N_{k} Q_{0}}\right.$ e $\left.\sigma_{k_{Q, Q_{0}}}\right)$ ambos dados pelo certificado de calibração da câmara de ionização e, finalmente, $\sigma_{k_{T P}}$, que é o fator de correção de temperatura e pressão. Dado que a câmara de ionização utilizada no arranjo experimental fornece a leitura de kerma no ar já corrigida para os valores temperatura e pressão, não houve a necessidade de incorporar o fator $\sigma_{k_{T P}}$ aos cálculos. Por fim, o parâmetro $\sigma_{k_{Q, Q_{0}}}$ foi considerado nas estimativas da incerteza da dose, mas não foi incluído aos cálculos incerteza final de dose absorvida devido à sua baixa influência, considerada desprezível em relação aos demais parâmetros de incerteza. 


\section{APÊNDICE B}

As figuras B1 e B2 apresentam as curvas de calibração construídas para a avaliação de dose absorvida proveniente dos protocolos de crânio helicoidais.

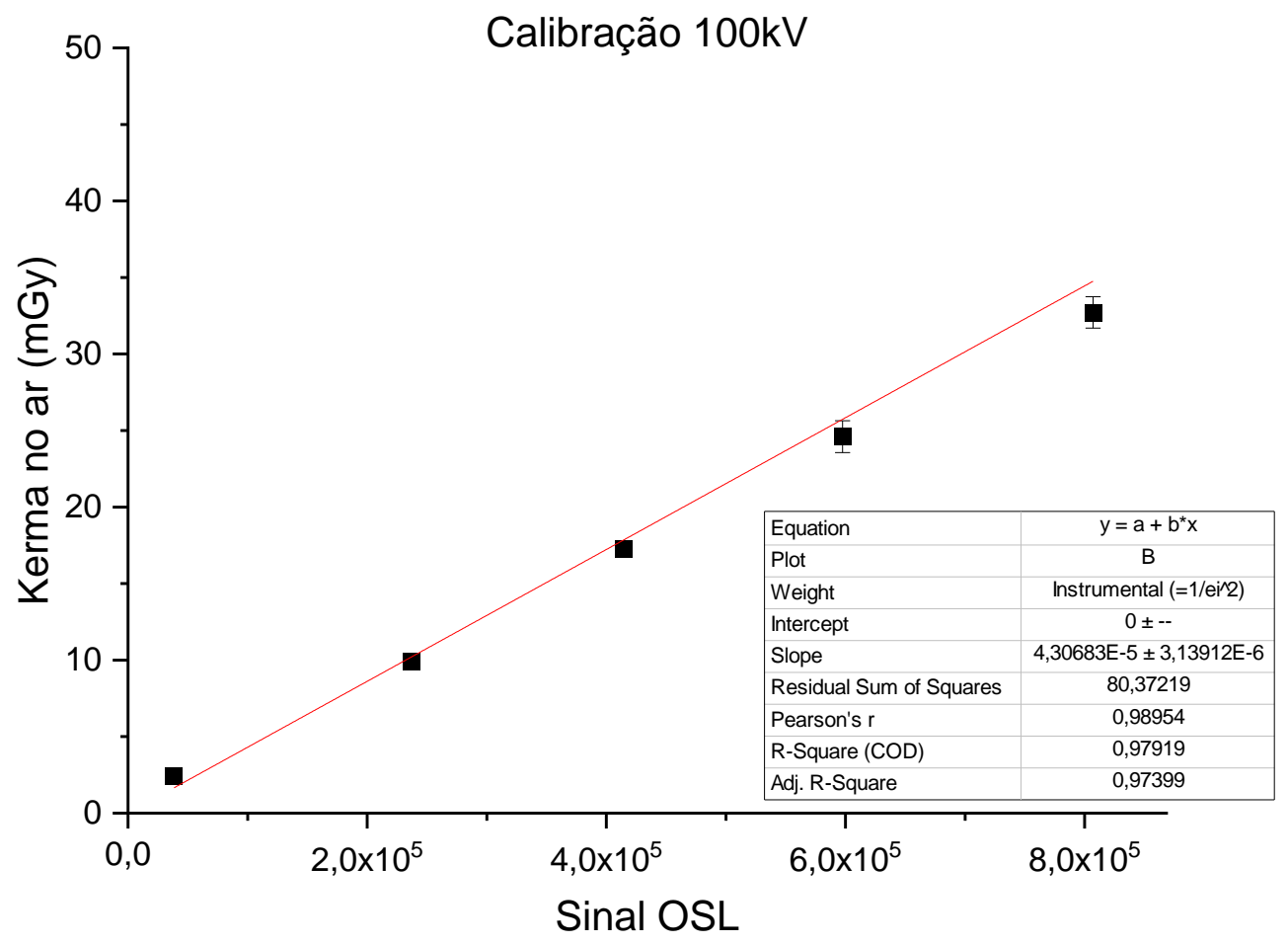

Figura B.1 - Curva de calibração utilizada na avaliação de dose do protocolo de crânio helicoidal otimizado (Crânio 3D Infantil). 


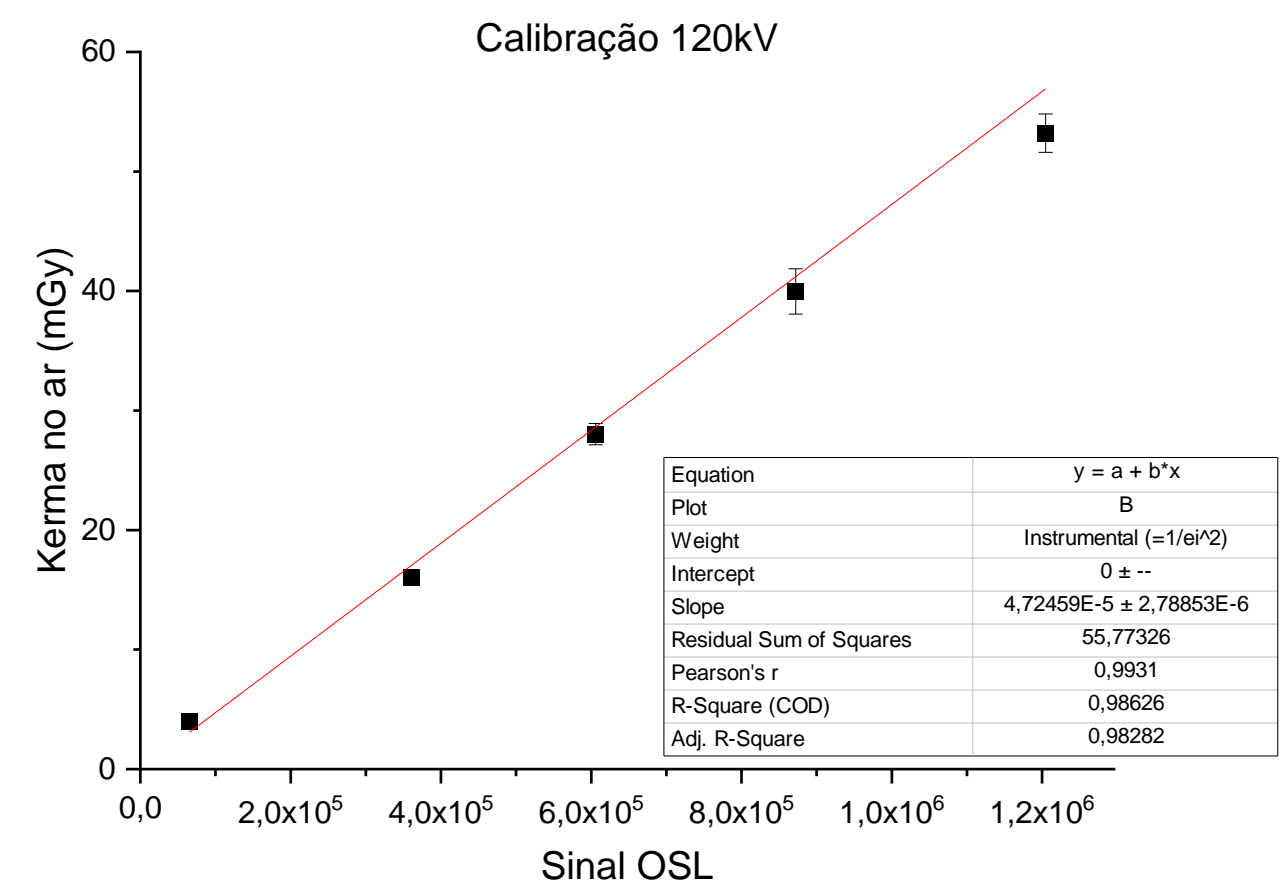

Figura B.2 - Curva de calibração utilizada na avaliação de dose do protocolo de crânio helicoidal não otimizado (Crânio 3D).

As figuras B3 e B4 apresentam as curvas de calibração construídas para a avaliação de dose absorvida proveniente dos protocolos de crânio helicoidais. 


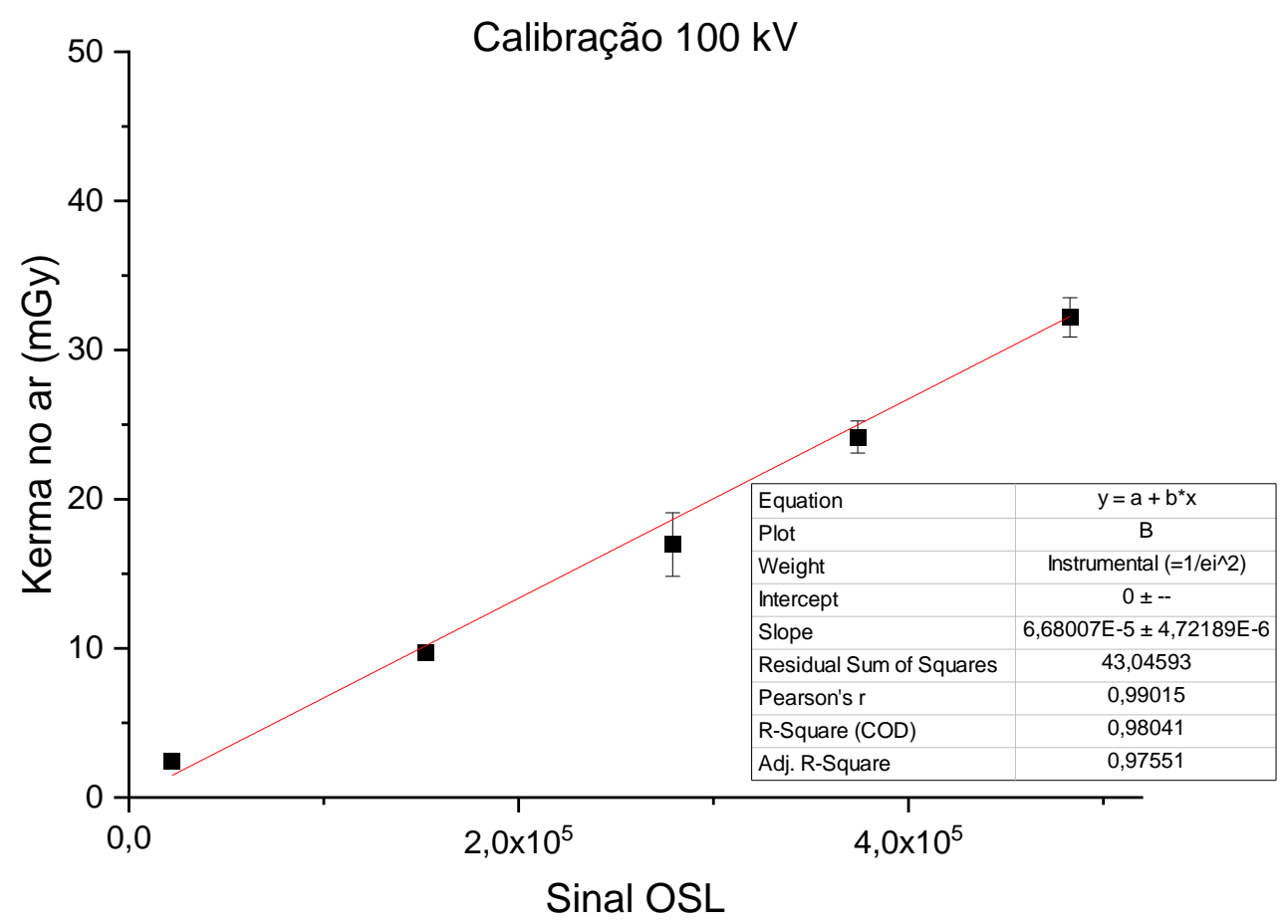

Figura B.3- Curva de calibração utilizada na avaliação de dose do protocolo de crânio axial otimizado (Infantil/Crânio 2-6 anos).

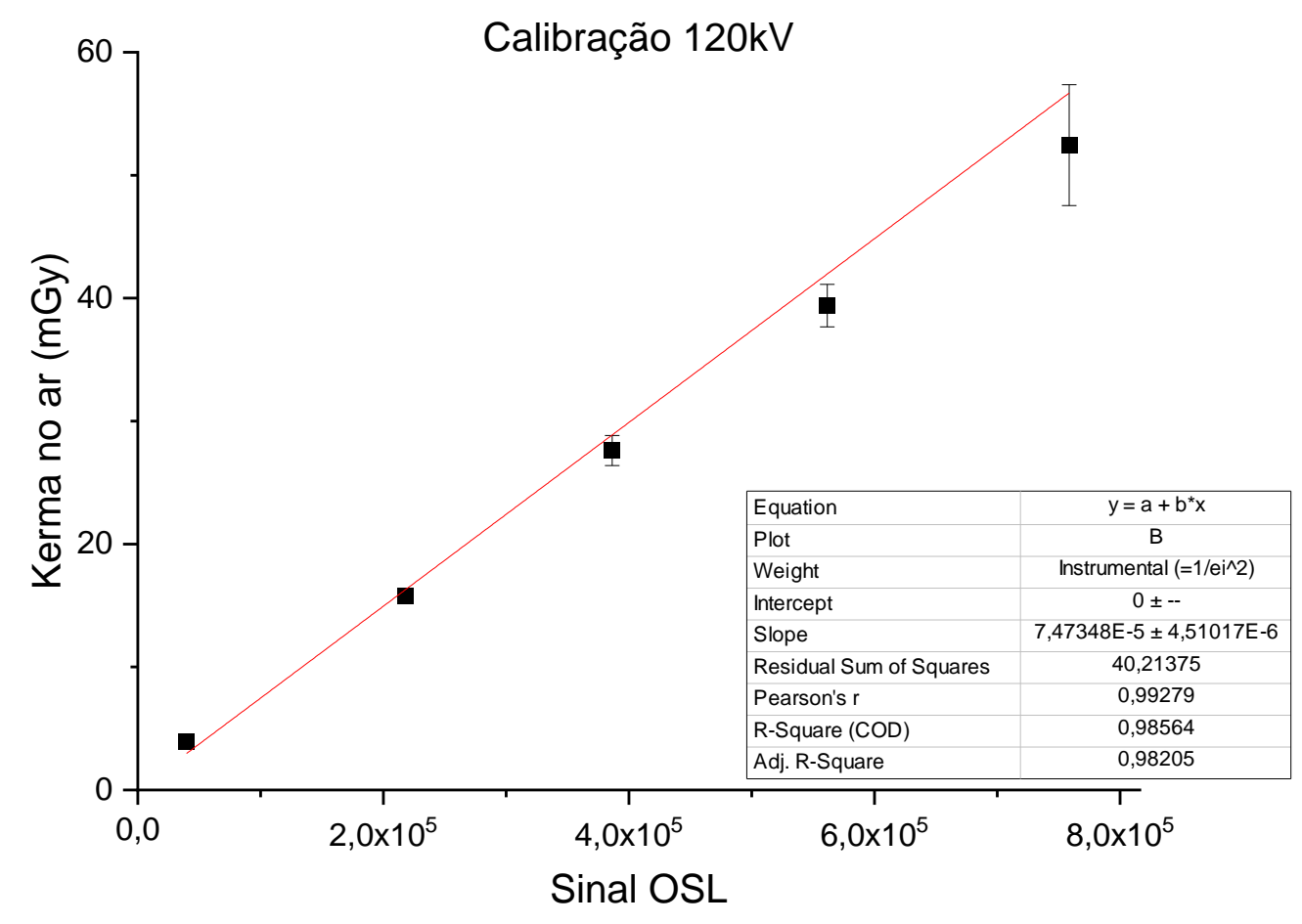

Figura B.4 - Curva de calibração utilizada na avaliação de dose do protocolo de crânio axial não otimizado (Crânio Criança Axial). 
As figuras B5 e B6 apresentam as curvas de calibração construídas para a avaliação de dose absorvida proveniente dos protocolos de tórax.

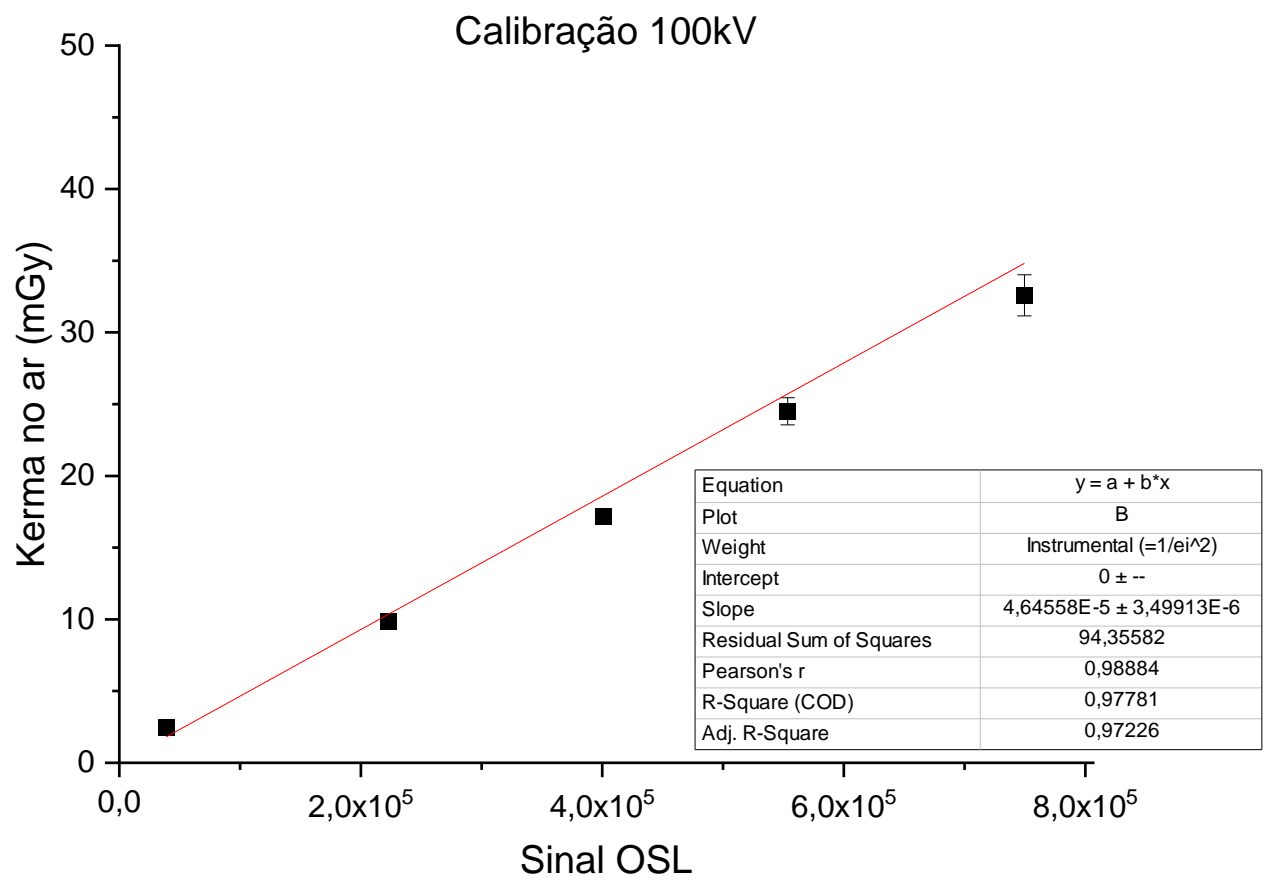

Figura B.5 - Curva de calibração utilizada na avaliação de dose do protocolo de tórax otimizado (Infantil/Tórax 110 anos). 


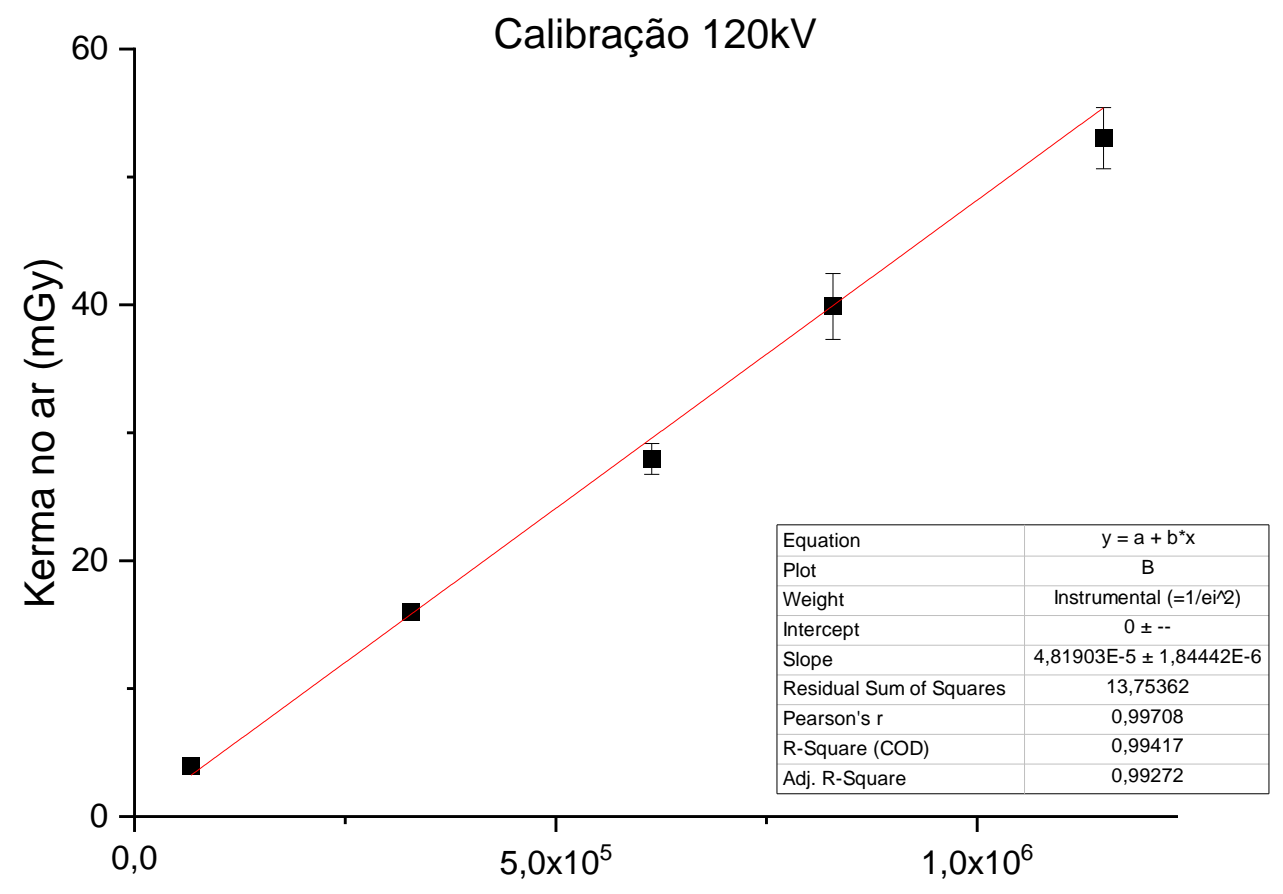

Sinal OSL

Figura B.6 - Curva de calibração utilizada na avaliação de dose do protocolo de tórax não otimizado (Tórax Infantil). 